\title{
Easing the Transition to Commercial Finance for Sustainable Water and Sanitation
}

A U G U S 2017

Amanda Goksu, Sophie Trémolet, Joel Kolker, and Bill Kingdom 


\section{About the Water Global Practice}

Launched in 2014, the Word Bank Group's Water Global Practice brings together financing, knowledge, and implementation in one platform. By combining the Bank's global knowledge with country investments, this model generates more firepower for transformational solutions to help countries grow sustainably.

Please visit us at www.worldbank.org/water or follow us on Twitter at https://twitter.com/search?q=\%40WorldBankWater\&src=tyah. 


\section{Easing the Transition to Commercial Finance for Sustainable Water and Sanitation}

A U G UST 2017

Amanda Goksu, Sophie Trémolet, Joel Kolker, and Bill Kingdom 
(C) 2017 International Bank for Reconstruction and Development / The World Bank

1818 H Street NW, Washington, DC 20433

Telephone: 202-473-1000; Internet: www.worldbank.org

This work is a product of the staff of The World Bank with external contributions. The findings, interpretations, and

conclusions expressed in this work do not necessarily reflect the views of The World Bank, its Board of Executive Directors, or the governments they represent.

The World Bank does not guarantee the accuracy of the data included in this work. The boundaries, colors, denominations, and other information shown on any map in this work do not imply any judgment on the part of The World Bank concerning the legal status of any territory or the endorsement or acceptance of such boundaries.

\section{Rights and Permissions}

The material in this work is subject to copyright. Because The World Bank encourages dissemination of its knowledge, this work may be reproduced, in whole or in part, for noncommercial purposes as long as full attribution to this work is given.

Please cite the work as follows: World Bank. 2017. Easing the Transition to Commercial Finance for Sustainable Water and Sanitation. World Bank, Washington, DC.

Any queries on rights and licenses, including subsidiary rights, should be addressed to World Bank Publications, The World Bank Group, 1818 H Street NW, Washington, DC 20433, USA; fax: 202-522-2625; e-mail: pubrights@worldbank.org.

Cover design: Jean Franz, Franz \& Company, Inc. 


\section{Contents}

Acknowledgments

vii

Executive Summary

ix

Abbreviations

$x v$

Chapter 1 Introduction

1.1 A Global Commitment to Water and Sanitation for All

1.2 Purpose and Scope

1.3 The Broader Agenda: It's Not Just About Money

1.4 Target Audience

1.5 Report Content

Note

Chapter 2 Why Is a New Financing Framework Needed?

2.1 The Status Quo Is Not Enough

2.2 The Investment Gap Is Widening

2.3 The Financial Landscape Is Changing

2.4 The Potential Benefits Are Immense

2.5 How Is the WSS Sector Currently Funded?

2.6 Conclusion

Notes

3.1 Easing the Transition

3.2 Why Does WSS Not Typically Attract Commercial Finance? 19

3.3 A New Financing Framework 21

3.4 Conclusion
21

Notes 
Chapter 5 Component 2: Improve Service Providers' Performance and Governance

5.1 What Needs to Change? 33

5.2 The Status Quo 33

$\begin{array}{ll}5.3 & \text { Incentives for Efficiency }\end{array}$

5.4 Conclusion 39

Note $\quad 40$

Chapter 6 Component 3: Leverage Public Funds to Attract Commercial Finance 41

6.1 What Needs to Change? 41

6.2 How Blending Can Help Bridge the Finance Gap 41

6.3 Building Demand 43

6.4 Building Supply 46

6.5 Conclusion $\quad 49$

$\begin{array}{ll}\text { Notes } & 49\end{array}$

Chapter 7 Bringing It All Together $\quad 51$

7.1 Recapping the Objectives 51

7.2 Finance as Part and Parcel of Broader Sector Reform 51

7.3 Conclusions and Strategic Recommendations

$\begin{array}{lll}\text { Appendix A } & \text { Types of Commercial Finance } & 57\end{array}$

Appendix B Analysis of Lending Parameters on Borrowing Costs 61

Debt Service: Short Term Affordability versus Total Cost $\quad 61$

The Impact of Foreign Exchange Fluctuations

The Cost of Delay

Note $\quad 66$

$\begin{array}{lr}\text { References } & 67\end{array}$

Boxes

ES.1. What Is Commercial Finance? $\quad \mathrm{X}$

1.1. SDG 6: Water and Sanitation for All by $2030 \quad 2$

1.2. Relevant WGP Publications on Financing Universal WSS Access 3

2.1. Three Key Differences between the MDGs and the SDGs 5

2.2. The Camdessus Panel: A First Attempt to Break the Status Quo 7

2.3. The Potential of Climate Finance 8

2.4. The Real Cost of Water for the Poor 9

3.1. Lessons from the East Asia Financial Crisis 18

4.1. The Cost of Misaligned Incentives $\quad 24$ 
4.2. The Capacity to Spend Effectively 25

4.3. Strategic Financial Planning (SFP) 25

4.4. Implicit Subsidies Cannot Be Well Targeted 30

4.5. Making Fiscal Transfers Dependent on Good Performance in Egypt 31

5.1. What Makes a Service Provider Creditworthy? 35

5.2. Key Considerations for Promoting Efficient Service Delivery 36

5.3. Cost-Recovery Policy Catalyzes Utility Turnaround in Vietnam 38

6.1. Blended Finance to Reduce Rural Sanitation Costs in Bangladesh 43

6.2. Typical Blended Finance Strategies 44

6.3. Incentives for Sector Performance in Kenya 46

6.4. Colombia’s Municipal Development Fund 47

6.5. A Pooled Municipal Bond Issue to Help Small Providers Access Private Finance in India 48

7.1. The Evolution of WSS Sector Reform in Mozambique 53

\section{Figures}

ES.1. WSS Financing Framework xi

1.1. The Cycle of Improved Sector Performance 4

2.1. Costs of Extending WASH Access under SDGs (2016-30) Relative to MDGs (2000-15) 6

2.2. Access to Improved Sanitation and Under-Five Mortality Rate, by Population Size, Selected Countries, $2015 \quad 9$

2.3. Traditional Revenue Sources for the Water Sector 10

2.4. Uses of Commercial Finance, by Borrower Size and Financing Need 12

2.5. Sources of Finance vs. Implementation Models 13

2.6. Composition of WASH Sector Funding, by Type, for Brazil, Ghana, and Mali 14

3.1. Proposed WSS Financing Framework 21

4.1. Example of Financing Strategy for the Rural Sanitation Subsector 24

4.2. Virtuous Cycle of Providers' Customer-Orientation and Financial Sustainability 28

5.1. Vicious Cycle Affecting Many Service Providers 34

5.2. Efficiency Improvements that Help Utilities Reach Financial Viability 38

5.3. How Tariffs, Taxes, and Efficiency Can Transform Each WSS Subsector 40

7.1. Potential Pathways to Fill the WSS Financing Gap 52

B.1. $\quad$ Effect of Loan Maturities on Tariffs 62

B.2. Affordability vs. Total Debt Service: Loan Repayment Amounts, by Year, at Different Maturities 63

B.3. Foreign Exchange Costs on a 15-Year Concessional Loan 64

B.4. Consequential Costs of FX Concessional Loans, with and without Five-Year Delay 65

\section{Tables}

2.1. WASH-Related MDG and SDG Definitions, by Target 6

3.1. Benefits of Mobilizing Commercial Finance for the WSS Sector 18

3.2. Objectives of Service Providers and Lenders 20

4.1. Global Population Still Lacking Access to WSS, by Type and Subsector, 201626 
6.1. Measures that Help Commercial Finance Work for Borrowers and Lenders 42

6.2. How Select Blending Instruments Can Support Different Types of Commercial Finance 44

B.1. Loan Repayment on a Local Currency Loan at Different Maturities 62

B.2. Comparison of Foreign and Domestic Currency Loans 63

B.3. 15-year Foreign and Local Currency Loan Repayment at 3 Percent Interest 64

B.4. Concessional Loan Costs, with and without Five-Year Delay 65 


\section{Acknowledgments}

This report was written by Amanda Goksu (Consultant, Water Global Practice), Sophie Trémolet (Sr. Economist, Water Global Practice) and Joel Kolker (Lead WSS Specialist, Water Global Practice) under the leadership and guidance of Bill Kingdom (Lead WSS Specialist, Water Global Practice). The authors are grateful to Aldo Baietti (Consultant, Water Global Practice) for his critical contributions. This work forms part of a larger effort undertaken by the Water Global Practice of the World Bank, led by Joel Kolker and Sophie Trémolet, to address the need for further guidance and advocacy on financial options for meeting the Sustainable Development Goal (SDG) for water. An initial version of this report was prepared for the High-Level Panel on Water (HLPW), which was convened by the United Nations Secretary-General and the President of the World Bank Group, consisting of 11 sitting Heads of State and Government and one Special Adviser, to provide the leadership required to champion a comprehensive, inclusive and collaborative way of developing and managing water resources, and improving water and sanitation related services. Subsequent development was undertaken jointly by the World Bank and UNICEF in support for the preparation of the Sanitation and Water for All High-Level meetings held in April of 2017 in Washington, DC. These meetings gathered Ministers of Finance and Ministers responsible for Water, Sanitation and Hygiene from over 50 low- and middle-income countries to discuss the way forward for achieving universal access to water and sanitation services.

The team would like to thank peer reviewers Yogita Mumssen (Sr. Infrastructure Economist, Water Global Practice), George Butler (Principal WSS Specialist, IFC), Charles Delfieux (Sr. WSS Specialist, Water Global Practice), Helen Mary Martin (Sr. PPP Specialist, Water Global Practice), John Ikeda (Sr. Financial Specialist, Water Global Practice), Mark Giblett (Sr. Infrastructure Financial Specialist, Water Global Practice) and Jemima Sy (Sr. Infrastructure Specialist, Water Global Practice) for their inputs. Dominick de Waal (Sr. Economist, Water Global Practice), Guy Hutton (UNICEF) and Sanjay Wijesekera (UNICEF) also provided input into the earlier version of this report for Sanitation and Water for All. Finally, the team is very thankful for the support and guidance of Guangzhe CHEN (Sr. Director, Water Global Practice), Jyoti Shukla (Director, Water Global Practice) and Maria Angelica Sotomayor (Practice Manager, Water Global Practice). 


\section{Executive Summary}

\section{The Challenge}

Since the turn of this century, many countries have made significant progress toward meeting their water and sanitation access goals. At a global level, the Millennium Development Goal (MDG) target for water was achieved by 2010, but the target for sanitation was not achieved by 2015. During the MDG period a total of 2.6 billion people gained access to improved water, and 2.1 billion gained access to improved sanitation (WHO/UNICEF 2015).

Despite this worldwide effort, 660 million people still lack access to clean water, and $\mathbf{2 . 4}$ billion lack access to sanitation. Coupled with the growing challenges of the 21st century-rapid urbanization, climate change, pollution, and higher demand for water resources-the challenge of bringing water supply and sanitation (WSS) to all remains immense.

Eager to meet this challenge, the global community has responded by endorsing Sustainable Development Goal 6 (SDG 6)-the so-called "water SDG"-which calls for universal access to WSS services by $\mathbf{2 0 3 0}$ that are safe, affordable, and available when needed. In addition, there are targets for increasing efficiency of water use across all sectors, protecting and restoring waterrelated ecosystems, and improving water quality.

The cost of meeting the targets of SDG 6.1 and 6.2 is substantially higher than current annual WSS investment levels. Historical levels of funding for extending access to water supply, sanitation, and hygiene (WASH) services during the MDG era were estimated at $\$ 16$ billion in 140 countries, whereas what's needed to ensure universal access to safely managed services by 2030 is around $\$ 112$ billion per year (World Bank/UNICEF 2017). In essence, the sector is currently only financing about 15 percent of the estimated needs. Clearly, the status quo financing model in many low- and middle-income countries relies on public funds that are insufficient, poorly targeted, and often crowd out, rather than crowd in, new sources of financing. This model will not deliver on the SDG targets.

A new paradigm is therefore needed that turns this approach on its head and asks governments to work toward "crowding in" commercial finance to supplement existing sources of finance. This approach will help ensure that service providers strive toward more efficient services and that scarce public funds are used in a more targeted manner. The overall objective is for those currently without WSS services, who are predominantly poor, to have the same access that wealthier citizens already receive-and at a price that is affordable to them.

\section{The Possibility}

Increasing the level of commercial finance for the sector would allow service providers to borrow and invest in expanding and improving the quality of WSS services, without having to wait for scarce public resources to be made available. A gradual move to mobilizing more finance requires improving the financial performance of service providers through a mix of improved technical and commercial efficiencies and through governance and regulatory reforms. These improvements will generate the financial surplus needed to access commercial finance, thus complementing limited public funds.

\section{Although commercial finance generally comes at a higher} up-front cost, it has many significant benefits over concessional finance, including faster access to finance, more flexibility in the use of the funds, and greater responsiveness to changes in circumstances (box ES.1). Taken together, these advantages will translate into 
BOX ES.1. What Is Commercial Finance?

In this report, commercial finance refers broadly to various types of finance that are neither concessional finance nor official development finance, and which are usually provided at market rates. In the water sector, this can range from microfinance loans to bonds and can be offered to service providers, local governments, individual users or user groups. Providers of commercial finance may include domestic commercial banks, microfinance institutions or capital market investors (via bonds or equity).

faster results and benefits on the ground. Commercial finance is also associated with further improving the governance and accountability of service providers. Moreover, commercial finance can help countries tap into domestic financial resources that are new to the sector, such as pension funds or institutional investors. And when dominated in local currency commercial finance does not carry foreign exchange risk.

Borrowers can blend concessional with commercial loans to reap some of these benefits while maintaining affordability, as evidenced by the many countries that have already started the transition:

- Indonesia's ambitious WSS targets are backed by a financial strategy that leverages commercial finance.

- The Arab Republic of Egypt is using public funds as an incentive for improving the performance of sanitation service providers.

- Kenya is pioneering the use of shadow credit ratings to attract a new cadre of financiers.

- In Colombia, donor-funded credit enhancements have already paved the way to a commercially viable sector.

- Countries from Bangladesh to Malawi are expanding the use of microfinance in WSS.

\section{The Proposal}

This report calls for countries to place a greater priority on leveraging commercial finance into the sector while at the same time bolstering public funds for the sector.
The question is not whether to finance with public or private money. More of both will be needed-and sooner rather than later. This will require a transition to a more balanced mix of public and commercial financing, which must be driven by changing mindsets across all sector stakeholders: central governments, local governments, customers, donors and financiers.

The proposed framework (figure ES.1) advocates a transition that uses public funds to leverage commercial finance. This transition is not just about money. It requires attention to better targeting of scarce public funds, improving the efficiency and governance of service providers, using capital more efficiently, and developing new financing relationships in the sectorbetween service providers (as borrowers) and banks (as lenders).

The net effect is to build a sector that uses every dollar of scarce public funds to deliver maximum benefit to society. Countries can prioritize efficiency and leverage their resources through working on the framework's three components (figure ES.1):

- Plan, budget, and allocate public resources more efficiently

- Improve service providers' performance and governance

- Leverage public funds to attract commercial finance

The three components of the framework can progress in parallel. However, in nearly all cases it will be critical to first work on the main foundational components so as 
FIGURE ES.1. WSS Financing Framework

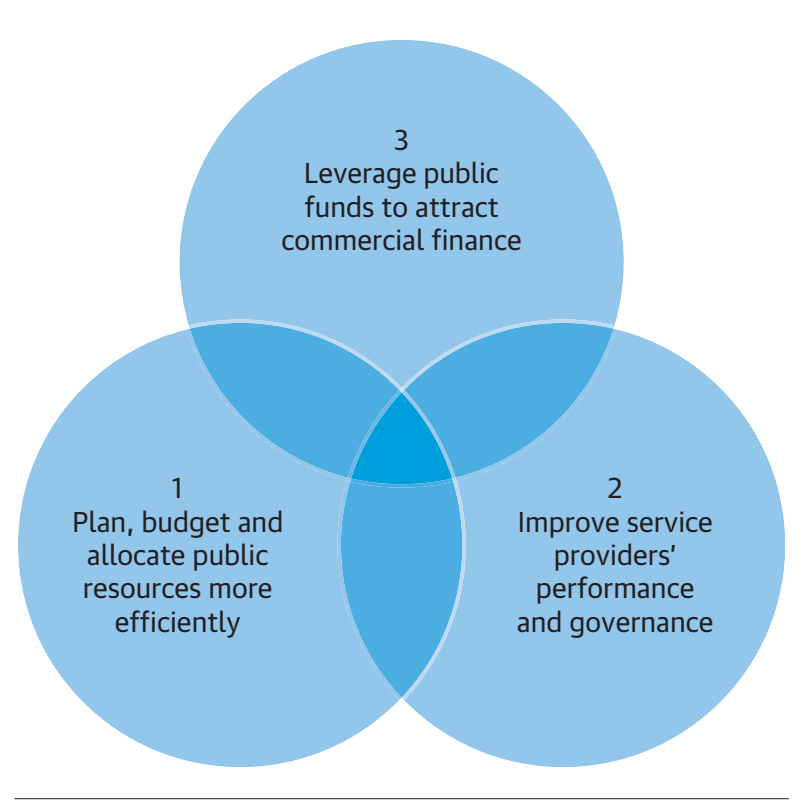

Note: WSS = water supply and sanitation.

to improve sector efficiency and targeting of existing resources and thus enable the leveraging of commercial finance.

Reforms made within each component will be iterative and incremental to allow for policies and capacity to align. There are also significant feedback loops among the components as represented by the overlapping circles. For example, investor scrutiny resulting from actions in component 3 can improve transparency and efficiency in component 2.

\section{Component 1: Plan, Budget, and Allocate Public Resources More Efficiently}

Governments need to establish the policy, planning, and governance frameworks that will improve sector efficiency and creditworthiness to attract the commercial finance required to meet WSS goals. In most countries, major sector reforms will be needed. Sector policies need to be realistic, fully funded, and integrated with investment plans that, at the local level, include well-defined and well-targeted subsidies. Incentives need to be created to improve performance. Policies need to encourage mobilization and efficient use of additional funding (particularly domestic financing) from tariffs, charges, and government taxes. Given the range of possible government financing sources in the sector, this will require close coordination and policy enforcement across a range of line ministriesincluding finance and water and sanitation-as well as local governments.

\section{Component 2: Improve Service Providers' Performance and Governance}

Efficiency gains are a source of untapped finance, and inefficiencies represent an opportunity cost to the government or service provider. Improving both operational and capital efficiency allows service providers to deliver better services more cheaply, thereby freeing up resources to invest in improving or extending services. Moreover, improved efficiency and service quality can help justify increased tariffs and transfers from government sources because stakeholders are more willing to pay or allocate funding when services improve.

Governments should expect more from service providers and incentivize improved efficiency, in terms of both operational performance and the use of capital. Under the right corporate governance and incentive structures, service providers will recover more costs, use less capital, and become more self-sufficient-building the foundations that will enable them to attract commercial finance on their own.

\section{Component 3: Leverage Public Funds to Attract Commercial Finance}

Public funding should be used to leverage commercial finance to the extent possible at any time. This will require governments, through their line ministries and local governments, to take leadership in the design and implementation of an integrated and consistent approach to sector financing built around policies that encourage efficiency and mobilization of new sources of capital. Such leadership is based on an acceptance that change is needed, and that financing costs may 
increase, but that the benefits flowing from faster access to improved WSS services will outweigh the cost of failing to act now to mobilize these new sources of financing.

Building the foundations for commercial finance in the sector will take time. Creating new markets between lenders and borrowers will also require ongoing support from the public sector. Commercial borrowing terms will normally be less attractive at face value than those of concessional finance, but using domestic commercial finance has the potential to save money in the long run, especially in countries with high currency risk.

Affordability is often given as a reason for not accessing commercial finance. However, such concerns can be addressed, in a practical and transitional way, by blending concessional or public funds with commercial finance-for example, with grants and tenor extensions. These approaches will mitigate the potentially higher borrowing costs of private finance relative to concessional funds, which currently dominate the sector.

It is important to recognize the "supply side" of this new paradigm. Even if service providers are efficient and well governed, that doesn't mean lenders will immediately respond to new lending opportunities when they are presented. Certain financing tools can be catalyzed to de-risk the sector and make it more attractive to lenders-including, for example, guarantees, benchmarking, creditworthiness assessments, and project preparation funds. Political leadership is needed to pioneer the use of de-risking tools in nearly all countries, and especially in less-developed countries where financial markets are still evolving.

\section{The Paradigm Shift}

Crowding in will take the place of crowding out, or simply ignoring, commercial finance. This is a new mindset for a sector that has traditionally relied on public or concessional funds for the bulk of its investments, particularly in emerging markets. It will require new thinking and new policies that are not yet readily available. It will also require all stakeholders to buy into, and support, this new paradigm and for each to take responsibility for those parts they can influence. The goal is to deliver universal access to sustainable WSS services.

It is important to note that accessing commercial or private finance does not equate to privatizing the sector. In fact, in many high-income countries, publicly owned water service providers have leveraged substantial commercial finance without relinquishing control over management of the service or selling shares. For example, the majority of people living in the United States are served by publicly owned water utilities. Many of these utilities have relied for the past 40 years on State Revolving Funds created by the Clean Water Act to tap into domestic bond investors. This is because the source of finance is separate and different from the implementation model (that is, who owns or manages the assets).

As with any paradigm shift, the transition will require strong political will and government leadership. Recognizing that the current funding model will not deliver WSS goals by 2030, governments need to take a holistic and long-term policy view of the sector. Initial investments will have high rewards in the medium and long term, but will require the strategic use and targeting of limited public and donor resources to facilitate the new model. Consistent application of a national sector policy to encourage new sources of finance will be important. Regression to a politically expedient public-finance-only model will undermine progress toward the new, balanced financing model proposed here. Political leadership is therefore critical if the sector is to reach the ambitious goals of universal access.

The Water Global Practice (WGP) of the World Bank supports this paradigm shift, which is in line with the 
Financing for Development agenda outlined at the Addis Ababa conference in July 2015. Access to finance requires technical and financial efficiency of sector institutions, as well as a strong enabling environments and governance that guide institutions via the right incentives. This paper refers to other recent publications prepared by the WGP on these broader topics. 


\title{
Abbreviations
}

\author{
GLAAS Global Analysis and Assessment of Sanitation and Drinking-Water \\ IBT increasing block tariffs \\ IDA International Development Association \\ KPI key performance indicator \\ LMICs low- and middle-income countries \\ MDB multilateral development bank \\ MDG Millennium Development Goal \\ NGO nongovernmental organization \\ NRW non-revenue water \\ O\&M operations and maintenance \\ ODA Official Development Assistance \\ OECD Organisation for Economic Co-operation and Development \\ PPP public-private partnership \\ PSP private sector participation \\ RBF results-based financing \\ SDG Sustainable Development Goal \\ SFP strategic financial planning \\ SOE state-owned enterprise \\ SSIPs small-scale independent service providers \\ TA technical assistance \\ WASH water supply, sanitation, and hygiene \\ WSCs water and sanitation companies \\ WSS water supply and sanitation
}

Note: All dollar amounts are in U.S. dollars, unless otherwise noted. 


\section{Chapter 1 Introduction}

\subsection{A Global Commitment to Water and Sanitation for All}

Providing sustainable water supply and sanitation (WSS) services in developing countries remains an immense, and increasingly urgent, challenge. Although the Millennium Development Goal (MDG) target was metto halve, by 2015, the gap in access to improved WSS services-some 660 million people still lack access to clean water. The MDG target for sanitation was not achieved, and approximately 2.4 billion people lack access to improved sanitation, while 1 billion people still defecate in the open.

Adopted in 2015, the Sustainable Development Goals (SDGs) set the bar even higher. These global goals call for universal, safe, and affordable WSS access by 2030, along with other improvements in the way water is managed as a resource. The costs are commensurate with the heightened ambition. Existing sources of funding do not come close to covering the need for new infrastructure investments, and countries will need to tap into new sources of finance to meet the growing demand for WSS services.

At the same time, global demand for water-in urban areas especially-is rising alongside population growth and economic development, while the quality and availability of this resource is becoming more variable. The urban populations of Africa and Asia are expected to double between 2000 and 2030, changing where and how water is being managed to generate energy, fuel industry, produce food, and keep more people living healthy and productive lives. The opportunities afforded by development will come at an environmental cost as urban centers find their surface and groundwater resources more polluted. These water stress factors combine to put a higher price tag on delivering sustainable WSS services.
Moreover, rural areas are likely to remain relatively poorer and isolated from the benefits of urban development, including access to WSS services. In 2015, most people without WSS services were poor and living in rural areas in Africa and Asia. Fewer than 15 percent of countries in Africa report having ways to explicitly reduce inequalities in access to sanitation for the poor, and less than one third for access to water (WHO/ UN-Water 2014a). In Nigeria, 34 percent of rural residents live more than two hours from a functioning water source (World Bank, 2017a). The high levels of inequality in some countries will continue to deepen unless governments make a concerted effort to rebalance the use of public resources.

Meeting WSS goals, whether SDGs or lower levels of service, will require multiple institutions working in parallel toward the same end, each within its own sphere of influence. All sector stakeholders must not only bolster their individual performance-in governance, policy, technical capacity, and public and private finance-but also integrate these reforms in a way that can translate more and better-targeted investments into more and better services. The water sector, as a composite of multidisciplinary institutions, must address multiple challenges, from regulation to efficiency to affordability. The sector can only attract the financing needed to ensure sustainable services for this generation and the next if substantial progress is accomplished on such foundational elements.

\subsection{Purpose and Scope}

The purpose of this report is to bring together the current state of knowledge on water sector finance in developing countries and to set out the World Bank's vision for how countries can finance their WSS-related goals under increasingly challenging contexts. The report articulates 
a framework to help countries use public resources more effectively to crowd in new sources of finance and formulates practical recommendations for doing so.

It focuses specifically on financing the Water SDG (Goal 6), particularly on the WSS-related SDG targets 6.1-6.4 (box 1.1). The scope includes both urban and rural services provided for domestic, commercial, and limited industrial uses.

\subsection{The Broader Agenda: It's Not Just About Money}

Mobilizing finance, while the main topic of this report, is clearly not the only challenge to achieving universal access. Strong institutions are a prerequisite for translating investments into safely managed services. Other challenges include identifying the right technological solutions that can extend services to the hardest to reach, putting in place fair regulatory arrangements that maximize efficiency gains while ensuring affordability for the poorest, and dealing with rising uncertainty due to climate change. All of these aspects will have an impact, either direct or indirect, on how sector financing can be mobilized.

This report draws on a series of publications that the World Bank's Water Global Practice (WGP)-in its support to the High Level Panel on Water-produced to articulate a proposed approach to tackling the challenge of financing universal access to WSS. - These documents are highlighted in box 1.2.

This report is in line with the agenda outlined at the July 2015 Financing for Development conference in Addis Ababa, and it proposes a new approach to bringing the sector toward universal and sustainable WSS service delivery. The stepwise approach to finance,

BOX 1.1. SDG 6: Water and Sanitation for All by 2030

SDG 6 comprises eight ambitious targets rolled into one, including both universal and equitable access to safe and affordable water supply, sanitation, and hygiene by 2030 , as well as more sustainable water resource management. These goals go far beyond the challenge of access to services. They address the entire cycle affecting the availability and quality of those services. This starts with abstraction-to ensure efficient and sustainable use of water resources-and ends with the proper treatment and disposal of waste generated by WSS services, including wastewater and fecal sludge.

This report focuses on the four targets most closely related to WSS:

6.1. Achieve universal and equitable access to safe and affordable drinking water for all.

6.2. Achieve access to adequate and equitable sanitation and hygiene for all, and end open defecation, paying special attention to the needs of women and girls and those in vulnerable situations.

6.3. Improve water quality by reducing pollution, eliminating dumping, and minimizing release of hazardous chemicals and materials, halving the proportion of untreated wastewater, and substantially increasing recycling and safe reuse globally.

6.4. Substantially increase water-use efficiency across all sectors and ensure sustainable withdrawals and supply of freshwater to address water scarcity, and substantially reduce the number of people suffering from water scarcity.

Source: Adapted from the United Nations Sustainable Development Knowledge Platform 2015. 
BOX 1.2. Relevant WGP Publications on Financing Universal WSS Access

1. Achieving Universal Access to Water and Sanitation by 2030: The Role of Blended Finance (Leigland, Trémolet, and Ikeda 2016). The WGP prepared this discussion paper and associated case studies to support countries' efforts to mobilize commercial finance for service provision.

2. Financing Options for the 2030 Water Agenda. (Kolker et al. 2016). Targeted to multilateral development banks, this WGP Knowledge Brief was prepared to orient the actions of the High Level Panel on Water (HLPW) to mobilize financial resources and scale up investment for SDGs 6.1 and 6.2. It aimed to underpin the formulation of recommendations and commitments at the Budapest Water Summit 2016 and beyond.

3. Aid Flows to the Water Sector: Overview and Recommendations (Winpenny et al. 2016). This paper, in support of the HLPW, provides a complete picture of recent trends in aid to the water sector.

4. Training courses on creditworthiness and financing access were delivered to World Bank staff and clients in 2016 and 2017.

5. Sanitation and Water for All: How Can the Financing Gap Be Filled? (World Bank and UNICEF, 2017). This discussion paper supported preparations for the Sanitation and Water for All Finance Ministers' Meeting, held at World Bank headquarters in April 2017.

6. Briefing Note on Capital Efficiency in the Water, Sanitation, and Wastewater Treatment Sector (World Bank, forthcoming [a]). This discussion paper recommends the most efficient use of capital spending funding flows for delivering the municipal and rural domestic elements of SDG 6.

7. Global Study on Institutional, Policy, and Regulatory (IPR) Incentives for WSS Services (World Bank, forthcoming [b]). This WGP flagship output consolidates the experiences of 11 countries in WSS sector reform.

8. Utility Turnaround Framework (World Bank, 2017b). This WGP flagship publication conceptualizes key attributes of successful turnarounds based on recent global experiences.

presented in figure 1.1, aims to instigate a virtuous cycle of sector performance such that service providers will climb the ladder toward creditworthiness to be able to attract increasingly larger volumes of commercial finance.

\section{Two foundational components are required for the transi-} tion to commercial finance to take shape. As shown in the orange bars in figure 1.1, an enabling environment must first be created through strong governance and institutional arrangements. Second, performance incentives must be put in place through institutions, policies, and/ or regulation for service providers to start efficiency improvements.

This cycle of continuous improvement happens over a long period of time, with many incremental steps happening within each block in a given country. Thus, to give the audience a more realistic view of how reforms happens in an incremental and iterative way, this report proposes a "financing framework" (figure ES.1) derived from the cycle shown in figure 1.1. Rather than providing steps to 
FIGURE 1.1. The Cycle of Improved Sector Performance

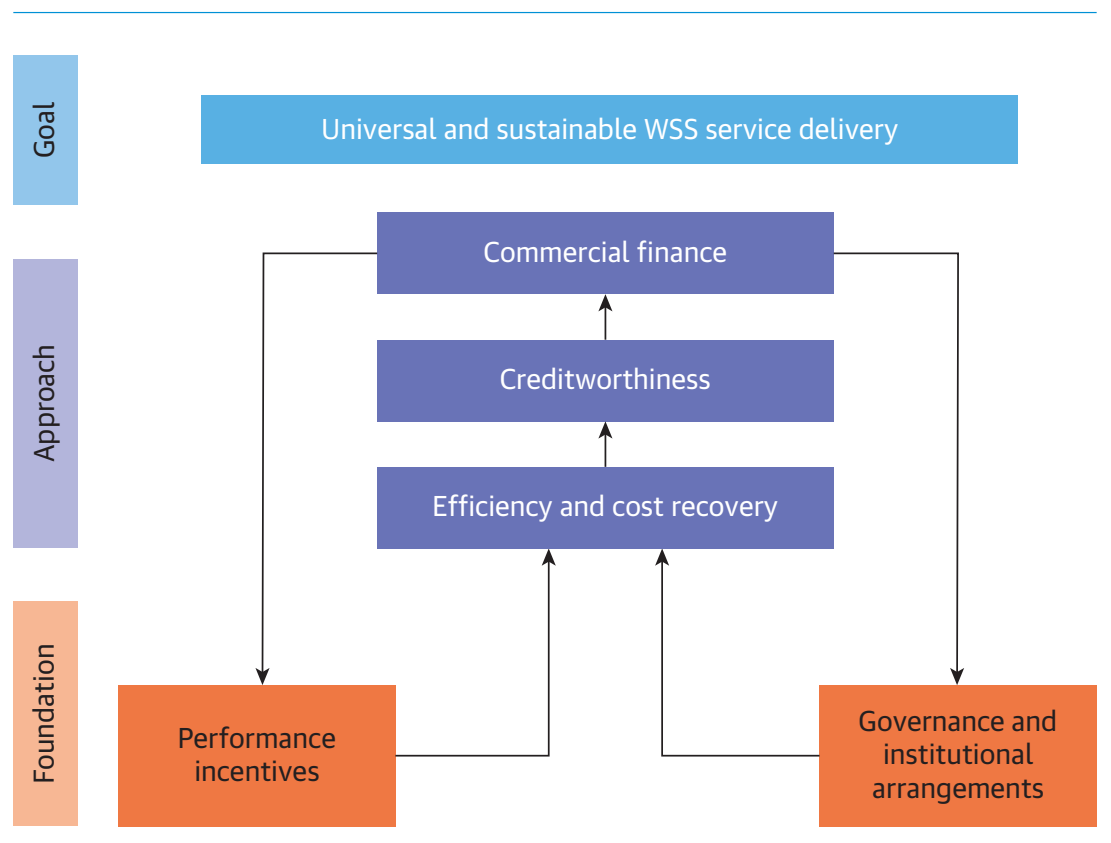

out how they can engage in the water sector more actively.

\subsection{Report Content}

Chapter 2 sets out how the sector is currently funded and why business as usual is insufficient for meeting WSS-related goals, covering the size of the investment gap, and the challenges presented by the status quo.

Chapter 3 proposes a financing framework toward more effective use of existing funds to enable the mobilization of new sources of finance, and explains the benefits and costs of commercial finance.

Chapters 4 to 6 detail the three components of the financing framework, providing practical advice and global experiences that demonstrate how countries can begin to make progress.

Chapter 7 summarizes how stakeholders can bring the three components together to mobilize commercial finance, and provides the main conclusions and recommendations of the report.

\section{Note}

1. The High Level Panel on Water (HLPW), convened by the UN Secretary-General and the President of the World Bank Group, focuses on the commitment to achieve SDG 6 and to contribute to the achievement of other SDGs that rely on the development and management of water resources. For more information, see the HLPW website on the UN Sustainable Development Knowledge Platform: https://sustainabledevelopment.un.org /HLPWater. 


\section{Chapter 2 \\ Why Is a New Financing Framework Needed?}

\subsection{The Status Quo Is Not Enough}

Inadequate water supply and sanitation (WSS) service costs low- and middle-income countries (LMICs) an estimated $\$ 260$ billion per year through various economic impacts-from poor health to environmental degradation-which equates to 1.5 percent of global gross domestic product (GDP) (WHO 2012). In some very poor countries, this figure may rise to 10 percent of GDP.

Access is highly unequal within countries and can be a significant factor in exacerbating poverty. For example, in Mozambique, 90 percent of underweight mothers also only have access to an unimproved sanitation facility. The divide is also clear between urban and rural areas: in Ecuador, 93 percent of people in urban areas have access to improved water services, but 24 percent of the rural population still drinks contaminated water (World Bank, forthcoming [c]).

\section{New global water stressors, from urbanization to climate} change, are compounding the challenge at a steady pace. LMICs are becoming more urban and more industrialized. They have higher standards of living and evolving tastes that demand more and higher-quality WSS services. By 2030, under current water management and pricing regimes, water demand will exceed supply by about 40 percent (2030 WRG 2012).

\section{Communities also need better ways of coping with more} intense water-related hazards. Floods and droughts are particularly menacing, destabilizing communities and creating humanitarian crises. Drought has been deemed the deadliest physical hazard that exists today, affecting more than 2 billion people since the beginning of the 20th century (WWAP 2012). Water insecurity is a drag on economic development on the order of
\$500 billion annually-excluding environmental and other nonmonetized impacts (Sadoff et al. 2015).

\subsection{The Investment Gap Is Widening}

Providing sustainable WSS services in LMICs remains an immense, and increasingly urgent, challenge. Although the Millennium Development Goals (MDGs) were partially met, none of the 48 least-developed countries met the WSS targets. The achievements left behind large parts of the global population-primarily the poor, rural residents and many people living in South Asia and Sub-Saharan Africa.

Adopted in 2015, the Sustainable Development Goals (SDGs) set the bar even higher (box 2.1). These global goals call for achieving universal and equitable access to safe and affordable water supply, sanitation, and hygiene (WASH) and for ending open defecation-and the costs are commensurate with the heightened ambition (figure 2.1, table 2.1). Existing sources of funding do not come close to covering the need for new infrastructure investments, and countries will need to tap into new sources of finance to meet the

BOX 2.1. Three Key Differences between the MDGs and the SDGs

1. Universal coverage: From halving the population without access to achieving universal access

2. Comprehensive coverage: From a focus on WSS to considering the whole water cycle

3. Sustainable coverage: From basic access to safely managed access 


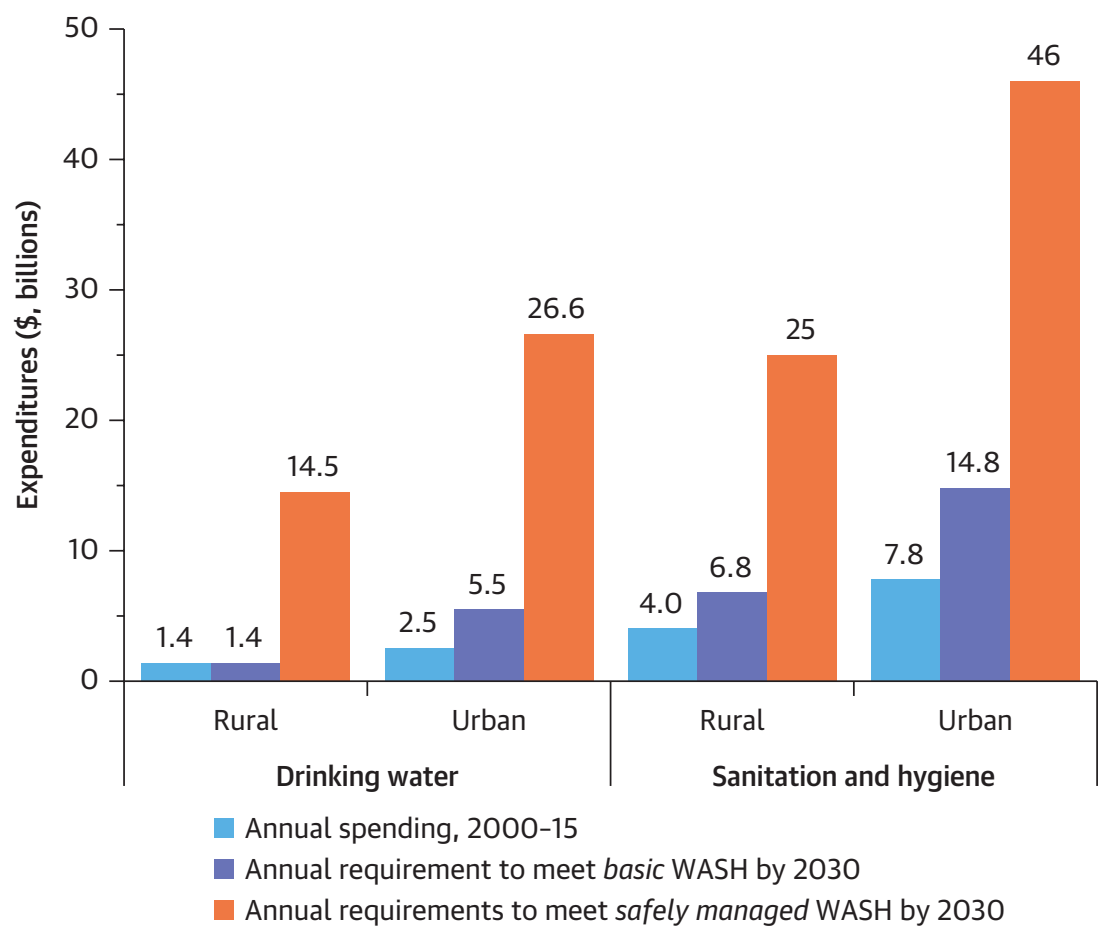

Source: World Bank/UNICEF 2017.

Note: WASH = water supply, sanitation, and hygiene.

TABLE 2.1. WASH-Related MDG and SDG Definitions, by Target

\begin{tabular}{lll}
\hline & MDG & SDG \\
\cline { 2 - 3 } & Basic access $^{\mathbf{a}}$ & Safely managed access \\
\hline Drinking water & $\begin{array}{l}\text { - Within a 30-minute } \\
\text { round trip }\end{array}$ & - On premises \\
& - Available when needed \\
& • Free from contamination \\
\hline
\end{tabular}

Sanitation and - Hygienic separation of human - Not shared with another household hygiene excreta from human contact - Proper disposal and treatment of waste

Note: MDG = Millennium Development Goal; SDG = Sustainable Development Goal. a. Formerly known as "improved" under the MDGs.

growing demand, not just for more services for more people, but also to fund adequate operations and maintenance $(\mathrm{O} \& \mathrm{M})$ as well as supervision for more sustainable services.

Capital and operating costs for WSS service provision needed under the SDGs will be much higher than current spending levels. Although information is scarce because of a lack of an adequate system for tracking WSS sector spending, investments in extending access to WASH services were estimated at $\$ 16$ billion per year during the MDG period (Hutton and Varughese 2016). This is less than the capital costs of expanding basic access to WASH services. (What now qualifies as "basic" under the SDGs was referred to as "improved" under the MDG definitions.) What's needed to deliver universal access to safe services under the SDGs is around $\$ 112$ billion per year (ranging from $\$ 74$ billion to $\$ 166$ billion), or 0.39 percent of GDP. Most of this investment will be needed for sanitation, with 40 percent for urban sanitation and 20 percent for rural sanitation (figure 2.1). Moreover, O\&M costs are expected to be 1.6 times more than capital costs per year by 2029 (Hutton and Varughese 2016).

\section{To provide safely managed services} in a sustainable manner, both the assets and the quality of service they deliver must be maintained over time. Many countries do not routinely consider the long-term O\&M costs of existing infrastructure or include those costs in costing exercises. Moreover, few countries have monitoring systems in place to measure the functionality of rural water points, or the use of septage treatment facilities several years after construction. A recent calculation by the U.K. Department for International Development (DFID) of value for money of rural WASH services in six countries showed that information on sustained outcomes 
was lacking in all but one country-Bangladesh-and also showed that 85 percent of public deep tube wells remained in service after six years (Trémolet et al. 2015). To deliver sustainable services, more funds will need to be directed to measuring the continued use and quality of WSS infrastructure.

\subsection{The Financial Landscape Is Changing}

Previous attempts at changing the approach to sector financing were made more than a decade ago. Shortly after the MDGs were articulated, the World Panel on Financing Water Infrastructure (referred to as the "Camdessus Panel," after its chairman) was formed to identify what was needed to mobilize finance in the water sector (box 2.2). The panel's report was one of the first comprehensive investigations into a wide range of financing options for WSS (Winpenny 2003).1

Neither the Camdessus report nor subsequent reports of this nature triggered significant increases in flows of private finance to the water sector. Change has been minimal, and LMICs have experienced varying levels of success with leveraging private finance. There are two likely reasons for this. First, from the supply side, although ODA has since doubled, flows were not redirected in a way that would facilitate more private sector lending or lending to subnational governments. Most concessional financiers have continued to lend primarily to national governments and to benefit from sovereign guarantees, with little or no effort to leverage private finance. Second, on the demand side, service providers have remained largely inefficient and unable to attract private finance on their own.?

Today's financing landscape has been further altered by the $\mathbf{2 0 0 8}$ global financial crisis and subsequent banking sector reforms. The resulting banking regulations (including Basel III) have generally reduced international financiers' risk appetite for longer tenor loans. Moreover, new international development partners are joining the field, including the Bill and Melinda Gates Foundation, the Asian Infrastructure Investment Bank (AIIB), and a number of national development banks in middle-income countries. Finally, another potential new source is climate finance.

Given that most of the impacts of climate change will be felt through water resources, climate funds hold the promise of mobilizing additional aid and private flows to the sector. In 2014, \$392 billion was invested globally toward climate action, more than a third of which

Box 2.2. The Camdessus Panel: A First Attempt to Break the Status Quo

The World Panel on Finance Water Infrastructure presented its findings in March 2003 at the 3rd World Water Forum in Kyoto, Japan. The report's extensive list of 90 recommendations included improved governance, tariff reforms, sector planning, and using official development assistance (ODA) in a more catalytic way to facilitate more private finance. The report called for doubling all financial flows to the sector from all sources, including private finance. Among the options for accelerating private investment flows were credit ratings, multilateral development bank (MDB) guarantees, and political risk coverage; the use of securitization and collateralization of loan-debt obligations by banks; public-private partnerships (PPPs); output-based aid (OBA) subsidies; and credit pooling by subnational governments. To mitigate foreign exchange risk for international water financiers, the report also recommended the creation of a devaluation liquidity backstopping facility.

Source: Winpenny 2003. 
came from and was invested in LMICs (Buchner et al. 2015). Overall, domestic investment constitutes 74 percent of all climate finance, mostly from private project developers. There is huge potential to match water projects with increasing opportunities for climate finance (box 2.3). However, some of these funds are concessional and are constrained by certain requirements (such as sovereign guarantees), while some are not.

As private participation in the water sector is decreasing and commercial banks are being more selective, it is more important than ever for development partners and governments to work together to make the sector more attractive. Only through attracting new sources of finance, including commercial finance, will governments be able to achieve their WSS goals.

In contrast, there is a large global savings glut, with much of the money looking for reliable investments. Globally, pension funds, insurance companies, mutual funds, and sovereign wealth funds hold around \$100 trillion in assets under management. Sovereign wealth funds and central banks alone currently have assets of about
\$15 trillion (IMF 2016). Total development finance from MDBs in 2015 was equal to just 1 percent of this, at around \$127 billion (World Bank 2015a).

\subsection{The Potential Benefits Are Immense}

The projected global (average) economic return on universal access to water supply and sanitation is $\$ 4.3$ for every $\$ 1$ invested (WHO 2012), and is higher for sanitation than for water. The benefits of improved livelihoods include reduced mortality and morbidity, more-productive people (less illness and less time spent collecting water), improved dignity, lower rates of sexual violence, and a clean environment.

Investments, particularly in sanitation, can reap huge benefits for long-term economic growth. The link between access to improved sanitation and reduction in mortality for children under age 5 is clear. Countries with higher sanitation access have lower mortality rates. In figure 2.2, the size of each circle represents a country's population. A second correlation, between poor sanitation (and high population density) and stunting, a form of undernutrition, has also been proven. In India,

Box 2.3. The Potential of Climate Finance

Water is a small piece of the global climate action agenda; most funds are used to finance renewable energy projects. An estimated 80 percent of funds are for mitigation and 20 percent for adaptation. The WSS sector's share of mitigation funds is split under an array of measures, including energy efficiency, nonrevenue water reduction, pump replacement, network optimization, and reductions in greenhouse gas (GHG) emissions. For adaptation, water and wastewater management received \$15 billion in funding, of which 71 percent went to low- and middle-income regions of East Asia and the Pacific, Sub-Saharan Africa, and Latin America and the Caribbean (Buchner et al. 2015).

A larger portion of these emergent funds could be tapped if water projects were better prepared to articulate the cobenefits and the impact they could have on mitigating the effects of climate change. The World Bank aims to increase its support of climate resilience and GHG reductions to nearly one-third of its annual commitments ( $\$ 16$ billion) and to leverage cofinancing of $\$ 13$ billion per year by 2020 , or the equivalent of all ODA currently going to WSS. 


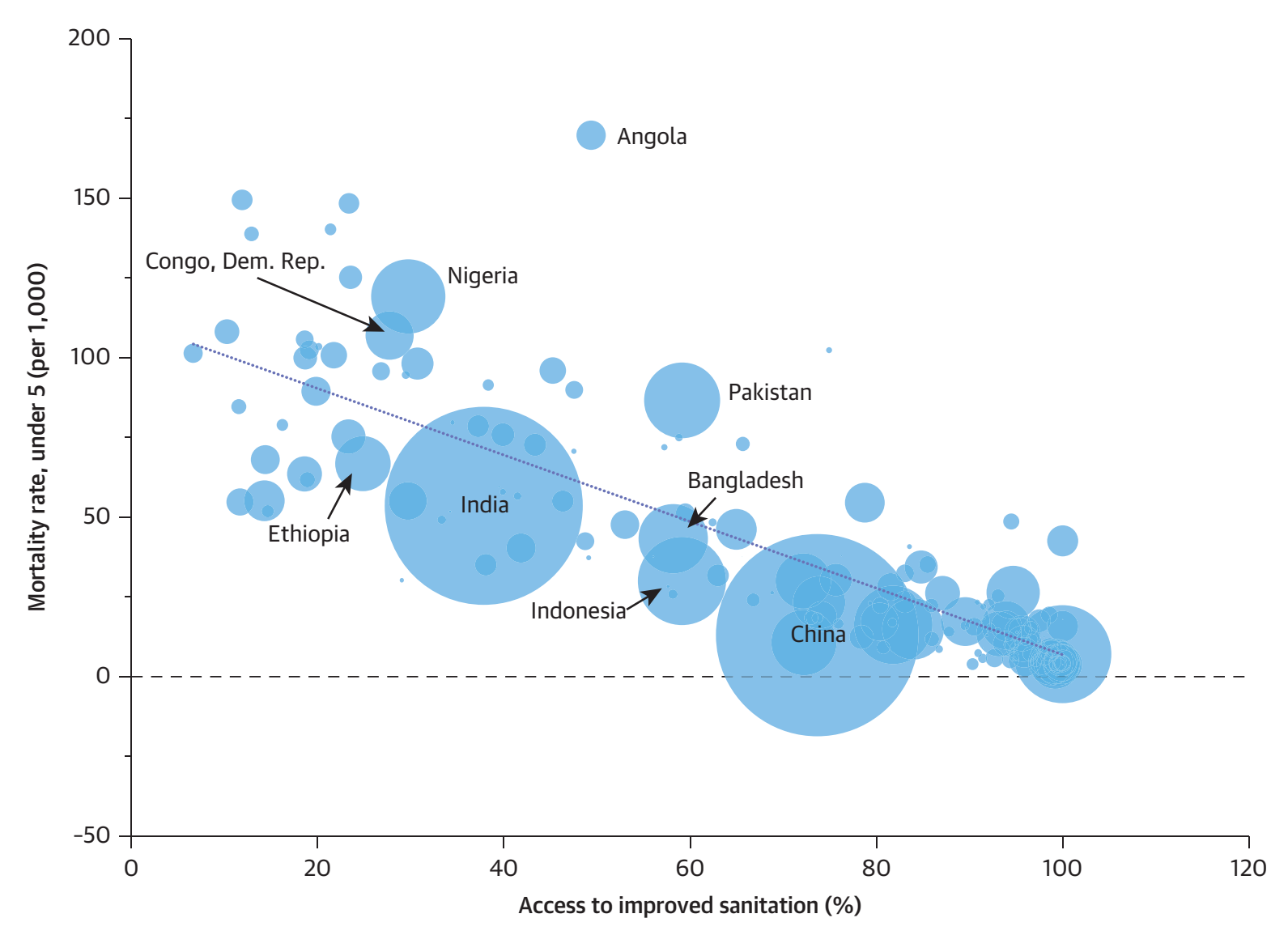

Source: World Bank 2015b.

where nearly half of all children are stunted, a 2013 study shows that a 10 percent increase in open defecation increases stunting and severe stunting by 0.7 percentage points (Spears, Ghosh, and Cumming 2013).

Finally, the poor will pay less for water. Studies show that purchasing water from vendors, or drilling wells at the household well for self-supply, can cost 10-15 times more than what is charged by service providers. Living without access to a formal and improved water service forces many communities to buy from private vendors, some of which operate illegally and charge exorbitant rates. For the poor, buying water can take a large portion of their low incomes (box 2.4). Formalizing service can cut these rates by 10 to 15 times while at the same time generating tariff revenues for formal service providers.

BOX 2.4. The Real Cost of Water for the Poor

Fifty liters of water per person per day (the minimum World Health Organization [WHO] requirement) from a private vendor costs the following, based on a typical daily salary of a low-income person living in each city:

- Port Moresby, Papua New Guinea: 54 percent of daily salary

- Accra, Ghana: 25 percent of daily salary

- Maputo, Mozambique: 14 percent of daily salary

Source: WaterAid 2016. 


\subsection{How Is the WSS Sector Currently Funded?}

The WSS sector is funded by a mix of public and private sources, some of which need to be repaid (figure 2.3). Service providers receive revenue from three main sources: tariffs, domestic tax revenues, and voluntary transfers from external sources (commonly known as the “3T's") (Winpenny 2003). These sources are preferred because they do not require repayment, but they are seldom sufficient to fill the financing gap when there is a substantial coverage deficit. Many countries and service providers also borrow money on concessional or commercial terms to be repaid over time. Regardless of whether funding or finance is used, reductions in one revenue stream require increases in another to meet the shortfall.

\subsubsection{Funding Sources}

There are three main traditional sources of sector funding, which are nonrepayable (figure 2.3 ):

- Tariffs, user fees, and household investment include all payments, charges, or direct investments made by water users themselves in exchange for a service they receive, including, for example, household payments for on-site sanitation or "sweat equity" contributions to family-owned, small-scale independent service providers (SSIPs). Water service providers are generally in charge of collecting tariffs to cover their costs. In LMICs, tariffs generally only cover, or do not even cover, O\&M costs.

- Domestic tax revenues include all funding allocations from the public budget. These funding flows are allocated by governments (at the central or local level) for investment, subsidies, and general sector funding (for example, to pay for government staff who are in charge of supervising or monitoring the sector). They are used to contribute to both O\&M costs and capital costs.

- Transfers from external sources refer to funds from international donors, charitable foundations, NGOs, decentralized cooperation, local civil society organizations, or remittances from nationals working abroad. These transfers typically come from sources external to the country: that is, they are contributed

FIGURE 2.3. Traditional Revenue Sources for the Water Sector

Funding sources ("3Ts")
Tariffs
User fees for services provided and
households' investment for self-supply

Note: $\mathrm{NGOs}$ = nongovernmental organizations; ODA = official development assistance . 
by taxpayers or donors in other countries. They are mostly grants and are used mainly to support capital costs. They are not predictable and therefore most often used to support capital, rather than operating, expenses.

Tariffs should be the largest and most stable source of sector revenues. 3 When they are insufficient, the gap needs be filled by taxes or transfers from external sources. Many of the world's poorest countries keep tariffs low and seek to rely on public funding and external transfers to build and maintain WSS infrastructure. However, these are seldom sufficient, and deficits in building or maintaining assets cannot be overcome, because service providers are locked into a vicious cycle of inadequate maintenance and limited services.

Most countries allocate a small portion of government budgets to WSS. During the MDG era, governments in Africa would have needed to spend an estimated 2.58 percent of GDP on average to meet WSS MDG targets. Indeed, Morocco and South Africa spent 2 percent and 4 percent, respectively, with significant improvements in WSS access. However, a review of public expenditure in five low-income countries in Africa showed an average annual investment of just 0.32 percent, or $\$ 1.71$ per person, with more funding going to the urban than rural sector (van Ginneken 2011). The global average is not much higher; in 2017, government coordinated expenditure for WSS was estimated at 0.42 percent of GDP (WHO/UN-Water 2017).

\subsubsection{Financing Sources}

In many countries where financing needs are high, investments need to be front-loaded to meet WSS targets. To that end, it will be necessary to mobilize repayable financing up front, which will then be repaid over time. Concessional finance sources, which have been the main source of repayable financing in most developing countries up to this point, have not been and will not be sufficient in the future. Much greater emphasis will be needed on leveraging commercial finance, both national (from domestic sources) and international, despite higher costs.

As shown earlier (figure 2.3), there are two kinds of repayable financing:

- Concessional finance is repayable finance offered by multilateral and regional development banks, bilateral donors, and domestic development banks. It is provided at a lower interest rate with a longer tenor than commercial finance. These "softer" payment terms are made possible thanks to a grant element wrapped into the interest rate and grace period of the financing terms. It tends to be available in hard currencies.

- Commercial finance is defined as market-based finance, including debt, equity, and certain kinds of guarantees. It is market-based in the sense that the cost of this type of financing is determined by supply and demand in capital markets rather than by governments or other regulatory bodies. Most forms of market-based finance are repayable to their providers.

\section{Concessional Finance}

Although it makes up only about 10 percent of the investment costs needed to achieve SDG targets 6.1 and 6.2, concessional finance can be critical for some countries. Concessional finance is the single largest flow for 24 of the world's 45 most underresourced countries (WaterAid 2015). ODA to water is about $\$ 13.3$ billion per year (2012-14 average). 4 One-third of ODA comes from MDBs, with the rest from bilateral funders. ODA, provided as a mix of grants and loans, includes investment not only in infrastructure but also in technical assistance to prepare for implementing loans, project preparation, and guarantees that can serve as a bridge to private finance. About twothirds of official development finance is ODA, with another one-third (about $\$ 6$ billion per year between 2009 and 2014) provided in the form of nonconcessional loans to mostly middle-income countries. 
However, donor incentives are not always aligned with supporting the countries or subsectors with the highest need for aid. ODA in WSS is mostly targeted to large systems in urban areas rather than toward providing basic WSS services or services in rural areas. And although the regions in greatest need (Sub-Saharan Africa and South Asia) received nearly half of all aid in water, the largest country-level recipients are generally not the lowest-income countries.

Unlike concessional finance-which tends to require a sovereign guarantee and therefore typically flows to national governments-private finance can be accessed by both public and private water sector providers and local governments, depending on the financial architecture in the particular country. Project finance can also be used in cases where specific projects are investment ready.

\section{Commercial Finance}

Commercial finance comes from various sources and can be used to meet the great diversity of investment needs. This type of financing can be grouped into five categories: vendor or supplier finance, microfinance, commercial bank loans, bonds, and equity (figure 2.4). Providers of commercial finance can include water equipment suppliers, microfinance institutions, commercial banks, private investors, or investment funds via capital markets. (For definitions of each category of commercial finance, see appendix A.)

This report focuses on commercial bank loans, which make up a large portion of commercial finance and are the most straightforward instrument to compare with alternative public sources, including concessional finance.

FIGURE 2.4. Uses of Commercial Finance, by Borrower Size and Financing Need

Size of financing needs

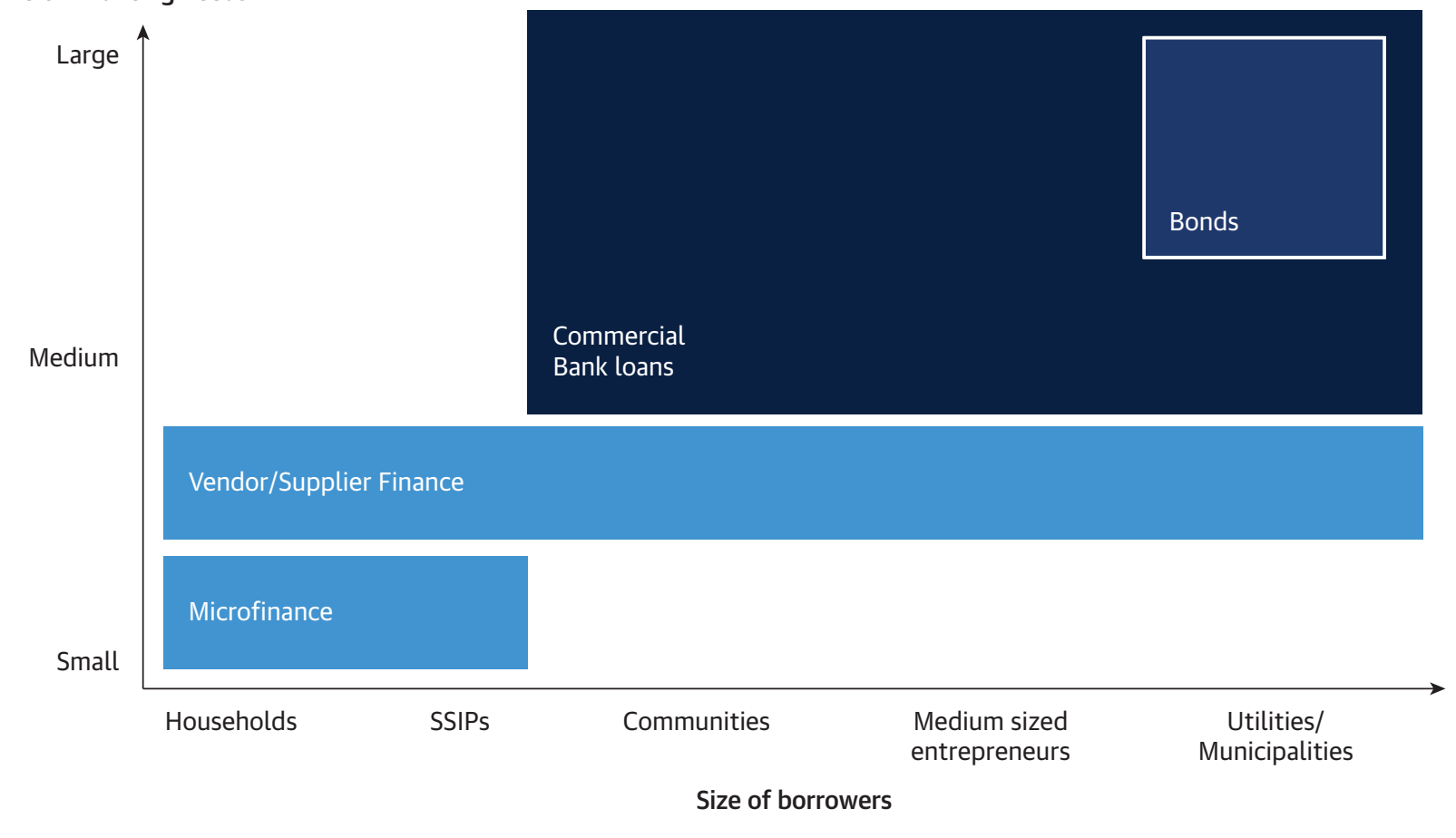

Source: World Bank/UNICEF 2017. 
The various providers of commercial finance are generally willing to take on varying levels and types of risk, which can be complementary. For example, banks may have the capacity and interest to lend at commercial rates for the construction phase, while capital market instruments can better match the longer tenor requirements to finance the operational phase. Commercial bank finance constitutes the largest share of private finance to global infrastructure. In the aftermath of the global financial crisis, commercial banks face greater restrictions on long-term financing, making capital markets a more attractive source (Garcia-Kilroy and Rudolph 2017).

Commercial finance can come from both domestic and international sources, each with its respective costs and benefits. International financiers generally have significant volume and sector expertise, including project finance expertise, but are active in a subset of countries. International commercial finance is provided by financiers operating in global markets and is typically provided in hard currency such as U.S. dollars or euros, except in cases where currency swaps are available, making service providers-whose revenues are in domestic currency-susceptible to foreign exchange risk. Although global interest rates are at a historical low, high country and borrower risk premiums applied by international finance providers make such financing costly for water service borrowers.

Accessing commercial finance is not equivalent to privatizing the sector. In fact, in many high-income countries, publicly owned water service providers have leveraged substantial amounts of commercial finance without relinquishing control over management of the service or selling shares. This is because the source of finance is separate and different from the implementation model. The implementation model determines who owns or manages the assets and who delivers the service. Various models exist, from fully public to fully private. For those that involve some form of private sector participation (PSP), this can come in the form of service contracts, management contracts, or leases that leverage private sector expertise and enable the sharing of risk (figure 2.5). Private participation in financing simply means that public or private operators can access private finance to fund their infrastructure needs, usually through debt instruments.

Although no aggregate numbers are available on total amounts of commercial finance in WSS, the sector on average attracts only 3 percent of all PSP in infrastructure (energy, transport, and water) projects (2009-14) (World Bank 2016c). This number tends to reflect only PPPs and not debt instruments that supported water-related infrastructure. To grow this number, it will be critical for governments to support private sector finance by investing in sound enabling environments (such as economic and environmental regulation or governance frameworks) that protect consumers. Governments also need to ensure that potential lenders understand the risks and benefits of investing in WSS. In addition, governments may need to advocate for and engage citizens on the benefits of private finance, especially in countries where there is strong opposition from prior negative PSP experiences.

FIGURE 2.5. Sources of Finance vs. Implementation Models

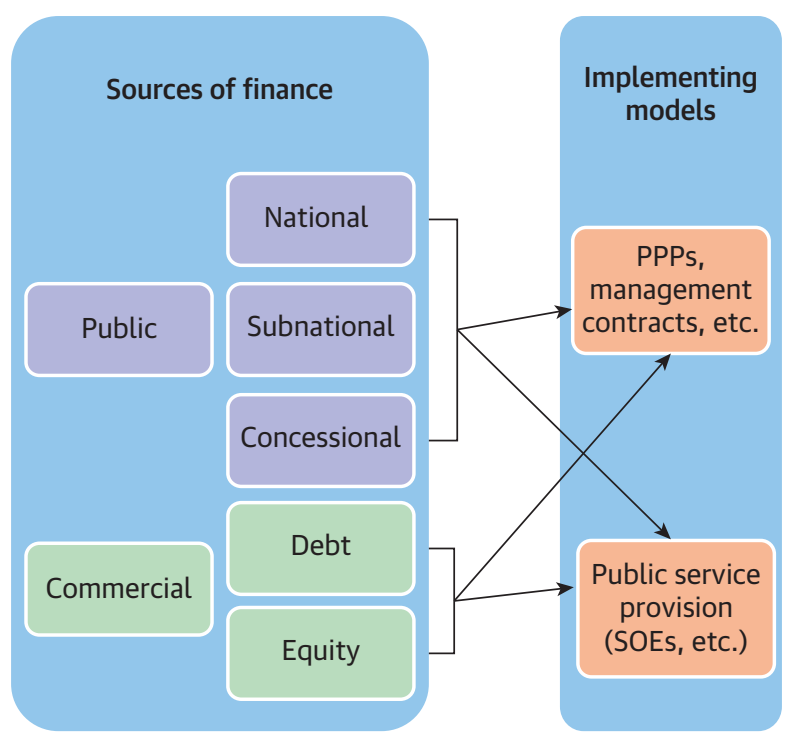

Note: PPPs = public-private partnerships; SOEs = state-owned enterprises. 
Financing in the water sector can come from either public, private, or mixed sources. As noted earlier, the source of finance-whether a concessional loan from an MDB or private equity from an individual investor-differs from the implementing modality selected to deliver a service. Implementing modalities include a host of options, including an SOE, a private operator, a public utility under a management contract, local government, and others (figure 2.6).

\section{No "Typical" Financing Regime}

Because each country has its own unique mix of public and private sources of finance, there is no aggregate view of the way the WSS sector is currently funded at a global level. A WHO-UN-Water TrackFin initiative is making such data available at the country level to enable comparisons. Brazil, Mali, and Ghana, show drastically different arrangements, with relatively larger shares of repayable finance in Ghana, household (self-supply) in Brazil, and external sources and government funds in Mali (figure 2.6).

Different countries leverage their WSS revenue (tariffs, transfers and taxes) to mobilize different types and volumes of repayable finance. Many LMICs extensively borrow concessional finance for capital works, compared to high income countries where commercial finance often makes up a large share of capital expenditure finance, even when WSS services are owned and managed by the public sector.

\subsection{Conclusion}

The status quo is insufficient to meet the widening WSS investment gap. The supply of public funding and private finance is not equivalent to the potential benefits a country can reap from a well-functioning WSS sector-which can be immense not only for the poor but also at a national and macroeconomic scale. These benefits should be weighed in decisions about how to scale up sector funding.

This stark reality calls for a major shift in the way resources are allocated and used in the sector. Each country is different and will require a customized solution that, where possible, leverages public funding and concessional finance to mobilize commercial financeeither international or domestic. It is critical to note that commercial finance is not the same thing as privatized service delivery; private finance can be mobilized by service providers owned and operated by government entities.

\section{Notes}

1. The Camdessus report was the first in a series of water sector reports focused on financing, including a report by the Gurria 
Task Force, released at the 4th World Water Forum in Mexico (Van Hofwegen 2006); recommendations formulated for the 6th World Water Forum in Marseille (WWF/CS2 2012); and a 2015 report by the Organisation for Economic Co-operation and Development (OECD) with the World Water Council and Global Water Partnership (GWP), released for the 7th World Water Forum in Daegu, Republic of Korea (WWC/OECD 2015).

2. "Service provider" refers to all entities that are responsible for water services, which can include, but are not limited to, the delivery of WSS services through utilities, small-scale independent service providers (SSIPs), subnational governments, or specialized state-owned enterprises (SOEs).
3. In some higher income countries national policy dictates that government funds cover most or all of the cost of service, for various reasons, with only a small portion coming from tariffs. However, this is often not possible in many LMICs.

4. Official development assistance (ODA) is a measure of aid flows. It refers to flows of official financing that have the main objective of promoting the economic development and welfare of developing countries and that are concessional in character, with a grant element of at least 25 percent (using a fixed 10 percent rate of discount). By convention, ODA flows comprise contributions of donor government agencies, at all levels, to developing countries (bilateral ODA) and to multilateral institutions. 


\section{Chapter 3}

\section{A Proposed Framework for Financing Universal Access}

\subsection{Easing the Transition}

Facing a lack of funding, some countries can only invest in the water supply and sanitation (WSS) sector if and when money becomes available from donor agencies. Grants and concessional loans, coupled with low tariffs, can create a stop-and-start mode of investment that does not culminate in sustainable sector improvements. Moreover, this status quo, tolerated by both governments and donors alike, entrenches poor governance and inefficient service delivery and fuels further deterioration in performance.

Transitioning toward more commercial finance, and less concessional finance, can help reverse these trends. For example, commercial finance, working within a public sector framework, brings incentives, innovation, transparency, and fiscal discipline that can be hard to replicate with grants or concessional finance alone. A 2017 case study of a well-performing utility (CESAN) in Espírito Santo, Brazil, found that "Securing private funds compels CESAN to be contractually accountable and to generate expected financial returns.” (World Bank 2017b). By setting the right governance framework, governments can meet their WSS goals.

\subsubsection{The Relative Benefits of Commercial Finance}

The main benefits of mobilizing commercial finance can materialize in the long run, as efficiencies are realized for service providers and the country and sector as a whole. Mobilizing commercial finance where it is feasible frees up scarce public resources for other important purposes, including support of sector institutions to deliver important functions such as policy setting, monitoring, or regulation; and investment in activities that may not be able to attract commercial finance but that yield high economic returns for the country (such as rural sanitation).

Moreover, although commercial finance will likely be costlier, there are also some short-term benefits compared with pure concessional finance. These include faster access to and implementation of finance, more control over investment decisions, and lower transaction costs. These countrywide and sectorwide benefits are summarized in table 3.1.

While, at face value, commercial finance seems to have higher financial costs than concessional finance, that is not always the case. If all implicit costs are quantified, commercial finance can sometimes be less expensive in the long run than concessional finance. The major cost considerations are as follows: 1

- The repayment terms, which affect affordability

- The implicit costs associated with borrowing in foreign currency

- The implicit costs associated with waiting for concessional finance

First, costs can be quantified in annual payments as well as in total debt service. Commercial loans are generally paid off over a shorter period (3-10 years) than concessional loans (15-20 years). Thus, governments and service providers constrained by their annual capital budgets (and potential to increase tariffs) will see concessional loans as more affordable: they can be paid over a longer period and at a lower interest rate, making their annual payments smaller. Commercial loans, generate larger annual payments but could cost less overall if the impact of creeping currency devaluation, 
TABLE 3.1. Benefits of Mobilizing Commercial Finance for the WSS Sector

\begin{tabular}{|c|c|c|}
\hline Benefit & & How the benefit is realized \\
\hline \multirow[t]{2}{*}{ Countrywide benefits } & Fiscal discipline & $\begin{array}{l}\text { Commercial finance does not increase sovereign borrowing or crowd out other } \\
\text { sovereign borrowing. }\end{array}$ \\
\hline & Economic growth & $\begin{array}{l}\text { Public funding can be reallocated to other water subsectors (such as sanitation) that } \\
\text { cannot access commercial finance, enhancing the prospects for economic growth. }\end{array}$ \\
\hline \multirow[t]{5}{*}{$\begin{array}{l}\text { WSS sectorwide } \\
\text { benefits }\end{array}$} & Improved governance & $\begin{array}{l}\text { The additional scrutiny of investors fosters improvements in governance at both the } \\
\text { sector and corporate or service provider levels. }\end{array}$ \\
\hline & Sustainability & $\begin{array}{l}\text { Commercial finance reduces dependence on concessional flows, putting service } \\
\text { providers on the road to financial sustainability. }\end{array}$ \\
\hline & Improved performance & $\begin{array}{l}\text { The involvement of commercial lenders provides another layer of transparency and } \\
\text { accountability for maintaining service provider performance. }\end{array}$ \\
\hline & Faster financing & $\begin{array}{l}\text { Compared with concessional finance, commercial finance is not dependent on the } \\
\text { availability or timing of donor funds. }\end{array}$ \\
\hline & Lower transaction costs & $\begin{array}{l}\text { Compared with concessional finance, commercial finance can be accessed directly by } \\
\text { subnational service providers and is more often available in domestic currency. }\end{array}$ \\
\hline
\end{tabular}

Note: WSS = water supply and sanitation.

BoX 3.1. Lessons from the East Asia Financial Crisis

Many service providers in East Asia during the 1990s had foreign currency loans without accounting for foreign currency risk in their tariff formulas. The sudden and sharp devaluations of their local currencies as a result of the 1997 financial crisis drastically increased the cost of their financial commitments. The service providers attempted to confront the dilemma by increasing tariffs under conditions of substantial economic downturns, an exercise that proved largely unsuccessful. It was politically impossible to adjust tariff levels upward in the short term to recover current costs and regain lost ground. The impacts can still be felt today in Indonesia, where 300 service providers have successfully restructured through agreements with the Ministry of Finance and their local governments, yet most are still under significant financial turmoil and others bankrupt. This resulted in suspended investments and a decline in national coverage.

Source: Baietti 2001.

inflation and potential delays in arranging concessional financing, are factored in.

Second, although governments and service providers can borrow in either foreign or domestic currency, concessional finance is almost always denominated in foreign currency except in a few countries. 2 Revenues from WSS provision, on the other hand, are earned in local currency, providing a mismatch between earnings and expenses. If a local currency devaluation occurs, the repayment in foreign currency becomes costlier. This was a major lesson learned from the 1997 East Asia financial crisis (box 3.1). Local currency loans carry no such risk.

Even without incurring such a catastrophic devaluation, most currencies in developing countries would typically incur a “creeping devaluation”, partly linked 
to high inflation rates. The impact of such creeping devaluation when borrowing in hard currencies whilst generating revenue in local currency can be significant for water service providers, as shown in appendix B. Modelling presented in this appendix shows that, under relatively conservative assumptions, the impacts of domestic currency devaluation and of inflation can add about 30 percent to the total debt service of a concessional loan. All else being equal, a 15-year local currency loan at 10 percent interest can cost about the same as a 15 -year concessional loan at 3 percent interest in the event of a deterioration of the local currency.

Third, securing concessional loans can add another hidden cost: the cost of potential delays. Concessional financing can take time to arrange, due to internal bureaucratic processes both at the level of lenders and borrowers and taking account of the time needed to arrange sovereign guarantees, which are typically provided with such loans. Estimates summarized in appendix B show that, if a concessional loan is delayed by five years, the hidden added costs can exceed 80 percent of the loan value due to the impact of inflation and creeping devaluation during the "wait" period. Under such conditions, a concessional loan would become up to 30 percent more expensive than a commercial local currency loan. This estimate does not even consider the impact of "delayed benefits" from the investment, which would be even more significant and directly felt by the local population.

Overall, the issue is not whether a borrower should choose concessional or commercial finance, but rather how best it can leverage the benefits of each (or blend them) for specific investment needs. Commercial finance, for example, could be preferred for short-term investments (such as non-revenue water [NRW] reduction, increasing coverage, and performance improvements) where investment costs are quickly recovered. In contrast, concessional finance or commercial finance, which attracts institutional investors, is more appropriate for large projects with long repayment periods, such as network extensions.
In conclusion, governments should rely less on concessional finance in foreign currency for investments that have the potential to leverage some commercial finance in domestic currency. From a purely financial perspective, this is because it can cost them less in the long run-once the costs of currency risk, delay, and interest are factored in-while also conferring other social and economic benefits associated with faster implementation of loans. However, concessional finance will remain crucial going forward but should be better targeted to support upstream sector reforms and capacity building, in turn better enabling the unlocking of commercial finance in the long run.

\subsection{Why Does WSS Not Typically Attract Commercial Finance?}

WSS as a sector has the potential to attract commercial finance, but it does not frequently happen in low- and middle-income countries (LMICs). Investors that lend money for infrastructure assess the credit strength of the intended borrower, including the willingness and ability of the borrower to pay back the money. In high-income countries, lenders see the sector as presenting low-risk operations, with reliable, reasonable returns and clear and transparent governance structures. In LMICs, in contrast, they frequently conclude that water service providers are financially weak or not creditworthy. Several challenges contribute to this weakness.

First, water service providers (and particularly those at the subnational level) lack sufficiently reliable revenue streams. They have been constrained in their ability to increase tariffs to levels that would cover their costs, have limited access to tax revenues, and are supported by a mix of domestic subsidies and international concessional financing that vary over time.

Inadequate tariffs are the major constraint to reliable revenue streams. Decision makers need the political will to make smart policy choices and to communicate them effectively. For example, without tariffs the WSS 
sector cannot afford to provide sustainable services at all, and without well-targeted subsidies, the poor will not be protected. When subsidies are not well targeted, they keep service providers in a low-level equilibrium.

Second, given the monopolistic nature of the sector, commercial financiers would look for a strong sector regulatory regime to ensure predictable, transparent tariff-setting and service regulation-characteristics seldom encountered in LMICs. Service providers often cannot provide accurate, detailed information about their technical operations (assets, quality of service, losses) and financial operations (revenues, costs, customer data). Audit or disclosure rules may not be strictly enforced, and credit rating agencies may not exist or may be unfamiliar with the operations of the water sector.

Third, providers may lack sufficiently strong leadership, management skills, or corporate structure to enable them to prepare properly to access private finance. Together, these factors create a high-risk environment, which either demands higher returns for investors (meaning higher interest rates, which in turn could lead to higher tariffs) or causes investors to go elsewhere and place their money in other infrastructure investments or sovereign bonds. The bedrock of this challenge is weak operational efficiency and sector governance.

Fourth, institutional and legal restrictions may also be limiting private investment. Pension funds may be prohibited from purchasing securities that have not been listed on public exchanges for certain minimum periods, and are thus also prohibited from investing in initial sales of bonds. Banks may be allowed to invest only up to a certain percentage of their capital in securities sold by service providers. Service providers may be prohibited from issuing corporate bonds and limited to borrowing from government sources like intergovernmental loan funds or development banks. In some countries, banks are required to lend a certain percentage of their overall portfolio to local infrastructure projects in targeted sectors or regions.
These prescribed investments reduce the need for credit analysis but in turn keep these investors from developing knowledge of the water sector.

Even when the supply and demand for commercial finance align, lenders and borrowers are further constrained by their mismatched priorities. Service providers need to borrow money over long repayment periods, while the lenders that are most active in the sector (commercial banks) generally want short maturities and high returns (table 3.2). Institutional lenders, on the other hand, while well suited for long-term investments, are in lower supply in LMICs and have less exposure to the WSS sector. One way to address these issues is to use different financiers at different stages of the project cycle (that is, during construction as opposed to during operations and maintenance [O\&M]) given the changing risk profile.

Despite these challenges, a few private and public water service providers have tapped into local and international financial markets. These providers include Manila Water in the Philippines, Companhia de Saneamento Basico do Estado de São Paulo (SABESP) in Brazil, Nairobi Water in Kenya, and the Phnom Penh Water Supply

TABLE 3.2. Objectives of Service Providers and Lenders

\begin{tabular}{ll}
\hline Institution type & Objectives \\
\hline Governments and & - Long-term, stable financing \\
service providers & - Payments that match the useful life of \\
& the infrastructure \\
& - Low annual debt service costs \\
\hline Commercial banks & - Short maturities with high returns \\
& - Dedicated revenue streams in place of \\
& collateral \\
- Securitization measures for timely & repayment \\
- Ability to shift quickly into different \\
investments if needed
\end{tabular}


Authority (PPWSA) in Cambodia. In these cases, tapping into commercial finance has brought major benefits as commercial financiers hold the service providers to a high standard, keeping them on the track toward continuous improvement and better performance.

\subsection{A New Financing Framework}

This report proposes a new sector financing framework to help countries withstand external shocks while achieving their wSS goals. The three components of the financing framework (figure 3.1) are designed to bring commercial finance into the sector. Changes made within each component will be iterative and incremental to allow policies and capacity to align. There are also significant feedback loops among the components. For example, identifying and generating service provider efficiency gains allows for better planning and budgeting.

\section{FIGURE 3.1. Proposed WSS Financing Framework}

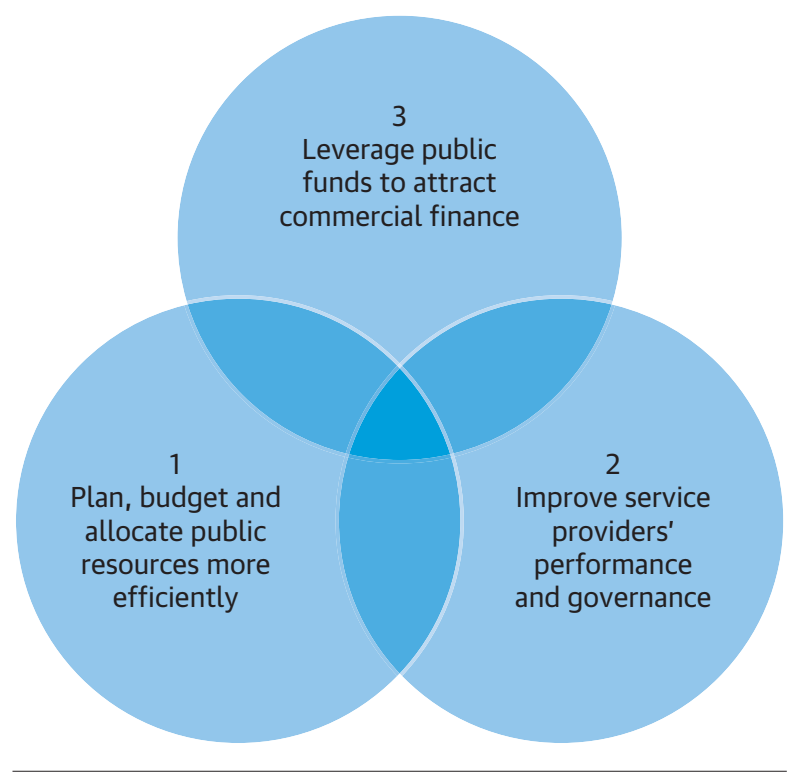

Note: WSS = water supply and sanitation.
The components are not necessarily sequential and can be implemented in parallel depending on local capacity and readiness for reform. However, where possible, the use of existing resources in the sector should be reformed first before new resources are mobilized.

In each country, this framework needs to be underpinned by the right governance and incentive structures at both the sector and service provider levels, and requires strong and sustained political support. The framework promotes the financial autonomy and self-sufficiency of service providers to ensure that recurring costs are paid for via user fees and tariffs, and with the limited use of well-targeted subsidies if needed. It then recommends ways to mobilize finance for capital investments from other sources.

\subsection{Conclusion}

Increasing the level of commercial finance for the sector would allow service providers to borrow and invest in expanding and improving the quality of WSS services without having to wait for scarce public resources to be made available. However, given that the current starting point is nonexistent or limited use of commercial finance, there needs to be a gradual move toward mobilizing such funds. This means improving the financial performance of service providers through a mix of improved technical and commercial efficiencies and through governance and regulatory reforms. These improvements will generate the financial surplus needed to borrow funds through private channels, thus complementing limited public funds.

\section{Notes}

1. For a more detailed explanation, see appendix B.

2. Some concessional lenders, such as the Asian Development Bank and Agence Française de Développement (AFD) are beginning to lend more in domestic currency but in a limited number of countries. 


\section{Chapter 4 \\ Component 1: Plan, Budget, and Allocate Public Resources More Efficiently}

\subsection{What Needs to Change?}

Public funds are critical, scarce, and pivotal resources in that they are the main funds available to support establishing the right framework and incentive structure to achieve sector goals. These funds should be used to support policies (such as those for water supply and sanitation [WSS], health, or poverty reduction) that are integrated and aligned with national objectives and enforced by institutions with sufficient capacity. Public funds can be most effectively used when the following elements are in place:

- Sound design of sector strategy and policies

- Comprehensive financial planning and budgeting

- The judicious allocation of resources and subsidies across WSS subsectors

- Funding and capacity building of sector institutions (for example, regulators or public-private partnership [PPP] units)

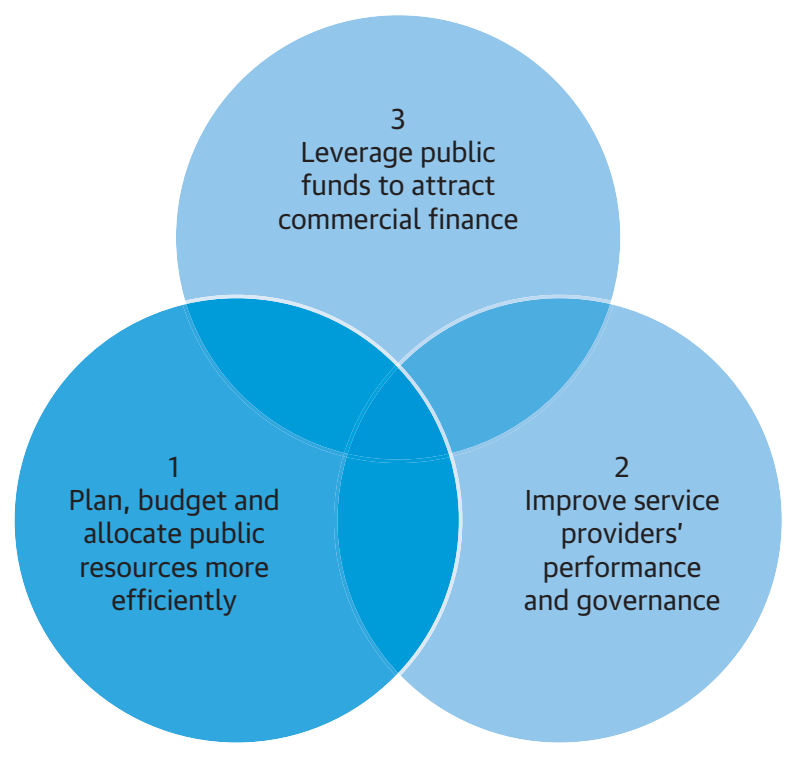

\subsection{WSS Sector Strategy and Policy}

WSS services have been recognized by many countries around the world as essential services through the human right to WSS.- Adopting the human right to WSS does not mean that water should be free; rather, it means that water tariffs should be affordable and that where subsidies are needed, they should be allocated on a transparent basis with clear allocation criteria and monitoring. Where there is a legal mandate, this provides the legal basis for defining long-term financing strategies for the water sector that realistically identify what revenue requirements can be covered through which funding source, and which consumers may benefit from subsidies to cover the residual financing gap (figure 4.1). In the cases where tariffs are insufficient to cover costs, tax revenues must be allocated to make up for the shortfall to maintain or achieve target service levels.

Defining sector goals is the first step in designing a realistic sector strategy. Policy makers in national and local governments will have a sound understanding of what it will take to achieve targets (like the Sustainable Development Goals [SDGs] or other WSS goals), how much it will cost, and where funding is likely to come from (including impacts on revenue requirements). The goals can then translate into policy statements or national plans and strategies that demonstrate the government's commitment.

\section{Countries are at liberty to set their own WSS goals in line} with, but not necessarily as ambitious as, the SDGs. For example, Indonesia's “100-0-100” national policy targets universal access to water and sanitation, ideally having zero people living in slums by 2019. Indonesia's targets are backed by a financial plan whereby national and subnational government funding makes up more than half 
of the required funding and is used to leverage about 20 percent in commercial and other forms of private investment (World Bank, forthcoming). Regardless of the level of ambition of WSS targets, they need to be realistic and achievable given the existing (or planned) institutional capacity and financial architecture.

FIGURE 4.1. Example of Financing Strategy for the Rural Sanitation Subsector

\begin{tabular}{|c|c|c|c|c|}
\hline Costs & & Costs & Funding & \multirow{3}{*}{$\begin{array}{l}\text { Provide subsidies to } \\
\text { reduce up-front financing } \\
\text { costs, internalize } \\
\text { externalities, address } \\
\text { affordability constraints }\end{array}$} \\
\hline $\begin{array}{l}\text { Maintenance } \\
\text { and } \\
\text { operating } \\
\text { costs }\end{array}$ & $\begin{array}{l}\text { Reduce } \\
\text { costs } \\
\text { through } \\
\text { innovation }\end{array}$ & \multirow{3}{*}{$\begin{array}{l}\text { Maintenance } \\
\text { and } \\
\text { operating } \\
\text { costs } \\
\begin{array}{l}\text { Capital } \\
\text { costs }\end{array}\end{array}$} & $\begin{array}{l}\text { Household } \\
\text { recurrent } \\
\text { payments }\end{array}$ & \\
\hline \multirow[t]{3}{*}{$\begin{array}{l}\text { Capital } \\
\text { costs }\end{array}$} & \multirow{3}{*}{$\begin{array}{l}\text { Lower cost } \\
\text { technology }\end{array}$} & & $\begin{array}{l}\text { Targeted } \\
\text { subsidies }\end{array}$ & \\
\hline & & & $\begin{array}{l}\text { Household } \\
\text { capital } \\
\text { investment }\end{array}$ & Micro-finance \\
\hline & & & & $\begin{array}{l}\text { Support/leverage } \\
\text { micro-finance to } \\
\text { support household } \\
\text { investment }\end{array}$ \\
\hline
\end{tabular}

Source: World Bank.
Policies should be part of a comprehensive framework to ensure that institutions work cohesively toward the same objectives. For example, Uganda set a policy target of 100 percent WSS coverage in urban areas by 2015, as one of several sector strategies under the country's framework Poverty Eradication Action Plan. The National Water and Sewerage Corporation (NWSC) then implemented propoor tariff policies and subsidized connections for the poor. These policies led to new services for more people (World Bank 2014b), and by 2015 nearly 96 percent of urban residents had access to improved water yet only 29 percent to improved sanitation.

\section{Where policies do not align or are} not pragmatically linked, they can create confusion and stall reform. Indonesia's prior attempts at sector reform show how perverse incentives structures can take

Box 4.1. The Cost of Misaligned Incentives

Indonesia's 1999 decentralization law gave local WSS service providers (PDAMs) the mandate for WSS service delivery and local governments the responsibility for investing in the sector. However, 90 percent of local government revenues were still coming from the central government. Moreover, under the corporatization law, local governments were allowed to corporatize PDAMs from which they could extract revenues, even when they were unprofitable. PDAMs were created in an ad hoc manner and had no real power over tariff setting, leaving no incentive to improve performance, increase access, or cut costs.

To bolster investment, a donor-funded, output-based aid program called Water and Sanitation Hibah was introduced in 2009 to expand access to water to 70,000 and access to sanitation to 10,000 poor residents. Local governments were required to install and pay for 50 percent of all connection costs. Although Hibah expanded much-needed services to the poor, the program was not aligned with the existing incentive framework. In 2016 there were 421 corporatized PDAMs, 20 percent of which were financially "sick." Those that expand coverage through such programs will have higher operating costs that will continue to be subsidized at low efficiency unless more effective incentives can be introduced.

Source: AusAID 2011; World Bank, forthcoming. 
hold when policies are not interlinked (box 4.1). Having learned from this experience, Indonesia's new 100-0100 strategy has been designed as part of the National Development Program rather than as a stand-alone sector strategy, which enables the corresponding incentives to be better aligned.

\subsection{Sector Financial Planning and Budgeting}

In many low- and middle-income countries (LMICs), the process for determining national sector budgets is political, top-down, led by the Ministry of Finance, and often not done on a consultative basis. In some cases, line ministries, local governments, and service providersall with a great stake in sector performance-do not provide strategic input into the process, such as the identification of long-term sector investment needs or where funds could be put to the most efficient use. Budgets may be too low when they are not linked to

Box 4.2. The Capacity to Spend Effectively

During the Millennium Development Goal

(MDG) era, governments in Africa on average needed to spend an estimated 2.58 percent of gross domestic product (GDP) to meet WSS-related MDG targets. A review of public expenditure in five low-income countries showed an average annual investment of just 0.32 percent, or $\$ 1.71$ per person. Of this amount, 12 percent went to recurring costs, with more than 87 percent to infrastructure. Budget execution (the portion of the total allocation actually spent) during this period (2000-15) was only 63 percent, showing a need for capacity building and skills development to more effectively spend existing funds, and as a prerequisite for increasing funding to the sector.

Source: Van Ginneken, Netterstron and Bennett 2011. and in support of sector policies and targets, or may be too high if they do not properly account for absorptive capacity constraints (box 4.2).

Of those countries responding to the 2017 GLAAS survey, only 34 percent and $\mathbf{4 2}$ percent, respectively, have and consistently follow an urban sanitation and urban water financing plan (WHO/UN-Water 2017). The rural subsector figures are even lower. Where capital investment plans exist, they are often developed with inadequate data, unrealistic service levels, poor links to affordability, and little or no relationship to financial plans.

Sector planning is a highly technical process that needs to be based on reliable data. Public funds should be strategically used to develop accurate and comprehensive capital expenditure plans and associated financial plans for water service providers. To promote comprehensive and realistic planning, the Organisation for Economic Co-operation and Development (OECD) has introduced an approach called strategic financial planning (SFP) (OECD 2009) (box 4.3).

BoX 4.3. Strategic Financial Planning (SFP)

SFP is a national approach to policy dialogue that looks at the demand and supply of finance for the sector over 20-30 years (GWP 2016). The country first sets a baseline, an economic forecast, and sector targets and then looks at the trade-offs (including costs and financing options) between different options for meeting the targets. SFPs can be done using standardized tools or financial models that are tailor-made for the country. However, for some countries, an SFP is the gold standard, and other, interim analyses using readily available data will be needed first.

Source: OECD 2009. 
Multiyear financial planning, whether as SFP or through more rudimentary processes, should provide a consolidated look at revenues and financing sources, presenting a basis for priority setting. These plans should also identify annual cash flow requirements, facilitating a link to the general budget process.

\subsection{More, and Better, Subsector Allocation}

\section{Local tax revenues to fund the sector can be targeted to} improve what are essentially localized services. A good use of existing funds is to provide incentives for efficiency gains or to correct market failures. Moreover, additional public funds can be mobilized at the local level, such as through increased use of property taxes or land value capture instruments, through which a portion of the increase in property or land values (residential and commercial) that results from nearby WSS investments is recovered.

\section{Allocation is a political process and subject to various factors, but it can be done in a way that ensures the most cost-effective investments are made and that resources are used in a catalytic manner to crowd in other types of investment. There are six questions to consider when looking to allocate funds across and within WSS subsectors:}

- Do we need to address a market failure? In rural areas, poor households often bear much of the cost of WSS services, and it consumes a higher proportion of their income. Where services are unaffordable, government failure to step in can have large negative economic and health impacts. In sanitation, low demand coupled with high negative externalities presents a market failure that only public funds can correct.

- Where are the biggest investment gaps? To answer this question requires understanding not only how many people, but also who, would benefit. Globally, more people need access to basic sanitation than to basic water (table 4.1), but the numbers vary greatly by country. 2
TABLE 4.1. Global Population Still Lacking Access to WSS, by Type and Subsector, 2016

\begin{tabular}{lll}
\hline Subsector & Basic access & $\begin{array}{l}\text { Safely managed } \\
\text { access }\end{array}$ \\
\hline Urban water & 1.4 billion & 2.0 billion \\
\hline Rural water & 0.9 million & 2.6 billion \\
\hline Urban sanitation & 1.7 billion & 3.2 billion \\
\hline Rural sanitation & 1.7 billion & 2.1 billion \\
\hline
\end{tabular}

Source: Hutton and Varughese 2016.

Note: WSS = water supply and sanitation.

- What are the policy trade-offs (for example, between providing basic access for all and safely managed services for a smaller population which generally already has basic access)? Although safe access costs three times more than basic access (global estimates), there are opportunities to "leapfrog" to higher service quality without the added cost, especially if using lower-cost, decentralized systems.

- How can policy goals be met at the lowest cost? Urban areas account for 70 percent of capital costs needed to achieve universal access globally (Hutton and Varughese 2016), but more people will be served from urban investments than rural investments. Unit costs vary greatly across countries and cities and it is important to consider relative unit costs in order to assess overall investment needs per sub-sector, before delving into more detailed planning assessments.

- Can investments be financed with commercial finance instead? Public resources are often allocated toward infrastructure investments with high visibility-in urban areas and to service providers that can generate significant tariff revenues and thus recover costs on their own. If a portion of these funds would be reallocated away from such providers, there may be a net positive impact in two ways: (a) reduction in perverse subsidies that keep providers from financial self-sufficiency, and (b) potential leverage of finance through other sources, including domestic commercial finance sources.

- What is the benefit-cost ratio of a particular investment? Estimated economic benefit-cost ratios of 
reaching universal access are higher for sanitation (5.5) than for water supply (2.0) (WHO 2012). However, these will vary at the project level. CESAN, the utility serving the state of Espírito Santo, Brazil, uses a ranking system to prioritize projects based on cost-benefit and net present value analyses. Those that cannot provide a positive economic return on investment are not considered for public funding (World Bank 2017b).

\subsection{Better Use of Tariffs and Subsidies}

\subsubsection{Tariffs}

The way in which tariffs are set affects whether a government can meet its WSS objectives. Tariff setting entails both defining how much should be recovered via tariffs (setting the tariff level) and defining how revenues should be recovered from different customer classes via tariff structures. Some typical sector objectives include cost recovery, efficiency in the provision and use of water, and affordability of the service. A service provider's ability to generate revenue is linked to the tariff levels and tariff structure, and to the associated incentives that they both generate.

A primary purpose of tariffs is to generate funding for service providers. In high-income and some middleincome countries, tariffs provide the vast majority of revenues for the water sector. No subsidies are provided for water services, on the principle that "water service should pay for water service." This has not always been the case, however, and it is not true everywhere. Most countries that have now achieved universal coverage mobilized domestic taxes or international transfers at different stages of their history. They have all gone through various stages of financial sustainability-from being heavily dependent on public finance to becoming creditworthy enough to access more mature private financial markets. Service providers that currently mobilize commercial finance usually cover their costs through tariffs.

Countries that are better able to fund their sector sustainably tend to be the ones with higher levels of costs covered by tariffs. Greater rates of cost recovery through tariffs lead to better sustainability of the investments because more funding is generated by users for operating, maintaining, and eventually replacing the investments that have been made usually with public funds.

Service providers tend to be more focused on their customers, and on the quality of their services, when their customers are the main source of their revenue. Users who directly pay for the amounts of water they use and who contribute to the upkeep of the investments are more likely to use water responsibly and to maintain water infrastructure when it breaks down. The link between customers and service providers, made via properly set tariffs, creates a virtuous cycle of improved performance (figure 4.2).

Systems that are funded with tariffs also have more predictable revenue sources and are therefore better able to invest in service expansion and conduct regular maintenance. For example, the World Health Organization's (WHO) TrackFin initiative found that in Brazil, 80 percent of total WASH sector costs were covered by tariffs as of 2011. By contrast, tariffs covered only 25 percent of total water sector financial requirements in Ghana-a country now confronted with a reduction in concessional finance because it has achieved middle-income status, while tariffs or domestic taxes have not been raised sufficiently to compensate for this drop (WHO 2015). .3

Wherever tariffs do not fully cover costs, a more moderate approach to "sustainable cost recovery" is warranted. The 2014 GLAAS Report found that two-thirds of the 94 countries participating in the survey indicated that tariffs were insufficient to recover O\&M costs (WHO/UN-Water 2014a). Government subsidies were most often cited as the means for covering the operational finance gap. In such cases, it may be more practical to aim toward "sustainable cost recovery," whereby the revenues of water service providers are covered through a mix of tariffs, subsidies, 


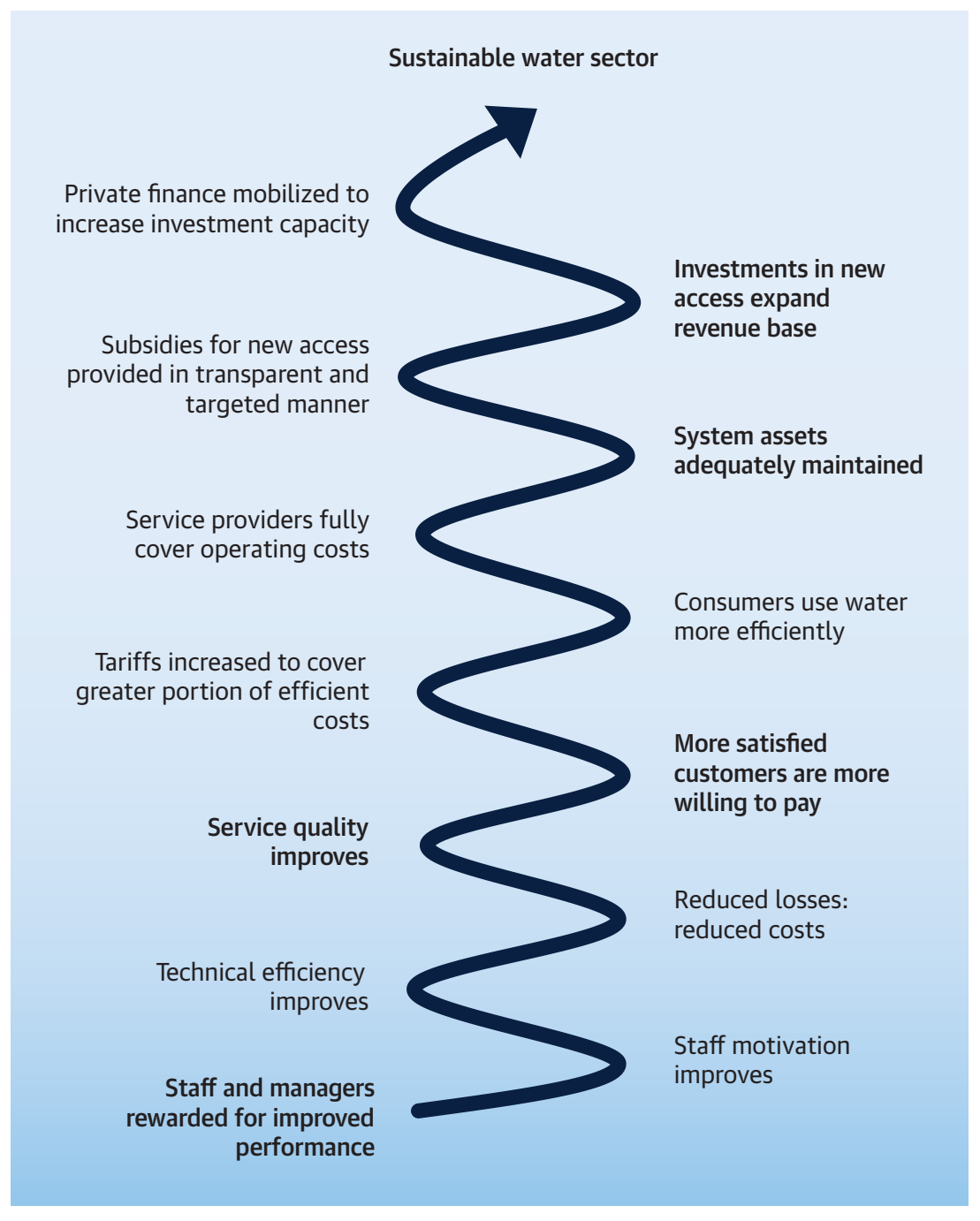

(c) World Bank.

and voluntary transfers (if available from external donors, for example). Since 2001, Burkina Faso has been using a financial equilibrium model to adjust tariffs and provide justification for fiscal transfers between the central government and the utility (World Bank, forthcoming). In the absence of such predictable and reliable revenues for the water sector, the ability of water service providers to plan investments is significantly weakened. tariff reforms because they are afraid of the social implications of such reforms. Affordability and cost recovery can both be addressed through well-designed tariff mechanisms, however. To achieve these objectives, the design of tariff structures needs to take into account local consumption patterns. For example, increasing block tariffs (IBTs) are often considered to be more progressive than volumetric tariffs because consumers who consume more face higher charges. An analysis of three countries with existing IBTs shows that a flat tariff would make water unaffordable for 65-85 percent of the population, greatly reducing the revenue base of the service provider. 4 In these cases, a large majority of households only consume the first (lowest) consumption block. There can, however, be concerns about using IBTs in service areas where lower-income families have many family members in one household, which means that poor families would end up consuming water in a higher tariff consumption block. Governments should carefully consider the implications of the various trade-offs involved in setting tariff structures and levels. They also need to evaluate all charges faced by consumers: in many countries, high initial charges to connect to the service often prevent poor families from connecting. As a result, they are often reliant on informal water sources, which can cost 10-15 times more than network water (as discussed earlier in chapter 2). 


\subsubsection{Subsidies}

Domestic taxes and external transfers are provided to the sector as subsidies, and are often used to support capital investments or operating costs, or to lower tariff

levels. It is important to note that subsidies can be a relatively sustainable source of sector funding as long as revenue sources for such taxes are reasonably predictable and secure.

Subsidies should be used primarily for the following purposes:

- To promote merit goods (whose value consumers may not fully realize, such as household sanitation and hygiene)

- To reward water providers for supplying public goods (such as public health)

- To generate external benefits (such as avoidance of groundwater pollution)

\section{Subsidies can be provided in two ways:}

- Capital cost subsidies: These can be provided in the form of grants, subsidized loans, or guarantees and can either be used to (a) build new infrastructure or connect users to a network, or (b) help users pay for latrines or toilets at the household level. When service providers are owned by municipalities, local government budgets are often not sufficient to cover such costs and would need to receive transfers from the central government.

- Operating cost subsidies: At a minimum, service providers should be expected to cover their operating costs through tariffs and user charges, but some LMICs continue to subsidize these costs. In South Africa, for example, municipalities often struggle to obtain adequate revenue from tariffs because of the Free Basic Water policy, which ensures that consumers can receive a first consumption block (considered to be a lifeline consumption) for free. The central government transfers an "equitable share" to local governments, which is a need-based allocation to cover operating expenses (Trémolet 2009). The subsidy is transparent ( $\$ 265$ per household per year), predictable, and targeted (based on the number of households in a municipality).

Subsidies can be difficult to target to the right populations to meet sector objectives. First, they often reach those who are already connected to a network. Studies abound showing that most poor customers must drill their own wells or purchase water from vendors, at a price that can reach 10-15 times the price charged by service providers. Thus, in a country where low volumetric tariffs are combined with high connection fees, low-income consumers would be excluded from the benefits of the subsidy. In Tunisia's capital city, rich households receive 1.4 times the subsidy the poor receive for water supply, and twice as much as the poor for sanitation because they consume significantly more water and wastewater services. In this case, plans to reduce subsidies would not generally hurt the poor and are estimated to generate $\$ 65$ million in savings, which could close the utility's financing gap (World Bank 2016d).

To be well targeted, subsidies must be transparent. Governments often provide implicit subsidies in the water sector, by providing free equity capital or buildings, or onlending loans at very subsidized rates. The costs of these implicit subsidies are rarely known or quantified as a subsidy. It is important to quantify these subsidies to get a complete understanding of public investment in the sector and to identify where, how, and for whom, different sector incentives are being created that may promote or inhibit efficiency (box 4.4).

Once implicit and explicit subsidies have been quantified, they should be aligned with sector policies and plans. In general, they should not support inefficient operations or operators that could alternatively access other sources of finance. Therefore, governments should move away from operating subsidies toward welltargeted capital subsidies that support policy 
BoX 4.4. Implicit Subsidies Cannot Be Well Targeted

Governments that borrow concessional finance generally onlend the funds to local service providers, transferring an implicit subsidy to the provider (equal to the difference between the concessional loan terms and those of an alternative commercial loan). A comparison of two such loans in Vietnam shows that a 20-year concessional loan at 4 percent interest and a 5 -year grace period yielded a subsidy equivalent to 66 percent of the loan value, when benchmarked against a commercial loan of similar size at 10.2 percent interest and 5-year maturity. In this case, providing a capital subsidy coupled with a commercial loan would have been more cost-effective in terms of delivering long-term results, and would also make service providers more accountable by taking on more appropriate risk levels. When stakeholders do not quantify such implicit subsidies there cannot be a policy debate regarding the alternative uses of public funds.

Source: Kingdom, Baeumler and Guzman 2012.

objectives like pro-poor service delivery and financial sustainability of the service provider. Experience gained in OECD and Central and Eastern European countries shows that transfers should be limited in time, phased out, and eventually ended when pre-agreed targets are achieved (OECD/EAP Task Force 2006).

Targeting subsidies to the right scale and type of service can generate more value for money. For example, many LMIC governments tend to subsidize sewers and associated wastewater treatment in urban areas while maintaining explicit policies not to subsidize on-site sanitation in periurban or rural areas. A WaterAid study in Dar es Salaam found that 99 percent of public funding for sanitation was allocated to sewerage and wastewater treatment, while these systems reached only 10 percent of the urban area's population (Trémolet and Binder 2013).

Subsidies need to be better targeted to households that meet certain criteria. For example, Chile and Colombia were early pioneers in applying targeted social tariffs in addition to applying cost-reflective tariffs to the nonpoor. In contrast, Burkina Faso introduced social tariffs in 2003, but for lack of targeting geographically or by income, they have not supported poverty reduction targets.
Many countries have indeed had success with using subsidies themselves as an incentive for good performance. The Arab Republic of Egypt is using fiscal transfers to reduce inefficiencies in the wastewater sector that amount to nearly $\$ 1$ billion per year. Capital grants are given based on the performance of rural sanitation providers in meeting a series of indicators (box 4.5). Similarly, the government of the State of Espírito Santo in Brazil provided the state water utility with $\$ 180$ million over a seven-year period for capital expenditures, contingent upon progress toward its strategic business plan. This way, subsidies will taper off over time as providers become more efficient and able to cover their own investments.

The potential for cross-subsidies needs to be further explored. Regarding sanitation, trade-effluent charges may be applied to industrial effluents to cover the additional treatment costs and potentially an additional margin, which can be used to cross-subsidize poorer customers. In water supply, cross-subsidies are used by eThekwini Water in Durban, South Africa, to institutionalize the country's Free Basic Water policy, thereby providing a basic quantity of water to poor households for free (50 liters per person per day) while charging higher levels of service and consumption at full cost. 
BoX 4.5. Making Fiscal Transfers Dependent on Good Performance in Egypt

Because of Egypt's decentralization process, regional water and sanitation companies (WSCs) need to manage the WSS assets they have inherited from the central government. Without sufficient tariffs, government fiscal transfers attempt to cover the gap at a rate equivalent to 1.25 percent of GDP. Large investments in wastewater treatment and sewerage networks have suffered from slow implementation and high capital and operational costs. The costs of inefficiencies in the wastewater sector in Egypt have been estimated at US\$1 billion per year.

Under the Sustainable Rural Sanitation Services Program for Results, the World Bank is helping the government to improve rural sanitation services in three governorates in the Nile Delta. The instrument transfers responsibility to WSCs, using formula-based fiscal transfers linked to service delivery performance in the areas of operations, financial management, institutional systems, and citizen engagement. Payments are made upon meeting any of six disbursement linked indicators (DLIs), providing reasonable cash flow to enable WSCs to make sequential improvements. Those WSCs meeting performance standards can then also receive performance based capital grants to expand access. These grants are allocated on a per capita basis to ensure cost-effectiveness.

\subsection{Funding and Capacity Building of WSS Sector Institutions}

WSS policies and strategies must also be supported by the appropriate institutional framework. This includes clear delineation of roles and responsibilities and an enabling environment that supports efficient delivery and allows for private sector participation (PSP), as needed. A strong institutional framework has associated costs, both in terms of transitory reform costs and in terms of ensuring that well-trained staff are adequately remunerated and equipped to deliver their tasks.

First, it is important to draw the resource and financial implications of supporting different institutional arrangements. For example, decentralizing services can bring more accountability because the service provider is closer to the customer, but this may also make it more difficult to design and enforce uniform policies for oversight and sustainability, including those associated with financing. Whether an independent authority or a municipality, the borrower must be a legal entity, and legal frameworks must be in place to enable PSP in service delivery, from allowing for certain contract types to allowing providers themselves to borrow money on commercial terms.

Second, regulatory frameworks need to be in place to monitor performance and service quality and enforce guidelines for tariff setting. Regulatory institutions should be designed for a specific country context. Regulation by contract in Burkina Faso and Senegal works as well as regulation by autonomous national regulatory agencies in Albania or Portugal. However, the more decentralized countries with higher numbers of regulated service providers (such as in Mozambique or the Philippines) will require more public resources dedicated to regulation (World Bank, forthcoming).

Third, institutions need staff with the right skill sets, and who are technically proficient and driven to help achieve sector strategies and policies. In the end, people provide the leadership that can transform a sector and thus the incentives for individual staff (in a service provider or a regulator) also matter. Governments 
should provide the incentives to attract and retain competent staff and managers who can lead a change process. Capacity constraints can present a serious challenge if and when more financing becomes available. Countries should be sure they can fully execute any new funds. Unfortunately, some of the countries with the highest WSS investment gaps also have low or insufficient capacity to execute new sector funds (as discussed in box 4.1).

\subsection{Conclusion}

Public funds are scarce yet critical for the proper functioning of the WSS sector. They should be used prudently to correct market failures and meet poverty and other sector goals in a manner that does not crowd out opportunities to tap into commercial finance.

At the national level, subsector allocations should be used to support integrated WSS policies aligned with national objectives. Public funds are also critical for setting the right sector and corporate governance and institutional frameworks, building human resource capacity, and attracting talent and leadership to the sector.
At the service provision level, tariffs and subsidies should provide the right incentives for both consumers and service providers toward achieving national objectives. Operations and maintenance (O\&M) costs should be covered-ideally by tariffs-and where they are not, taxes need to supplement to cover these costs.

\section{Notes}

1. Nearly three-quarters of countries (70 out of 94) that had completed the 2013 survey by the Global Analysis and Assessment of Sanitation and Drinking-Water (GLAAS) recognized the human right to water in their constitution (or the equivalent), and over two-thirds (63 out of 94) recognized the human right to sanitation (WHO/UN-Water 2014a). The GLAAS survey has been conducted by the World Health Organization (WHO) every two years since 2010. It aims to collect data on the "inputs" into the water supply, sanitation, and hygiene (WASH) sector, including those regarding policies and financial and human resources.

2. See table 2.1 for the definitions of basic access and safely-managed access.

3. WHO/UN-Water TrackFin Initiative, "Tracking Financing to DrinkingWater, Sanitation and Hygiene." For results of pilot testing initiative, see http://www.who.int/water_sanitation_health/monitoring/invest ments/trackfin/en/.

4. IBT analysis based on World Bank calculations using data from the International Benchmarking Network for Water and Sanitation Facilities (IBNET). 


\section{Chapter 5 \\ Component 2: Improve Service Providers' Performance and Governance}

\subsection{What Needs to Change?}

Efficiency gains are a source of untapped finance, and inefficiencies are an opportunity cost to the government or service provider. Improving efficiency allows service providers to deliver better services more cheaply, thereby freeing up resources to invest in improving or extending services. Moreover, improved efficiency and service quality can help justify increased tariffs and transfers from government sources because stakeholders are more willing to pay or allocate funding when services improve.

When viewed as part of a strategic shift, efficiency improvements are a critical part of the move toward financial sustainability and, eventually, creditworthiness. They are thus the first step in enabling providers to use commercial financing. Accessing commercial finance can, in turn, increase incentives for efficiency and help break the status quo.

Service providers' performance can be improved through

- More efficient upstream choices regarding capital expenditure;

- Achievement of short-term operational efficiency gains; and

- Aiming for financial sustainability, with the ultimate goal of creditworthiness.

Examples of activities under component 2 are mostly drawn from the urban water subsector because this is an area where financial constraints and applicable finance strategies have been analyzed in more detail and are better understood. However, the same logic can be applied to other water subsectors, such as water supply and

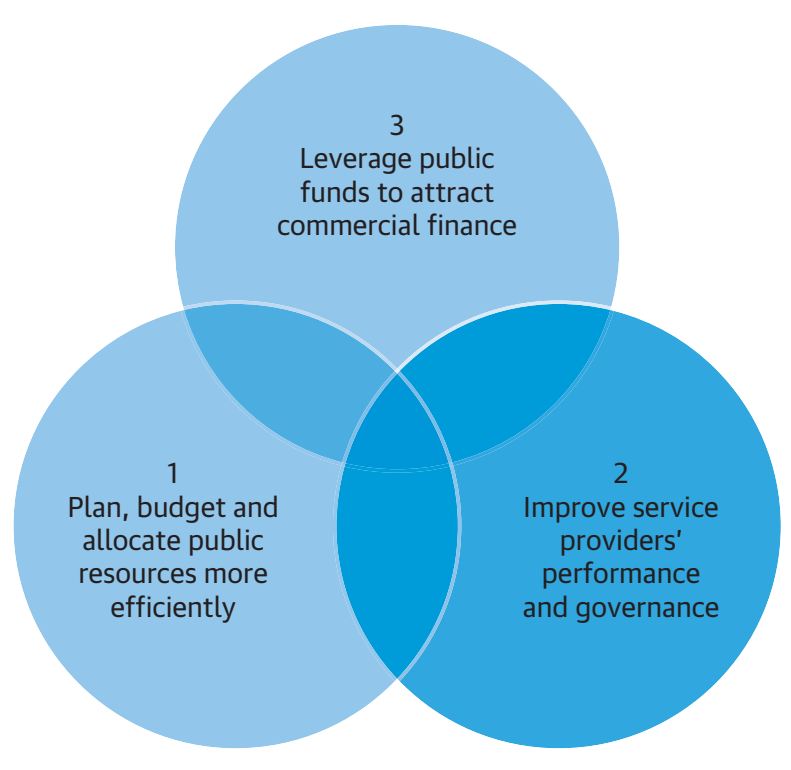

sanitation (WSS) services for rural and periurban areas, once service providers are ready to move beyond traditional sources of finance.

\subsection{The Status Quo}

As discussed in chapters 3 and 4, services tend to be funded through a mix of tariffs (which are typically too low) and transfers (which can be ad hoc), with the occasional injection of liquidity when concessional finance is secured for a specific investment. Low tariffs lead to low service maintenance and quality if shortfalls are not provided through reliable and adequate subsidies. The inconsistency of transfers and concessional finance can make it difficult to fill the gap at the right time, and the longer maintenance is deferred, the more money will eventually be required.

Capital and operational inefficiencies are greatly interlinked and are pervasive in the WSS sector. If not addressed, inefficiencies quickly lead to a downward 
FIGURE 5.1. Vicious Cycle Affecting Many Service Providers

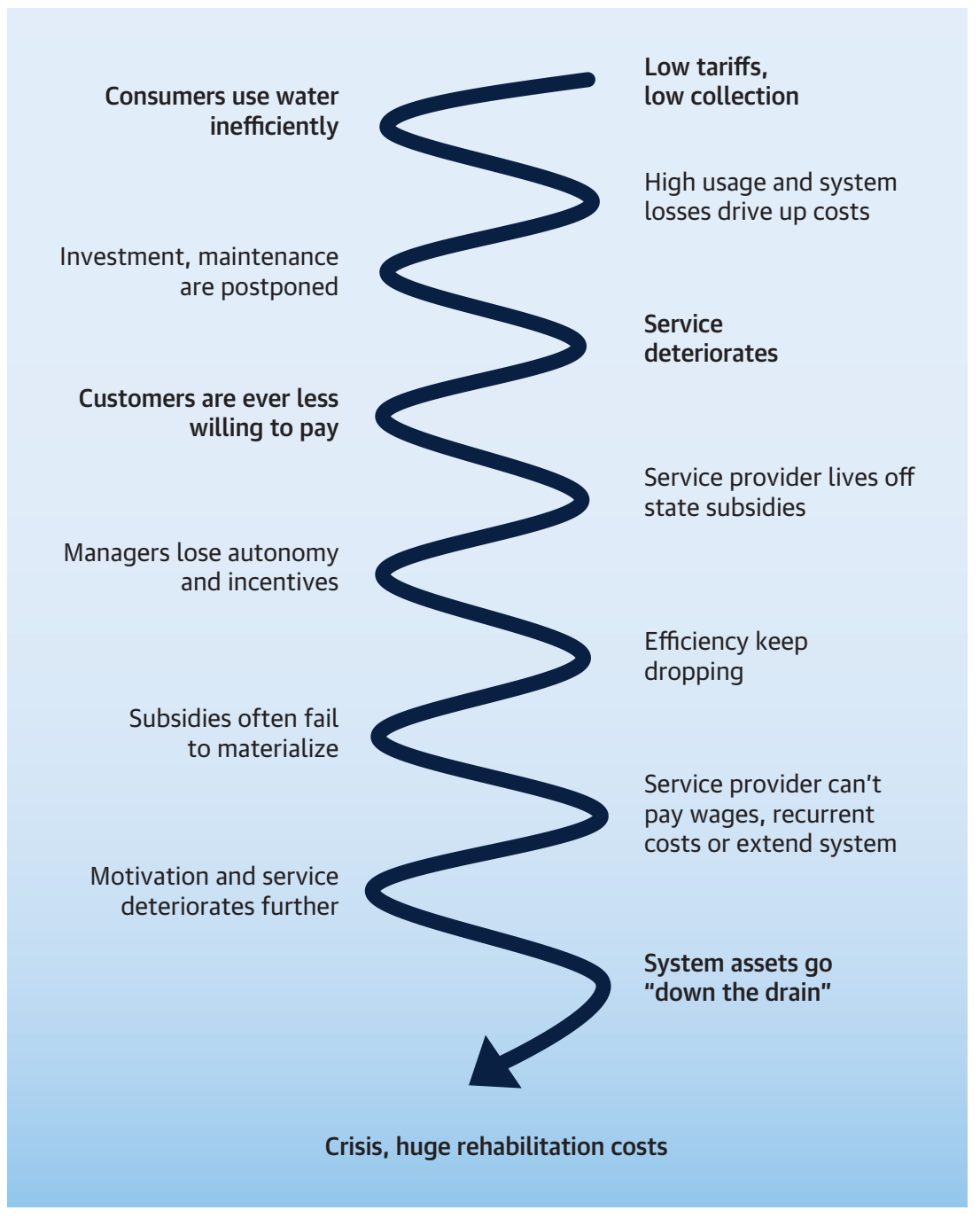

Source: PPIAF and WSP 2002

spiral of poor performance, unhappy customers, and huge rehabilitation costs (figure 5.1). If the water sector does not break out of this cycle, countries will not be able to mobilize the finance needed to meet Sustainable Development Goal (SDG) targets.

Many service providers in developing countries generate losses, and only a few are partially or fully creditworthy. National and local governments are the only entities that can set the correct incentives for service providers to improve the efficiency of their operations. This will, in turn, improve customers' willingness to pay, augment the revenue base, enhance the credibility of service providers, and set them on a path toward delivering universal, sustainable services.

Most private financial instruments and approaches work only with those providers that are already creditworthy, and yet only 4 percent of WSS service providers in low- and middle-income countries (LMICs) are creditworthy (Baietti 2017). Even when service providers are creditworthy (box 5.1), they do not always have access to commercial lenders, which is highly dependent on the maturity of the local financial market.

The focus for most countries, therefore, should be on how to bring poorly performing service providers to financial viability, and the marginally creditworthy closer to creditworthiness. For the former, improved efficiencies can lead to achieving positive cash flows, as further discussed in the next section. For the latter, a blending arrangement can help service providers qualify for loans by stretching out payments and reducing the overall cost of financing (an option further discussed in chapter 6).

\subsection{Incentives for Efficiency}

Incentives for improving efficiency come from policy makers and trickle down through local governments and service providers, including management and technical staff. Incentives should be set by sector policy and strategy and institutionalized through the sector governance framework, especially regarding the way the 
Box 5.1. What Makes a Service Provider Creditworthy?

Creditworthiness is a measure of a borrower's ability and willingness to service its debt obligations, which is more likely to occur when they recover 150 percent or more of their operating costs and have good debt service coverage ratios. To be creditworthy, the utility must demonstrate a reliable stream of positive cash flow from operations as well as sufficient cash reserves in the case that future cash flows are not sufficient. It is important that the evaluation of creditworthiness be based on the entire capacity of the utility and not just on analysis of the individual project. Concurrently, the creditworthy utility must have a plan to handle contingent or implicit charges, which may include unexpected cost increases and foreign exchange losses.

The degree of creditworthiness is judged through a valuation performed by lenders or independent parties to determine the borrower's potential for defaulting on its debt obligations. There are various tools available for assessing credit, from creditworthiness indexing to shadow ratings to credit ratings.

sector is financed. Sector governance has a large impact on corporate governance, which includes the legal status and policy mandates of the service provider.

\section{It is imperative that service providers take full ownership} of the design and implementation of their improvement programs as part of their efforts to continually improve their business. Well-performing providers are usually customer-oriented, have sound financial management systems, and benchmark their performance over time and against peer institutions. The world's top service providers use key performance indicators (KPIs) to constantly evaluate the key areas of their business to determine how they are improving over time. Management should have personal incentives for meeting or exceeding their KPIs.

\subsubsection{Governance and Efficiency}

Sector and corporate governance frameworks set out the responsibilities of the service provider with respect to other WSS institutions, which is essential to measure and improve efficiency. Corporate governance also details ownership, operating principles, and oversight of providers. These two sets of frameworks should link national policies to local institutional mandates on important issues like land tenure, affordability, service quality, and equity. Together, they provide clarity for financiers on how the sector will address such political issues. When properly aligned, they will promote efficient, well-run service providers. The criteria for efficiency for an urban water utility in Brazil is very different than for a small, rural service provider in West Africa, but in either case, efficiencies can be promoted by considering a few key variables (box 5.2).

\subsubsection{Capital Expenditure Efficiency}

In LMICs, most service providers are public entities that do not pay for the infrastructure they use to provide services. The lack of connection between the asset user and the asset financier weakens the accountability for proper management and use of the asset, and proper pricing of the services they provide.

The choices governments make today about sector investments will have a big impact on future sustainability of WSS service as they will significantly impact future operations and maintenance (O\&M) costs. Governments can follow some general principles to improve capital 
Box 5.2. Key Considerations for Promoting Efficient Service Delivery

Service standards. Standards may range from water quality parameters and hours of service to the standard at which sludge must be treated. Clarity on the standards expected is essential for measuring the efficiency of any water service provider. Some large service providers use key performance indicators, which are internationally accepted standards that enable service providers to benchmark their performance with other similar organizations. Internationally recognized service standards may not exist across all subsectors, but they are vital in terms of recognizing what service levels are expected.

Financial performance. Collection rates, operating ratios, and even credit ratings offer insights on the financial status of the institution, as well as on the efficiency level at which they operate.

Employee levels. This refers to the number of employees deemed adequate to achieve a given service standard; it may differ by subsector and the size of the water service providers. This number is generally a good indicator of whether the entity is operating efficiently or whether it is being used as a source of patronage.

Customer orientation. Measurements of customer satisfaction are another indication of the quality of service. They enable an evaluation of how services are being delivered, the quality of those services, and how resources and personnel may be redeployed to make improvements.

Energy costs. Moving and treating water are large, expensive components of water delivery systems, and their costs can be a large part of operational expenditures. Measuring the use and cost of energy per person served offers an important insight into the quality and efficiency of the water service provider.

Risk identification and mitigation. Every service, regardless of the sector, comes with some risks. It is important to identify those risks, plan for the related contingencies, and undertake measures to mitigate them. The ability to undertake this analysis and put systems in place to address these risks is a key indicator in determining efficiency.

efficiency (World Bank, forthcoming [a]). In general, governments should ensure that

- New infrastructure is indeed needed (options to manage demand have been exhausted);

- The right approach and sizing of infrastructure has been selected, and lower-cost options are considered (appropriate design standards are in place);

- Overpricing is mitigated (costs and contract awards are benchmarked to a reasonable and transparent standard); and

- Communities are engaged for local oversight.
First, in many countries, a substantial proportion of WSS infrastructure is lying idle, generating a massive waste of resources. Expensive or oversized treatment plants are constructed and not used to capacity while others are never connected to the sewerage network. Much of this happens because technical standards are directly imported from high income countries with minimal adjustments. Locally driven innovation could allow the costs of technical solutions that are put in place to be reduced. Greater emphasis on the potential complementarity of built ("gray") and natural ("green") infrastructure is required. 
Second, providers need to better maintain existing infrastructure. Too often, the preferred approach in the sector is to build new infrastructure when previously built infrastructure has fallen into disrepair for lack of adequate maintenance. An analysis of 20 countries in Sub-Saharan Africa shows that between 30 and 40 percent of rural hand pumps are not functioning (RWSN 2010). Prioritizing O\&M and placing greater emphasis on full asset life-cycle management should be done to ensure that what gets built is also adequately maintained and operated. Funding for maintenance is often the first to go when budgets are cut. In Tunisia, less than 5 percent of total sector costs are used for capital maintenance (World Bank, forthcoming [d]).

Third, myriad unnecessary costs are tagged on to the design, selection, and implementation of new infrastructure. These costs result from inefficient procurement processes, corruption, limited competition, overdesign of systems, and use of expensive technologies.

Better procurement and project management can cut costs. Larger projects, given their economies of scale, can have relatively lower transaction costs and can enable access to finance at better terms. Competitive procurement processes that enable new technologies to enter the market can put downward pressure on component costs. Performance-based contracts provide incentives to reduce expenses. Design-build contracts save U.S. utilities an estimated 39 percent in capital costs over design-bid-build projects (Adams 2003).

Alternative technologies and scales can offer the same level of service at a lower cost. In Dakar, Senegal, it was estimated that the annualized cost for sewerage services is nearly $\$ 55$, while on-site sanitation with fecal sludge management costs less than $\$ 12$ (Dodane et al. 2012). One project in Brazil cites a 43 percent reduction in costs when using condominial sewerage (decentralized systems) over conventional sewerage in informal settlements (Neder 2016).

\subsubsection{Operating Expenditure Efficiency}

The ultimate objective is to support service providers to become creditworthy entities that can access commercial finance at reasonable rates to expand and continually improve their services. Once service providers can access commercial finance, experience has demonstrated that the discipline of the market helps them to maintain service standards and reinforces transparent governance arrangements, in a virtuous circle.

Unfortunately, many service providers in LMICs are financially weak. Although part of this can be because of a lack of control over tariff setting, many service providers are also inefficiently operated. Decades of World Bank support to improve efficiency while adjusting tariffs levels has had mixed results. This report proposes a minimum expectation that tariffs cover O\&M costs, a concept that is not so easily achieved even in some middle-income countries.

In fact, only an estimated 15 percent of service providers cover their O\&M costs and create a surplus (assumed as having cash revenues exceeding costs by at least 20 percent). 1 This means that 85 percent of utilities would have difficulty mobilizing commercial financing unless they implement significant reforms to improve cost recovery. In doing so, they will be brought closer to financial viability, and thus, creditworthiness. Figure 5.2 shows how if they each implement four measures to cut costs and bolster revenue, 77 percent of the 690 utilities from the study would have sufficient cash surpluses to become financially viable, defined here as recovering 120 percent of operating costs. This is a step below full creditworthiness, which depends on several factors, but is more likely to occur when the provider recovers at least 150 percent of operating costs.

Experience shows that such reforms may be quick to implement from a technical perspective but first require political leadership and sector governance frameworks that provide incentives for reducing costs and increasing revenues. For example, governments need to authorize service providers to collect bills and give them the autonomy to restrict service to nonpaying customers. Such reforms in the early 2000s greatly improved the performance of service providers across Vietnam, 
including in the city of Da Nang, where between 2005 and 2014 the company more than tripled its connections $(14,000$ of which to the urban poor), reduced NRW to 17 percent, and lowered energy costs by 23 percent (box 5.3).
Efficiency gains also require initial investments but will pay for themselves, via lower operating costs or higher revenues, in a relatively short time. A recent Asian Development Bank (ADB)-funded assessment in Mongolia concluded that replacing pumps and making

FIGURE 5.2. Efficiency Improvements that Help Utilities Reach Financial Viability

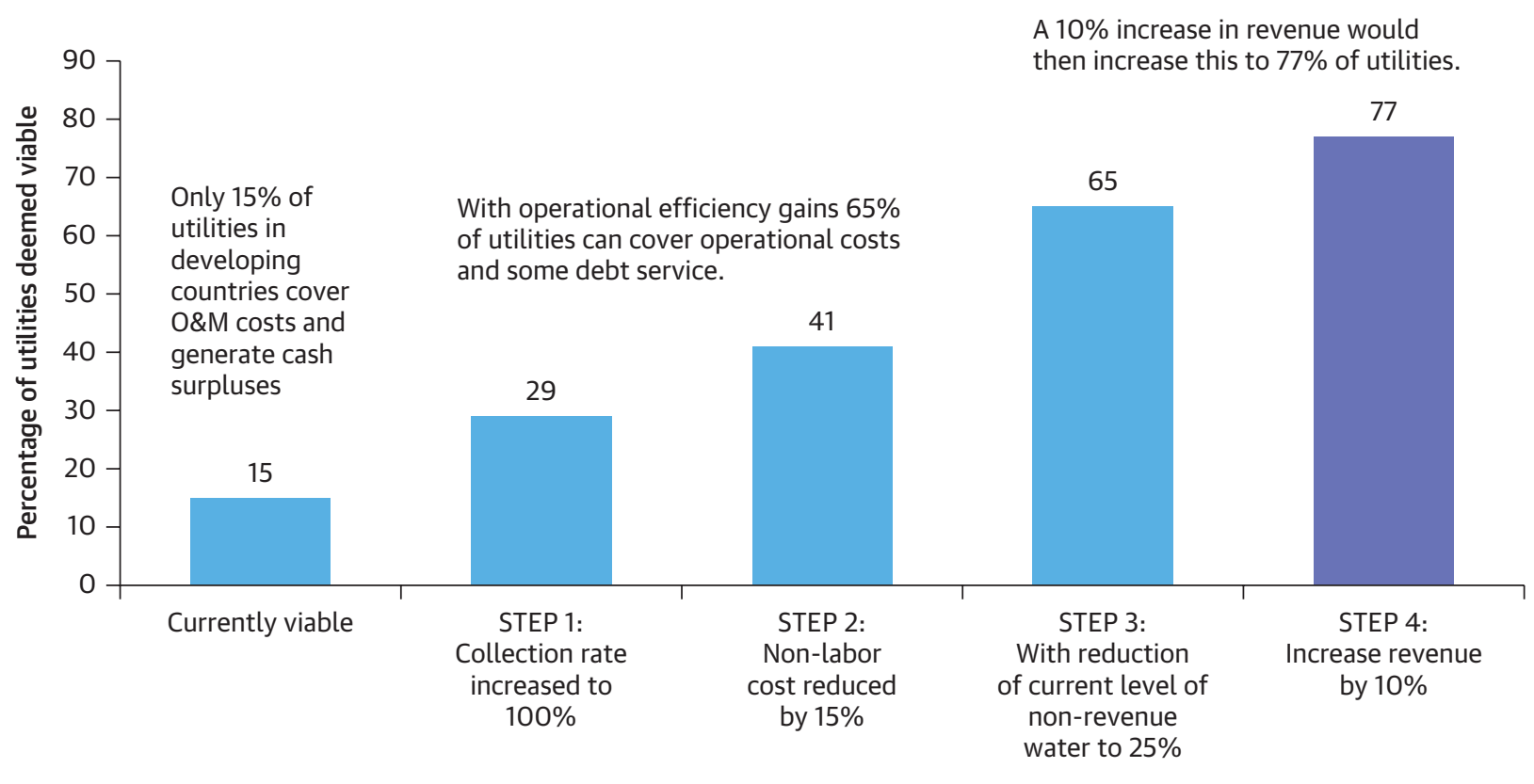

Source: World Bank calculations based on IBNET data.

Note: IBNET = International Benchmarking Network for Water and Sanitation Utilities; O\&M = operations and maintenance. Estimates from data on 605 utilities in low- and middle-income countries.

Box 5.3. Cost-Recovery Policy Catalyzes Utility Turnaround in Vietnam

At the start of the 21st century, service providers in Vietnam, as state-owned-enterprises (SOEs), received financial support from the government that inadvertently promoted inefficiencies. DAWACO, one such SOE serving the city of Da Nang with a population of 1 million, struggled with high levels of NRW and was only providing service to half of the population. In 2005, the government started a reform process to commercialize the water sector and eliminated operating subsidies to SOEs. A government decree required full cost recovery to be achieved by 2015 , and allowed service providers to propose tariff adjustments to cover costs. 
Box 5.3. continued

These changes forced DAWACO to set out on a turnaround path and to raise its own private capital. The plan was supported by the ADB and a €1.9 million grant for a Utility Support Partnership with Dutch firm Vitens Evides International (VEI). VEI provided technical and operational training to DAWACO employees to increase managerial efficiency, lower operating costs, and expand services, especially to the urban poor.

Today, DAWACO is a joint stock company with a mix of employee, government, and private ownership. DAWACO's strategy is now detailed in a business plan and a Water Master Plan, both conducted every three years. Success factors included DAWACO staff ownership of the turnaround process and cultural prioritization of continuous learning and improvement.

Source: World Bank 2017b.

slight improvements to operations will save 38 percent of current energy consumption with a payback period of just two years (ADB 2013).

When both capital and operational efficiency improvements are made, service providers are better able to move toward a more realistic tariff that is both reflective of the service quality and more affordable. Customers are more willing to pay for a better service, especially if they have been footing the bill for inefficient delivery in the past. This link between service quality and revenue makes providers more customer-oriented and better able to continue making improvements once they better understand their customer base.

\subsection{Conclusion}

Making service providers more efficient is the first step toward attracting commercial finance. It also puts them on a path of continuous improvement that will make them financially self-sufficient in the long term while delivering better services to users. Those service providers that can enhance their revenue base through better performance, free up resources for other government priorities, and even enable them to become net tax contributors.
Governments need to be careful to promote only cost-effective investments that will require a manageable level of O\&M in the long run. If taken together, the capital efficiency improvements outlined in the preceding section could cut an estimated 20-40 percent of the costs of an urban water project or 30-60 percent of an urban sanitation project (World Bank, forthcoming [a]).

Cutting operating costs not only provides a quick source of finance for the sector, but also can help move providers closer to creditworthiness. Actions to do so are relatively simple from a technical and managerial perspective, but require the right incentive structure to be in place. Numerous service providers under varying types of governance structures have succeeded in making quick turnarounds, but generally require proper planning, autonomy, transparency, strong technical capacity, and high-level government support.

Together, the recommendations under component 1 (chapter 4) and component 2 (chapter 5) can make a big difference in how the financing needs of the WSS sector as a whole can be met. The two main funding sources, as shown on Figure 2.3, are funding from users via tariffs and other investments and public funding (including from taxes and transfers). Figure 5.3 illustrates 


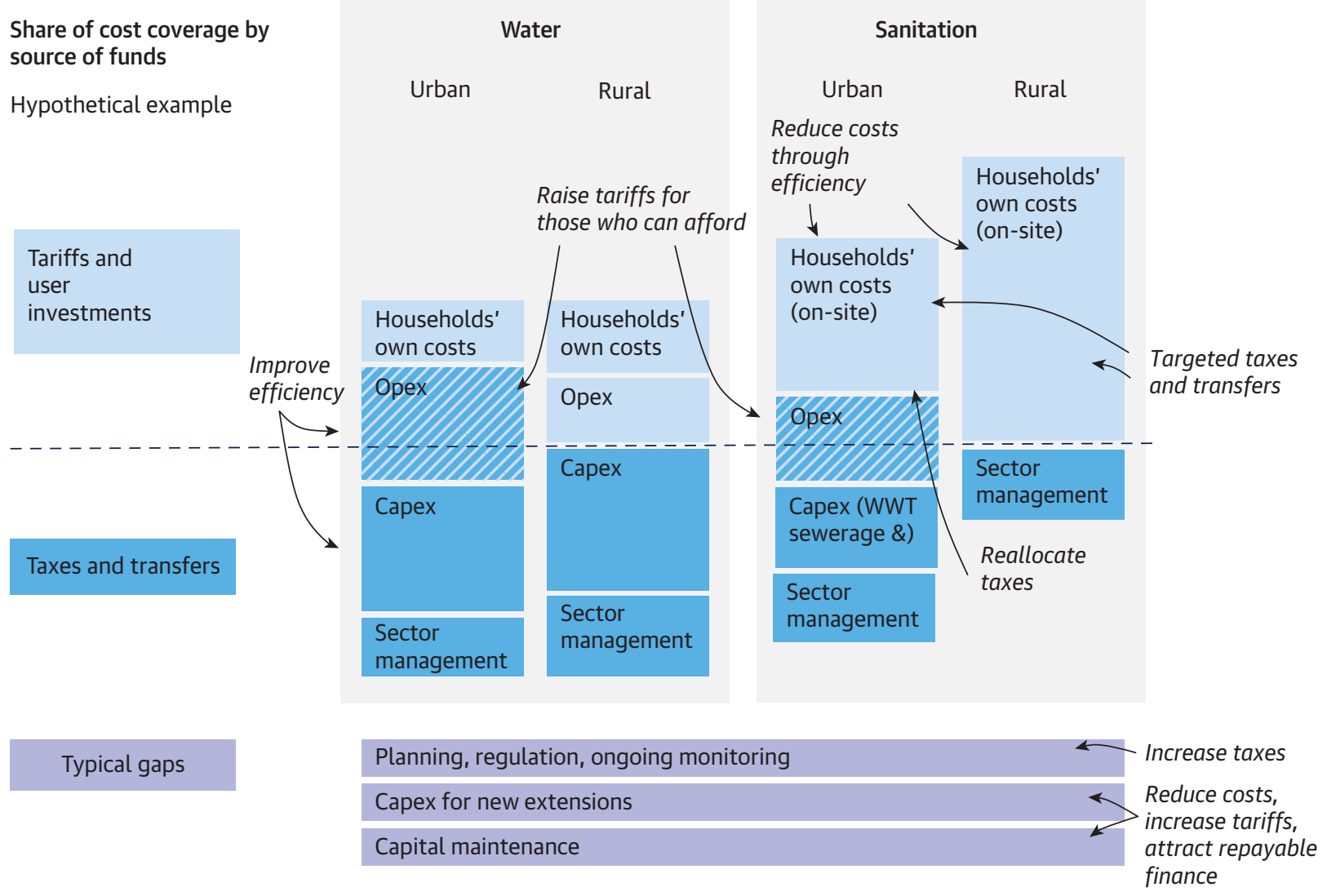

Source: World Bank.

Note: Capex = capital expenditures; Opex = operating expenditures; WSS = water supply and sanitation; WWT = wastewater treatment.

that the mix of funding sources typically varies for different WSS subsectors. For example, in many developing countries with limited or no sewerage coverage, the sanitation sector would largely be funded by users, in the form of user charges or direct investments in building household latrines, for example. Increasing funding for each WSS subsector will require different strategies, including a mix of interventions ranging from increasing the efficiency of operating expenditures and capital expenditures, increasing tariffs for those who can afford them, using taxes in a more targeted manner to catalyze investments, and ensuring that critical sector oversight mandates are funded. Such strategies will reduce the total needs for mobilizing financing from external sources, although financing will always be required in systems that are expanding and need to be actively maintained.

Although the component discussed in this chapter (Improve Service Providers' Performance and Governance) has focused on efficiency improvements in the urban water sector, the same concepts can be applied to the other three subsectors.

\section{Note}

1. Although this analysis is based on data from just 690 LMIC utilities in the 2013 database for the International Benchmarking Network for Water and Sanitation Utilities (IBNET), they are highly representative. 


\section{Chapter 6 \\ Component 3: Leverage Public Funds to Attract Commercial Finance}

\subsection{What Needs to Change?}

With the correct structuring, risk management, and regulation, the water sector is suitable for large-scale commercial finance, as is the reality in most Organisation for Economic Co-operation and Development (OECD) countries. A primary challenge today in low- and middle-income countries (LMICs) is to prepare investment-ready projects and incentivize service providers to become creditworthy. A secondary challenge surfaces when lenders are new to the water supply and sanitation (WSS) sector and require certain enhancements to reduce the perceived risk of the sector or country.

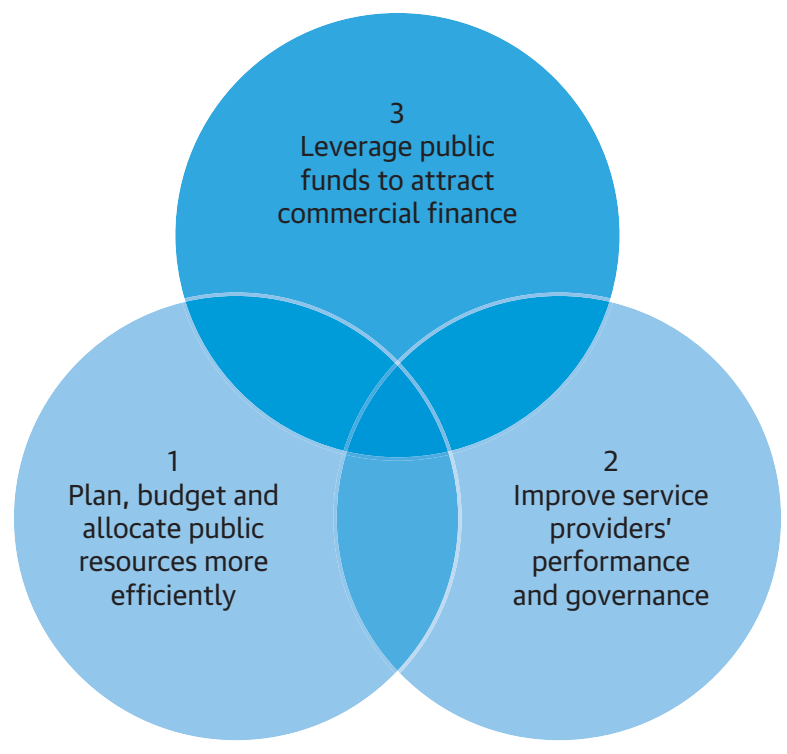

Commercial finance will likely have higher annual repayment costs than concessional finance, but overall borrowing costs could potentially be lower once other factors, such as devaluation and inflation, are factored in (see appendix B). The costs can also be partially mitigated through a slow transition (just 10-20 percent) to commercial finance.
Attracting commercial finance-a necessity for meeting the Water Sustainable Development Goal (SDG)-requires efforts to promote both the supply of and demand for finance. Governments are the key to transitioning the sector from a wait-and-see mode of investment to a proactive engagement with commercial financiers as part of a long-term strategy to meet its goals. Governments can serve as brokers between service providers or local governments looking for finance, and lenders who need to better understand the benefits and risks of investing in WSS. Governments can blend commercial and concessional sources to make borrowing more affordable while at the same time reducing the risk of the lender. $\underline{-}$

The eventual payoff is significant, including a more transparent and accountable sector, and an ability to tap into increasingly larger volumes of capital. By accessing these funds it is possible to bring societal benefits forward that would otherwise materialize only once more public funds could be mobilized or until tariffs could fully recover costs. Governments and donors can leverage their funds to help countries attract commercial finance through the measures outlined in table 6.1.

\subsection{How Blending Can Help Bridge the Finance Gap}

Blended finance refers to the complementary use-or "blending"-of both public (or concessional) and commercial finance to make finance available to targeted projects. It is the combining of grants with loans, equity, or other risk-sharing mechanisms and is an important vehicle for leveraging additional resources for the WSS sector (table 6.2). Different types of blending can be provided to address diverse challenges and will result in different levels of commercial sector 
TABLE 6.1. Measures that Help Commercial Finance Work for Borrowers and Lenders

\begin{tabular}{ll}
\hline $\begin{array}{l}\text { Demand-side measures to make commercial finance more } \\
\text { affordable for borrowers }\end{array}$ & Supply-side measures to reduce lender risk \\
\hline Blending concessional and commercial loans & Blending concessional and commercial loans \\
\hline $\begin{array}{l}\text { Catalyzing financial tools: tenor extensions, project preparation } \\
\text { facilities, results-based financing }\end{array}$ & $\begin{array}{l}\text { Catalyzing financial and regulatory tools: insurance, hedging } \\
\text { instruments, pooled finance, guarantees, revenue intercepts, } \\
\text { benchmarking, credit ratings }\end{array}$ \\
\hline $\begin{array}{l}\text { Designing blended approaches that adapt to the state of } \\
\text { financial market development and sector investment needs in } \\
\text { target countries and for targeted service providers }\end{array}$ & $\begin{array}{l}\text { Promoting advocacy and knowledge of the sector to commercial } \\
\text { financiers new to the sector or country }\end{array}$ \\
\hline
\end{tabular}

financing. The ratio of public to private financing in specific water transactions could also evolve over time as markets develop, service providers improve their creditworthiness, and investors become more comfortable with the water sector.

\section{Blending offers two main benefits:}

- Demand side: Offers more affordable borrowing rates and reduces the annual cost of borrowing or stretches out repayment schedule

- Supply side: Entices lenders to the market by reducing risk perception through the participation and due diligence of donors or multilateral development banks (MDBs)

The intention behind blending is to use the concessional element to catalyze more commercial investment than would be the case without the blending. The continued use of blended finance in a given country can create new understandings, relationships, and potential opportunities between the water and the financial sectors, which can promote the long-term goal of increased commercial financing.

To date, blended finance in LMICs has not been widely used at scale in the water sector. A few transactions have been supported by international donors, but these have mostly been in middle-income countries, and they have so far failed to be replicated at scale. Examples of the use of blended finance range from facilitating access to microfinance for households to invest in WSS in Bangladesh (box 6.1) and Cambodia, all the way to setting up a revolving fund for providers in the Philippines (World Bank 2016a).

Blended finance can help correct market failures by giving an initial impetus to service providers that demonstrates their commercial viability. For example, it can be used to correct a classic market failure that occurs when banks deny credit to an early market entrant simply because the business area is new and unfamiliar to them as lenders. This can even happen when service providers are already creditworthy.

Blending reduces foreign exchange risk and lowers the cost of borrowing. For example, a loan that is a blend of 80 percent concessional finance and 20 percent domestic commercial finance has foreign exchange risk on only $\mathbf{8 0}$ percent, rather than $\mathbf{1 0 0}$ percent, of the loan. And although the total debt service will be higher than that of a pure commercial loan, payments are spread over 15 years rather than the conventional 5-10 years.

Different blending instruments (seen in table 6.2 as well as throughout this chapter) serve different purposes, but when used together most help to bolster both the supply of and demand for commercial finance. The main objectives of these tools are (a) reduced costs (which support the borrower), (b) increased transparency and reduced exposure to risk (which support the lender), or a combination of both. 
Box 6.1. Blended Finance to Reduce Rural Sanitation Costs in Bangladesh

Rural populations worldwide generally invest their own financial resources to purchase or build latrines or toilets. But the costs can be prohibitive, especially for poorer households or where there is a lack of competition between providers.

This is the case in rural Bangladesh, where despite high demand for sanitation facilities, households cannot afford to purchase them without paying in instalments. To address the issue, the country is now embarking on a new project to blend output-based aid-under the World Bank's Global Partnership on Output-Based Aid (GPOBA)-and microfinance loans to lower the cost of a latrine and spread repayment out in weekly instalments over an entire year. The subsidy consists of about $\$ 15$ per household and will reduce the weekly payment by 11 percent. A second benefit of the subsidy is that it reduces the risk of the microfinance institutions in their lending.

On the supply side, the financiers are also extending loans to microbusinesses that sell latrines and latrine construction. This work is augmented by World Bank technical assistance grants to train entrepreneurs for construction and help the financiers identify and reach poor households. The blending is expected to leverage $\$ 22$ million in household contributions.

Source: World Bank 2016a.

To be effective, these tools must be utilized at a specific place and time to support service providers that have the capacity to borrow but cannot yet access commercial markets. Their limited accessibility may be due to information asymmetries or political uncertainty. Once sufficient experience exists within a country for accessing commercial finance, the use of these tools should be reduced or stopped altogether to prevent moral hazard.

\subsection{Building Demand}

Demand creation starts with the first two components of this framework: more efficient public resource allocation and improved service provider performance. Service providers should have the incentives to improve performance and climb the ladder toward creditworthiness. Governments also have a role in supporting broader policies that define the legality to borrow. Where barriers to borrowing exist, they should be identified and solutions promoted.

\subsubsection{Where Should Governments Focus Their Efforts?}

A range of service providers can benefit from blended finance-from those that can finance only part of their capital expenditures themselves, to those that are close but not fully creditworthy. Such service providers likely account for about 36 percent of all providers as defined as recovering between 100 and 150 percent of their operating costs.? For the commercial lender, the ability of the service provider to maintain future positive cash flows is critical.

\footnotetext{
A range of tailored blended finance strategies can be used to help mobilize commercial finance depending on local financial market conditions and on the way in which a water sector accesses market-based financing. A blending strategy can have many different forms (box 6.2), but each resulting strategy aims to achieve the required debt service coverage ratio (a measure of the cash available to pay current debt service obligations) throughout the projection period and to do so without the need for additional external finance.
} 
TABLE 6.2. How Select Blending Instruments Can Support Different Types of Commercial Finance

\begin{tabular}{|c|c|c|c|}
\hline $\begin{array}{l}\text { Donor or MDB } \\
\text { instrument }\end{array}$ & Grants and subsidies & Concessional loans and equity & Credit enhancements \\
\hline Overall approach & $\begin{array}{l}\text { - Capacity building and training to bridge the } \\
\text { commercial financing gap } \\
\text { - Reduce costs to private providers of services or } \\
\text { of financing }\end{array}$ & $\begin{array}{l}\text { Provide liquidity to commercial } \\
\text { financiers }\end{array}$ & Reduce risk perception \\
\hline Supplier finance & $\begin{array}{l}\text { - Develop or pilot new models } \\
\text { - Results-based grants }\end{array}$ & $\begin{array}{l}\text { - Soft loans to vendors and } \\
\text { suppliers }\end{array}$ & $\begin{array}{l}\text { - Guarantees to vendors } \\
\text { and suppliers }\end{array}$ \\
\hline Microfinance & $\begin{array}{l}\text { - Sensitize microfinance providers to sector needs, } \\
\text { support them in assessing water risks and developing } \\
\text { tailored products, train potential borrowers } \\
\text { - Targeted subsidies to lower borrowing costs } \\
\text { - Help microfinance lenders access capital markets }\end{array}$ & $\begin{array}{l}\text { - Provide liquidity: loan capital via } \\
\text { lines of credit, seed funding for } \\
\text { revolving funds } \\
\text { - Take equity shares in } \\
\text { microfinance providers }\end{array}$ & $\begin{array}{l}\text { - Guarantees to } \\
\text { microfinance } \\
\text { providers help them } \\
\text { mobilize capital from } \\
\text { commercial banks or } \\
\text { investors }\end{array}$ \\
\hline $\begin{array}{l}\text { Commercial loans, } \\
\text { bonds, equity }\end{array}$ & $\begin{array}{l}\text { - Technical assistance (TA) to sensitize banks to } \\
\text { - TA to assess investment projects } \\
\text { - TA to structure transactions } \\
\text { - Training of borrowers, project preparation } \\
\text { activities, shadow credit ratings } \\
\text { - Support of water sector pooling or grouping to } \\
\text { access larger commercial finance providers } \\
\text { - For bonds: transaction advice or structuring }\end{array}$ & $\begin{array}{l}\text { - Blend concessional with } \\
\text { commercial finance to soften } \\
\text { lending terms } \\
\text { - "First loss" agreements } \\
\text { - For equity: participations with } \\
\text { expectation of below-market } \\
\text { returns }\end{array}$ & $\begin{array}{l}\text { - Guarantees to } \\
\text { commercial lenders } \\
\text { - Revenue intercepts and } \\
\text { escrow accounts }\end{array}$ \\
\hline
\end{tabular}

Box 6.2. Typical Blended Finance Strategies

- Targeting service providers that are either already creditworthy or close to creditworthiness through performance improvements

- Linking commercial finance with public or concessional finance through complementary instruments

- Identifying and making third-party guarantees effective in a financing plan

- Arranging commercial financing and related loan servicing in periods when the default risks are lower

- Mixing grants and concessional loans to ensure that positive cash flows work over the projected period

Source: Baietti 2017.

The ratio of a blending arrangement will depend on the type of investment, and more importantly, on the profile of the service provider. For example, in the urban water subsector, blending can be used for two types of interventions. The first is high-cost, longer-return investments such as network extensions. The best fit for these long-term investments would be bonds. The second type is short-term investments to improve efficiency (energy reduction, for example) that would benefit most from commercial bank 
loans and potentially vendor or supplier finance. In either case, if the service provider already has a large revenue base, the investment needs for reaching universal access will be smaller, and they can thus rely less on the public contribution of the blending arrangement. Smaller providers with smaller revenue bases will need greater public leverage.

To address the critical need for increased commercial investment in water infrastructure across a broad range of LMICs, donors need a flexible and pragmatic approach toward the use of blended finance-one that adapts to the state of financial market development and sector investment needs in target countries. A conventional approach to blending could be used in higher-income countries with nascent capital markets and service providers with the potential to be commercially sustainable (Leigland, Trémolet, and Ikeda 2016). However, in countries facing severe constraints to commercial investment in the water sector, its gradual introduction via blending would be a legitimate objective.

While not without risks, the opportunity to blend concessional finance with commercial finance is perhaps the most promising mechanism to begin the process of closing the financing gap and reaching WSS goals. However, transactions will need to be tailored to the needs of the borrower, the domestic capital market, and the investors. The blending arrangements and ratios will evolve over time and clearly depend on the country context.

\subsubsection{Tools to Make Commercial Finance} More Affordable

Tools to reduce transaction or financing costs or spread them out among a group of service providers, or between current and future users of WSS services, all help make commercial finance a more affordable option for borrowers. These tools include tenor extensions, project preparation funds and results-based financing.

Tenor extensions are a mechanism to overcome one of the single largest challenges facing infrastructure finance in developing countries: the mismatch between the short tenors typically offered by commercial banks and the long lifetimes of infrastructure assets. Tenor extensions, when properly structured, reduce annual debt service costs and spread the responsibility across generations of beneficiaries.

Project preparation funds provide grants and other low-cost funds to help establish the viability of a project. Traditionally, up-front preparation costs are 3 percent of total project costs, but they can run as high as 10 percent. These funds can be critical for ensuring that projects are investment-ready and can attract the interest of concessional and commercial financiers. Project preparation should include upstream planning studies, feasibility studies, and detailed economic cost-benefit analysis to determine whether the project is economically and financially viable as well as affordable.

Results-based financing ( $\mathrm{RBF}$ ) is an alternative to traditional, input-based infrastructure development that provides incentives for improving performance or expanding access in a more efficient manner. RBF ties payment to the delivery of results, transferring more risk to the service provider, as in the case of the World Bank's São Paulo Water Recovery (REÁGUA) Project in Brazil, where payment is made for each cubic meter of water recovered in wastewater facilities (World Bank 2014a). RBF can reduce the risk of corruption by making payments more transparent while also including some up-front costs for construction as well as monitoring and supervision of outputs by a third party.

Since 2012 the World Bank has scaled up the use of RBF pilots to support investment projects with disbursements linked to results, including Program-for-Results instruments in the Arab Republic of Egypt (box 4.5) and a new series of performance-based financing (PBF) windows integrated into projects in Kenya (box 6.3). In India, a $\$ 1.5$ billion facility is helping up to 500 cities achieve universal access by developing and implementing turnaround programs that are partially prefinanced by loans from municipal governments, which bear some 
BOX 6.3. Incentives for Sector Performance in Kenya

As Kenya attempts to keep up with rapid urbanization, reaching universal access by 2030 becomes more challenging. The Kenya Water and Sanitation Development Project, currently under preparation, will allow counties or service providers to apply for several types of RBF depending on their operational and access targets. Proposals must meet standard criteria, including financial sustainability, water-source sustainability, cost-effectiveness, and cost-reflective user charges. Projects for priority funding are those with the lowest ratio between investment costs and results: (a) people gaining access, (b) reduction of cubic meters of NRW, and (c) improved reliability of supply.

To fund these improvements, the government of Kenya is tapping into the International Development Association (IDA) Scale-Up Facility, a window that offers soft loans that are considerably more attractive than commercial loans at 15 percent interest. The facility provides various options for the type of interest rates, grace periods (5-9 years), maturity limits (24-30 years), and amortization profiles. The government is considering on-lending by applying no surcharge for well-performing service providers, and a 2 percent charge for poorer performers. If combined with commercial borrowings, a blending approach could enable faster achievement of the sector targets. In time, this scheme could evolve into a sectorwide approach applied to the entire WSS sector regardless of financing source.

of the risk. Service providers pay off their loans using grants from the facility once results-made publicly available annually-have been achieved. Those providers that meet minimum standards are incentivized to become "beacons of change" through second-stage reforms that bring them closer to commercial viability.

\subsection{Building Supply}

\subsubsection{The Domestic Commercial Market}

Domestic financiers in LMICs do not always have experience and knowledge of the WSS sector. Coupled with the lack of creditworthy borrowers and political economy risks, domestic currency cannot always be sourced in long-term maturities and at affordable rates. These knowledge gaps can be filled by creating market intelligence and analytical tools, such as approaches for diagnosing the creditworthiness of service providers (indexes, shadow ratings, cash flow analysis, and tariff adequacy analysis) as well as greater promotion of risk mitigation products and how they should be used.
Effective, fair, and transparent economic regulation is a key factor for a lender assessing risk in a given country. Regulation must be in place to oversee the service provider and tariff setting. Creating comparison and competition in the sector via benchmarking can incentivize the sector to increase capacity and efficiency. For instance, the Kenya Water Services Regulatory Board (WASREB), with technical assistance from the World Bank, created the Creditworthiness Index report in 2015 to help estimate the financial status of select water service providers.

\section{It takes time to transition to significant levels of commer-} cial finance. Colombia's experience shows how initial donor support can escalate into more-sustainable commercial lending. The country created a second-tier lender nearly 30 years ago, which today has one-third of its capital invested in the WSS sector. The case of the FINDETER development bank is unique in that the lender simultaneously builds the capacity of both service providers and domestic banks. The use of an institution to slowly develop local markets has paid 
Box 6.4. Colombia's Municipal Development Fund

Colombia has been a pioneer in blended finance since 1989 when the government established FINDETER

(Financiera de Desarrollo Territorial), a government-owned, second-tier lender that has maintained a AAA

local credit rating. The agency provides loans to a first-tier lender, which is often a domestic commercial bank that finances infrastructure projects.

Municipalities and service providers must have their loan applications approved by both the bank and FINDETER, and they can also receive project preparation support from FINDETER. The bank gets the loan at a discounted rate. Combined, these elements promote bank participation, although the bank retains a 100 percent credit risk. The service provider essentially receives commercial loans on blended terms. A voluntary intercept provision further enhances the terms for lenders as the bank has the right to intercept municipal revenues flowing from the central government, if needed.

Donors were critical to the initial start-up of the fund by providing loans guaranteed by the government, and they continue to fund the facility. More liquidity is made available from the revenues of existing loans and the issuance of certificates of term deposits. The fund has extended maturities to 15 years compared with the 5 -year terms usually available in the market.

Source: World Bank 2016a.

off now that banks are lending directly to municipalities with their own resources (box 6.4).

\subsubsection{Tools to Increase Transparency}

Tools to increase transparency can help lenders understand and assess the performance of borrowers.

Credit ratings provide an independent assessment of the financial health of a water service provider. Ratings assist lenders in understanding borrowing risks and provide insights for service providers on how they may be viewed by the market. Although credit ratings are public information, "shadow credit ratings" are not a matter of public record and can offer a first step to expose public service providers to the needs and demands of the commercial lending market. Given the high resource requirements for designing and maintaining a credit rating system, there should be sufficient opportunity.

Benchmarking is another important instrument to measure and report on the technical and financial health of a water service provider. Key performance indicators look at an array of factors, including service levels, employees, revenues, and costs. These standardized measurements can be used by investors to assess and compare the overall health of the institution over time and with other institutions.

\subsubsection{Tools to Reduce Risk Exposure}

Tools to reduce risk exposure are used to mitigate the concerns of the private sector regarding repayment. In the WSS sector most assets are underground and therefore cannot be used as collateral in the case of default. Moreover, with the potential for politicization in the sector, securitization of payments on the basis of revenues can also be a risk. Tools that help mitigate the risk of nonpayment, by providing other options for recourse, include insurance, hedging instruments, pooled finance, and guarantees.

Insurance is used to mitigate an investor's risk. It can also be structured to share risk or tailored to address 
very specific issues. Insurance has been used to mitigate concerns addressing such diverse challenges as the political economy, key personnel, or catastrophic circumstances, including natural disasters.

Hedging instruments are another form of insurance used to support external investors financing an infrastructure project with a revenue stream in local currency. They insure investors against foreign exchange risk or interest rate risk. However, hedging instruments tend to be difficult to structure in smaller economies with less stable currencies.

Pooled finance is a mechanism used to bundle multiple water service providers with varying degrees of attractiveness to investors. The "collective approach" diversifies borrower risk and can provide access to capital markets by enabling the pooled facility to issue bonds and on-lend to service providers, as is the case in Tamil
Nadu, India (box 6.5) is particularly appropriate for small service providers.

Guarantees are a form of insurance and are among the most effective tools to reduce credit or political risks for commercial investors. The guarantor makes an obligation to pay part of the debt if the government borrower fails to perform in a timely manner (nonpayment, failure to redeem bonds, and so on). Guarantees are offered by some AA- or AAA-rated development partners (World Bank, export credit agencies, USAID, the African Development Bank, and the European Investment Bank) as well as by the private sector. Guarantees often extend maturities. In select cases they can improve the credit rating of a security, thereby lowering interest rates for the borrower. Guarantees are best used when the guarantee is tailored to mitigate specific constraints or overcome a specific risk.

Box 6.5. A Pooled Municipal Bond Issue to Help Small Providers Access Private Finance in India

In India, providers had been held back from accessing private finance by a lack of credit ratings or inability to cover bond issuance costs or legal fees. The State of Tamil Nadu in 2002 created a special-purpose facility-the Water and Sanitation Pooled Fund (WSPF)-to help 13 small- to medium-size Urban Local Bodies (ULBs) finance WSS services by accessing long-term domestic capital markets.

The AA-rated bond was for $\$ 6.2$ million, had a coupon of 9.2 percent per annum, and had a maturity of 15 years. The debt was repaid through general ULB revenues. Investor confidence was ensured through five different credit enhancement mechanisms:

1. State government debt-service reserve fund (DSRF): 1.5 times annual principal and interest payments

2. ULB escrow accounts: revenue accounts to pay annual debt service obligations early

3. Local debt service reserve fund: 5 percent of the principal borrowed by each ULB

4. State revenue intercept mechanism

5. Partial credit guarantee: provided by the U.S. Agency for International Development (USAID) to pay 50 percent of the principal in the case of default, paid through the DSRF

Source: World Bank 2016a. 
By enticing new lenders to a market, guarantees unlock access to new sources of finance. Guarantees also have an intrinsic value: the existence of a guarantee means that a project or service provider has already been duly assessed and potential problems have been addressed during the loan structuring, providing more comfort to potential lenders. Guarantees also

- Promote risk sharing;

- Help the lender better manage risk throughout a project;

- Ensure better-prepared projects;

- Provide a track record for borrowing from the private sector;

- Help develop local capital markets;

- Lower the cost of borrowing (longer tenors, lower interest rates); and

- Can lead to lower tariffs.

While difficult to quantify, guarantees from MDBs to all sectors make up about 4 percent of all development lending, totaling around \$37 billion between 2004 and 2013 (Humphrey and Prizzon 2014). 3 Over a three-year period (2009-11), guarantees mobilized an additional $\$ 15.3$ billion from the private sector (Mirabile et al. 2013). Although the Camdessus report (as discussed in chapter 2) called for an increase in guarantees for water sector investments, this has not materialized on a large scale, with current annual volumes around \$4 billion (2012-13).

There is room to expand the use of guarantees in WSS. The World Bank, for example, has committed to doubling the amount of these instruments over the next three years, including the use of a $\$ 2.5$ billion IDA Private Sector Window which includes a Risk Mitigation Facility and a Local Currency Facility.

Revenue intercepts are another form of guarantee whereby separate sources of revenue can be used to cover debt service in the case of default. These are generally fiscal transfers from the central government to subnational governments, including water service providers, and can be provided in lieu of collateral.

\subsection{Conclusion}

Where possible, public funding should be maximized by leveraging commercial finance. Governments and donors can serve as intermediaries-both in developing local financial markets and in assisting service providers in building a pipeline of investment-ready projects and improving borrowing capacity. Building the foundations for commercial finance in the sector is time-intensive and requires matching the objectives and priorities of lenders and borrowers, often with significant public sector funding.

A blended finance approach will help borrowers ease into the transition. In addition to blended loans, several proven regulatory and financial tools are available to bring more incentives for commercial financiers to enter a new market. Concessional financiers should consider these tools as part of a larger strategy to help "graduate" countries to a new playing field. The transition from aid-dependency to circumstances where providers or governments can access commercial finance on their own requires donors and governments to work together to ensure that they do not effectively crowd out commercial finance. Most of these tools will work better in countries where capital markets are more developed, but will require more effort on the part of donors and governments in more nascent markets to be innovative.

\section{Notes}

1. More detail on global experiences with blended finance can be found in the World Bank discussion paper, "Achieving Universal Access to Water and Sanitation by 2030: The Role of Blended Finance.” (Leigland, Trémolet, and Ikeda 2016).

2. IBNET database. https://www.ib-net.org/

3. Guarantees are not adequately measured or reported in international databases, including the OECD Development Assistance Committee (DAC) database. The maturities of guarantees are much shorter than for concessional loans, which also skews the analysis. 


\section{Chapter 7 Bringing It All Together}

\subsection{Recapping the Objectives}

This report aims to help countries take a new approach that focuses on efficiency, targeting, and leverage of public funds to attract commercial finance. It must grow from the implementation of clear and transparent governance structures and regulatory environments, setting out a pathway that will form differently in each country to contour to the variety of political and economic realities. The objectives are threefold:

- To bolster the currently low level of commercial finance in the sector

- To help decision makers develop the political will necessary to break out of the status quo

- To bring countries from the current low-level equilibrium to the achievement of their water supply and sanitation (WSS) goals

By following the components advocated in this report, service providers can begin to operate more efficiently, serve customers better, save costs, and eventually attract commercial finance to fill the remaining investment gap (figure 7.1).

\subsection{Finance as Part and Parcel of Broader Sector Reform}

Finance alone is not enough: improved service delivery and transparent governance need to be built alongside new and improved financing arrangements. This includes utility managers with high professional capability, sound financial management, effective use of benchmarks, strategic business plans, internal and external auditing, and transparent governance and regulation by technically capable and independent agencies.
WSS sector reform is a process that is unique to each country's economic and political context and can be instigated in various ways-both bottom-up and top-down (box 7.1). The government should focus its efforts on designing and funding sector frameworks that produce incentives aligned with efficiency and customeroriented service delivery.

Also important are the country-level enabling environments that affect all infrastructure sectors, including WSS. These frameworks set out the nature and extent of the financial architecture and determine which types of commercial finance would be available, as well as the use of intercepts, credit enhancements, credit provisions, and other financial provisions. Donors can help in the development of these frameworks, using global best practices.

The transition toward commercial finance will be a continuous and incremental process. Global experience with private sector participation in the water sector has shown that service providers do not need to be fully creditworthy to start accessing commercial finance. Governments can assist by supporting the right policies, regulations, and incentives and by providing transparent oversight. Regulation is key for lowering the risk for commercial financiers, and how the regulation is provided is less important that the lenders' perception of its effectiveness.

The new framework will require multiple institutions working cooperatively toward the same end, each within its own sphere of influence. All sector stakeholders must not only bolster their individual performance-in governance, policy, technical capacity, and public and private finance-but must also integrate these reforms 


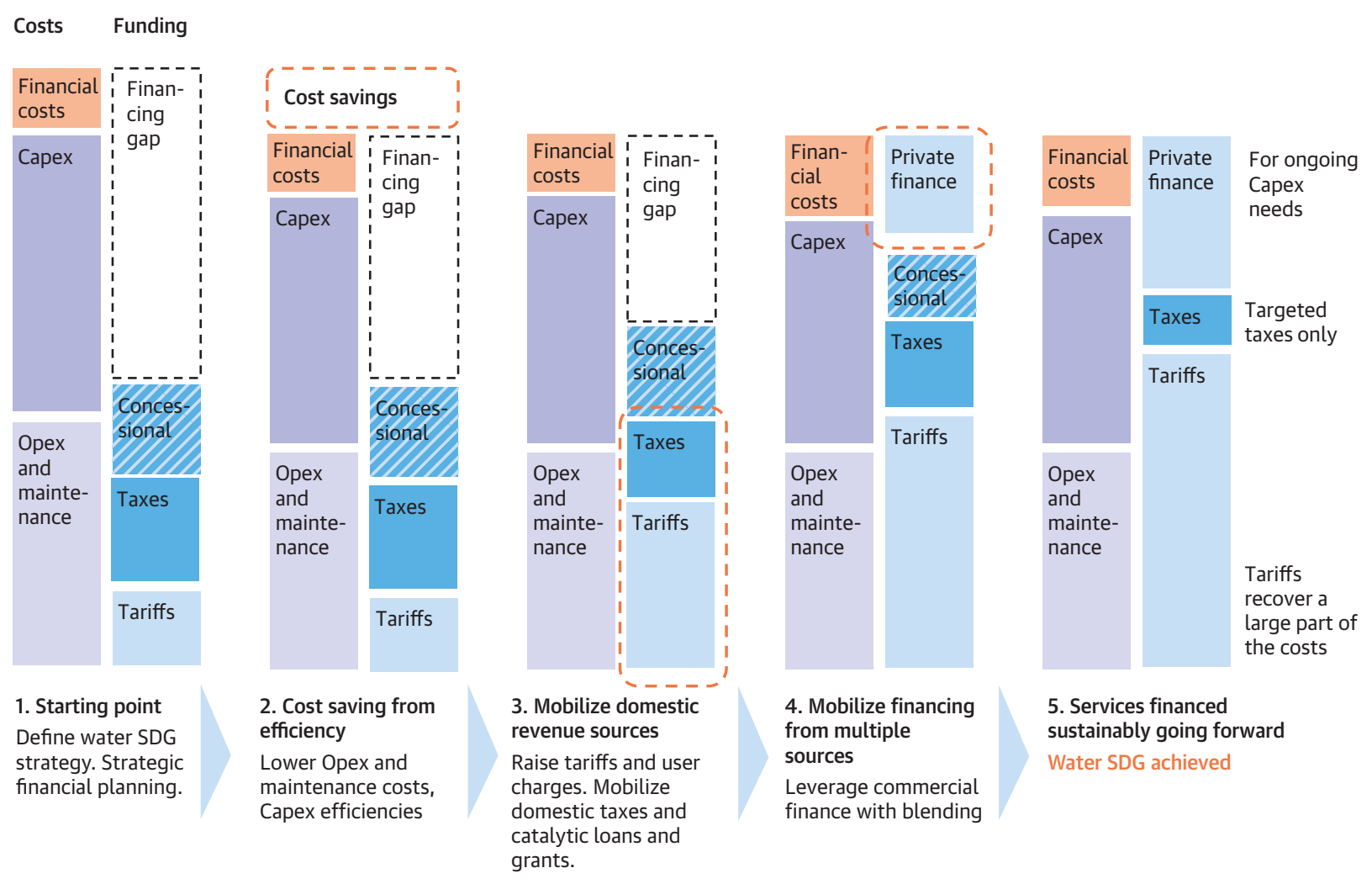

Source: World Bank 2016b.

Note: Capex = capital expenditures; Opex = operating expenditures; SDG = Sustainable Development Goal; WSS = water supply and sanitation.

in a way that can translate more and better-targeted investments into more and better services. The water sector, as a composite of multidisciplinary institutions, must address multiple challenges, from regulation to efficiency to affordability. Only with significant progress on such foundational elements can the sector attract the financing needed to ensure sustainable services for this generation and the next.

\subsection{Conclusions and Strategic Recommendations}

To meet Sustainable Development Goal (SDG) 6 and country-level WSS goals, a paradigm shift is needed in the way water services are currently financed. With current sector funding just 15 percent of what is expected to reach WSS goals, countries need more of both public funding and private finance, and to leverage their complementary benefits.

This section sets out recommendations to address the financing gap. These recommendations complement and build on those of the Camdessus panel, the Addis Ababa "Financing for Development" agenda, and other significant work, and are to be heeded by all parties working in tandem, including donors, governments, service providers, and the private sector.

\subsubsection{The New Financing Framework}

A more proactive, strategic use of public funds and concessional finance can crowd in currently untapped commercial finance. These funds should be scrutinized to determine how they can be used to "leverage in" commercial finance rather than exclude private 
BOX 7.1. The Evolution of WSS Sector Reform in Mozambique

The 20-year reform process in Mozambique was top-down and benefited from significant and long-term donor involvement. A delegated management framework (DMF) gave responsibility for WSS service provision to an asset holding company, FIPAG, which delegated asset operations to various public and private entities through management contracts.

For the first decade, a national regulator, CRA, oversaw only water supply in larger cities. It expanded to water and wastewater in secondary cities in 2009 when it decentralized its operations. Financial viability of service providers is achieved via the regulation of cost recovery tariffs. Policies provided an incentive for continuous service improvements, and the DMF provided a clear concept of the ownership, operation, and management of assets.

The process hit some major obstacles, such as low capacity and inappropriate incentives for staff. However, owing to the commitment to the long-term vision and a willingness to change course as needed, improvements were made over time. Today, services have improved, although coverage remains relatively low at 50 percent for water and 20 percent for sanitation.

Source: World Bank, forthcoming.

investment. Donors have strong incentives to lend to progressive service providers, even after they have reached the thresholds required for accessing commercial finance. Donors thus need to agree on a set of principles for helping service providers gradually stand on their own feet. To that end, the expansion of lending and borrowing in domestic currency would be helpful.

The impact of concessional funds could be amplified if donors and governments made a bigger shift in the water subsectors they support (rural versus urban, sanitation versus water). The development of dedicated climate financing mechanisms for subnational entities, including water service providers, which would exclude the need for sovereign guarantees would be particularly helpful.

Easing the transition to commercial finance should be an incremental and iterative process. Public funds will be needed to build up the foundational elements of an operative WSS sector, from effective regulation to sound governance and adequate capacity of sector institutions.

\subsubsection{Component 1: Plan, Allocate, and Budget Resources More Efficiently}

Recommendation 1: Integrate incentives: link strategy to policy, and policy to finance.

Governments should understand how the status quo creates explicit and implicit incentives and reform them as needed. Many countries have learned from past errors and are moving on from ad hoc sector management toward a more proactive approach to setting and achieving WSS goals. Their future success will depend on how cohesively their policies are linked to institutional mandates and allow for an efficient use of both public and concessional sources of sector finance.

\section{Recommendation 2: Use tariffs and subsidies in a smarter way.}

It is critical that subsidies are made explicit, quantified, and tied to policy objectives. To be effective, they must also be clear, transparent, predictable, and reliable. They can even be used as an incentive for improved service provider performance. Governments should also be aware of the intended and unintended 
incentives that public funds generate, which can include overconsumption of water, inefficient operations, or the crowding out of commercial investment.

In principle, public funds should be allocated to those areas that are least likely to attract commercial finance, such as sanitation or rural water supply. They may also be used to correct market failures. Although there are genuine concerns about affordability, these can often be addressed by tariff structures that provide lifeline tariffs for basic levels of consumption but allow for higher tariffs for those with greater capacity to pay for the service.

Recommendation 3: Invest in sector frameworks and institutional capacity.

Service providers should have the mandates, incentives, and capacity to deliver as expected. Regulatory frameworks are imperative not only for measuring progress internally but also for attracting potential commercial finance. Private participation in WSS will not only help fill the financing gap but also will reinforce good governance and efficient service delivery.

\subsubsection{Component 2: Improve Service Providers' Performance and Governance}

Recommendation 4: Set in motion a culture and cycle of improved sector performance.

All efforts to diversify or increase the sources of finance will have a minimal impact on the financing of water infrastructure if the service providers remain inefficient and unable to borrow. Service providers themselves must strive for clear lines of revenue, sustainable collection systems, high service standards, systems that maintain existing infrastructure, proper planning for new infrastructure, and completed audited accounts to help financiers and financial regulators understand the position of the service providers. These incentives can be created if governments set higher expectations for efficiency and hold providers accountable for achieving results, and if providers themselves work to bring better services to their customers.

\section{Recommendation 5: Aim for long-term financial} sustainability.

Capital efficiency is especially important for ensuring low operations and maintenance (O\&M) costs in the long term. Good governance and technical and financial operating efficiency are the foundation that ultimately creates creditworthiness and leads to access to commercial finance. Many service providers that have made strides in efficiency have done so through good leadership and incentives for staff to deliver on performance improvements. Once service providers gain access to commercial finance, experience has demonstrated that the discipline of the market coupled with effective regulation drives up service standards and effective governance arrangements, in a virtuous circle.

\subsubsection{Component 3: Leverage Public Funds to Attract Commercial Finance}

\section{Recommendation 6: Match the supply and demand for commercial finance.}

Commercial finance is a large untapped source that could help fill the financing gap in many countries. Most service providers are unaware of the needs of commercial financiers and the diverse range of instruments they offer, while most investors are wary of the WSS sector. Governments and donors must address the challenges on both the supply and demand sides to give both parties the right incentives to do business together. An incremental approach will help build partnerships between the public and private sectors in a given country, at a pace where both feel comfortable with the changing risk profile.

\section{Recommendation 7: Understand the benefits and costs of commercial finance.}

Borrowers should carefully consider the implicit costs and benefits of borrowing concessional and commercial finance. Although concessional finance may seem more affordable at face value, once foreign exchange and interest charges are taken into account, commercial finance can be a preferred option for some types of investments. Where commercial finance is more 
expensive, borrowers should also weigh the long-term benefits of making the transition.

\section{Recommendation 8: Leverage concessional funds by blending.}

Blending concessional and government resources, even with minimal levels of domestic commercial finance, is an efficient use of precious resources and a critical start to securing the financing to close the gap. Blending can be used to correct market failures-such as lack of credit for early market entrants when already creditworthy-or as a bridge to bringing the marginally creditworthy closer to accessing commercial finance on their own. As with any market correction, blending should be phased out once commercial finance can be accessed in its absence. Although the up-front costs of developing the financial architecture and becoming creditworthy will likely be high, the long-term payoff of eliminating the foreign exchange risk, closing the service backlog, and using public and donor resources more efficiently will save significant money over time.

\section{Recommendation 9: Build demand for commercial finance.}

Donor support should be provided to build a pipeline of commercially viable WSS infrastructure, even for partial commercial finance. In essence, better-prepared projects have the potential to attract more private interest, on better terms. Project preparation can also provide guidance on the best implementation model for the project. For example, bulk water supply and wastewater treatment tend to be more attractive for commercial financing, public-private partnerships, or both.

Governments and donors can also work with the private sector to help transition marginally creditworthy service providers up the ladder of financial sustainability. Once those providers can attract commercial finance, scarce public funds can be allocated to support those providers that are less financially viable.

\section{Recommendation 10: Use tools to make commercial finance more affordable.}

Donors should seek to help pioneer tools and instruments in new countries. Less-developed countries, with less-developed financial markets, have lower access to commercial bank loans and bonds. However, microfinance and vendor and supplier finance-for such investments as solar power and water pumpscan often provide a starting point from which larger or more traditional investments can be built. Tools to enhance the affordability of commercial finance include tenor extensions, project preparation facilities, and results-based financing, such as output-based aid.

\section{Recommendation 11: Use tools to de-risk the sector.}

An array of risk mitigation tools are available to enhance the attractiveness of water investments for commercial financiers, including hedging instruments, insurance, guarantees, credit ratings, and benchmarking. Resources are available from donors to help structure enhancements on specific transactions. Governments also have a broader role to play in providing comfort to lenders through effective regulation and ensuring predictable and sufficient revenue streams. The transition will be incremental and slow. It will have some up-front cost outweighed by very high long-term benefits. 


\section{Appendix A Types of Commercial Finance}

Vendor or supplier finance. Supplier finance occurs when a private company offers financing to a customer or a potential customer to purchase products or services. By doing this, the company increases its sales by financing its own products. This type of financing is used primarily in water supply. It has tended to focus on pumps and solar energy units, although service providers also offer financing to their customers to purchase household connections. It is important that such equipment is a relatively small portion of costs, especially compared with civil works, which make up the biggest portion of project costs. With nearly 10 percent of all energy costs associated with moving water, supplier finance is an important alternative, particularly in low- to middle-income countries (LMICs) where commercial lending either may not be available or may be prohibitive. More research and analysis identify how supplier finance might be scaled up. Financial models such as equipment leasing should also be further explored, such as for financing trucks that empty latrines to improve management of fecal sludge in urban areas.

Microfinance. SSIPs play an active role in supplying water infrastructure in periurban and rural areas, as well as in some urban areas. In most cases, they have limited access to commercial bank financing. SPSPs may lack formal legal status or be too small or informal to have financial statements that can be audited.

Some emerging economies now have relatively strong banking sectors with a variety of financial institutions (collectively referred to here as microfinance institutions, or MFIs) that serve small businesses and consumers: commercial banks (many have microfinance portfolios), microfinance banks, savings and credit cooperatives, and informal community-based financial service organizations. Countries like Bangladesh, Cambodia, India, Indonesia, Kenya, and Malawi have growing microfinance sectors that have experimented to various degrees with lending for water sector investments. These MFIs typically offer small loans to individuals, entrepreneurs, and communities that do not have access to traditional credit. These loans can finance items such as rainwater harvesting tanks, water connections, shallow wells, pumps, ventilated improved pit (VIP) latrines, septic tanks, sanitation slabs, and biogas toilets. Sanitation microfinance had huge growth potential, particularly to finance on-site sanitation (Mehta 2008) estimates. However, other more recent studies have concluded that, except in a few countries, existing experiences have remained limited and have not yet been scaled up (Trémolet, Mansour, and Muruka 2015). Water loans typically make up small percentages of MFI portfolios, although this is impossible to track with precision because microfinance providers do not usually track loan portfolios according to the purpose of such loans. Microfinance lending has yet to make any significant impact in water supply and sanitation (WSS) sectors of low-income countries. But given the important role played in the sector by SPSPs and households, and the high repayment rates for WSS loans where such loans have been provided, there is certainly a business case to be made for expanding this kind of commercial lending, possibly with more support from donors and multilateral development banks (MDBs). It will be essential to develop a better understanding of how governments and MDBs can support the scaling-up of microfinance approaches in a broader range of countries to help tackle the water infrastructure backlog globally. 
Commercial bank loans. Worldwide, commercial banks provide local governments and service providers with a tremendous amount of debt, but most of it is relatively short term (three to five years) and expensive, reflecting the inability or unwillingness of many commercial banking institutions to apply the resources necessary for adequate analysis of municipal credit needed for sector-specific lending, such as that needed for project finance. A large proportion of bank lending to local governments in many LMICs is in the form of "overdraft facilities," designed to assist with working capital needs and short-term cash flow problems. Commercial banks tend to be very low-risk lenders and usually seek to minimize the risks of lending to subnational providers by requesting collateral in the form of assets (assets considered liquid-that is, easy to sellare preferable, but land is also often used). Long-term lending for infrastructure by local commercial banks in LMICs is relatively rare. Project finance for large-scale water projects is mostly provided by MDBs or international commercial banks, sometimes with syndicate participation by local lenders. This kind of finance is much more widely used than bonds, at least for initial tranches of project finance, because dealing with a syndicate of bankers to adjust things like construction milestones is seen as being much easier than negotiating with bondholders. The water sector is somewhat unique in that most of its assets are underground and cannot be used as collateral, making revenue intercepts and guarantees much more critical for attracting private finance.

Domestic commercial finance can provide a more attractive alternative in countries with weak currencies, but markets are often not "deep" enough in countries with the greatest need. Domestic commercial financiers (international or national) located in the borrower's country provide financing in local currency, which limits the foreign exchange risk. Market conditions on domestic financial markets tend to be less favorable, however, with short tenors and relatively higher interest rates. Liquidity might also be an issue when they lenders lack the space to offer credit in the market. This capacity is called "banking depth" and is measured by a country's domestic bank credit as a percentage of gross domestic product (GDP). In Organisation for Economic Co-operation and Development (OECD) countries, banking depth averages 109 percent, whereas in Latin America (a region with relatively developed markets) the average is only 44 percent (García-Kilroy and Rudolph 2017). Conversely, in some countries, "captive" liquidities (that need to remain invested in the country, such as funds managed by institutional investors) may be substantial and in search of long-term financing opportunities on domestic markets.

Just as with service providers, local capital markets can improve over time to be able to offer private finance in the water sector. International and national banks can work together to offer syndicated loans to a single borrower. Through such transactions, the local banking sector gains sector-specific knowledge and new skills. Moreover, the presence of international banks fosters competition in the local market, which lowers the cost of borrowing. These benefits and synergies have been seen in public-private partnership (PPP) transactions in water throughout the world.

Bonds. Bonds are a debt instrument whereby the lender provides financial resources to the borrowing entity, which, in the water sector, might be a utility, local government, regional development authority, state-owned enterprise, transmission company, or bulk water supplier. Regardless of the borrower, most water institutions are subnational institutions that may borrow with, or without, the backing of the sovereign state. They may borrow based on their total obligations (known as general obligation bonds) or their specific revenues (generally referred to as revenue bonds). Tax implications differ by country, and the financial architecture and legal environment must be in place to underpin any water provider's bond issuance. Because bond finance is generally less expensive than bank finance, bonds have greater applicability in 
the refinancing of projects after construction is completed and implementation begins-in other words, after project completion risks have been eliminated.

Bonds are commonly used to finance water infrastructure in many high-income economies but have been used much less in most LMICs. Tenors tend to be longer, and interest rates are lower than most commercial banks, although the up-front costs can be high. Most MDBs have been encouraging their partners to look to capital markets to meet part of their infrastructure financing needs. In 2013, the African Development Bank published a comprehensive report on bond financing in Africa, identifying a selection of countries that were likely to be able to issue bonds immediately (Mbeng Mezui and Hundal 2013). A number of developing countries have tried to kick-start municipal bond programs, including programs to finance water sector investments. Notable examples include efforts in the late 1990s in India, Indonesia, and the Philippines, although none of these efforts have reached scale.

Several reasons have contributed to the slow take-up. One reason is that bond issues require significant preparation and expert assistance, which is limited in many LMICs. Grant finance for technical assistance can help in this regard. A second reason for so few successful bond programs is that many countries are still putting the institutional architecture in place to issue long-term debt. Finally, the investor community, which tends to target pension funds and insurance companies, has little experience with water investments and tends to prefer sovereign-backed issuances or energy sector bonds, where revenues tend to be higher.

Equity. Equity finance is the mostly widely used capital allocation mechanism for private businesses. It involves selling shares (also referred to as equity) to finance business operations. The shares can be sold in regulated stock exchanges, where a variety of formal listing requirements (including listing fees) must be met by the sellers. For public infrastructure, equity finance is a controversial form of finance because it entails some form or level of private ownership of assets used to deliver a public service. This is especially true in the water sector. Many groups oppose private ownership of water-related assets, and worldwide the public sector has tended to retain the ownership of water sector assets (Pinsent Masons 2012). Most listed water companies are in China, European OECD countries, North America, or the United Kingdom. A few listed companies exist in Asia (such as Manila Water Company in the Philippines) and Latin America (such as Companhia de Saneamento Basico do Estado de São Paulo [SABESP] in Brazil). 


\section{Appendix B \\ Analysis of Lending Parameters on Borrowing Costs}

This appendix further details the discussion in chapter 3 on lending terms, and focuses in particular on the relative costs and benefits of concessional foreign currency and commercial local currency loans. It is for illustrative and demonstrative purposes only.

The appendix provides conceptual comparative and simulation analyses of loans. Some of the loan characteristics discussed are not necessarily available in the markets of low- and middle-income countries (LMICs) but are rather used to demonstrate theoretical differences in financial costs. In most low- and middleincome countries it is not possible to find a domestic local currency loan with the same terms as a concessional foreign currency loan. Actual loan comparisons should be based on local factors and a much more rigorous market analysis.

The costs quantified for illustrative purposes are:

- Debt service costs as a factor of loan maturity and interest rates;

- Foreign exchange costs; and

- The cost of delay.

The combined effect of these different factors needs to be taken into account when deciding on the optimal financing package for a given investment program. Many utilities would be put off from considering commercial finance because they deem such financing to be too expensive compared to what they can charge their customers. However, the analysis presented in this appendix shows that the true costs of securing concessional financing can in fact be higher than what is initially conceived.

\section{Debt Service: Short Term Affordability versus Total Cost}

Affordability is a major consideration for water supply and sanitation (WSS) services, perhaps more so than for any other infrastructure subsector, and this often influences policy makers' decisions on loans and terms. For example, loans with shorter tenors may have lower overall debt service costs but require higher annual payments, while loans with longer tenors can be more affordable in the short term but end up costing more in total debt service. Most countries or service providers thus prefer longer-tenor loans with more affordable repayment plans.

Affordability is constrained by a service provider or local or national government's revenue streams, a large part of which is often current or anticipated revenue from tariffs. Given that tariff setting is often influenced by political economy factors, revenues from tariffs can fluctuate greatly, and if taxes do not compensate for a decline in tariff revenue, the revenue stream itself can fluctuate greatly.

From a decision maker's perspective, and given the long-term nature of major WSS sector investments, the terms of a loan borrowed today can affect future tariff levels. Shorter-maturity loans will maintain or put upward pressure on tariff levels to enable a borrower to pay back its obligations. Longer maturities may allow for lower tariffs. Figure B.1 is based on a compilation of data from various countries and shows the general principle that tariff levels would need to be higher (in this case, double) to back a 5-year loan compared with a 25-year loan (Baietti and Raymond 2005). 
FIGURE B.1. Effect of Loan Maturities on Tariffs

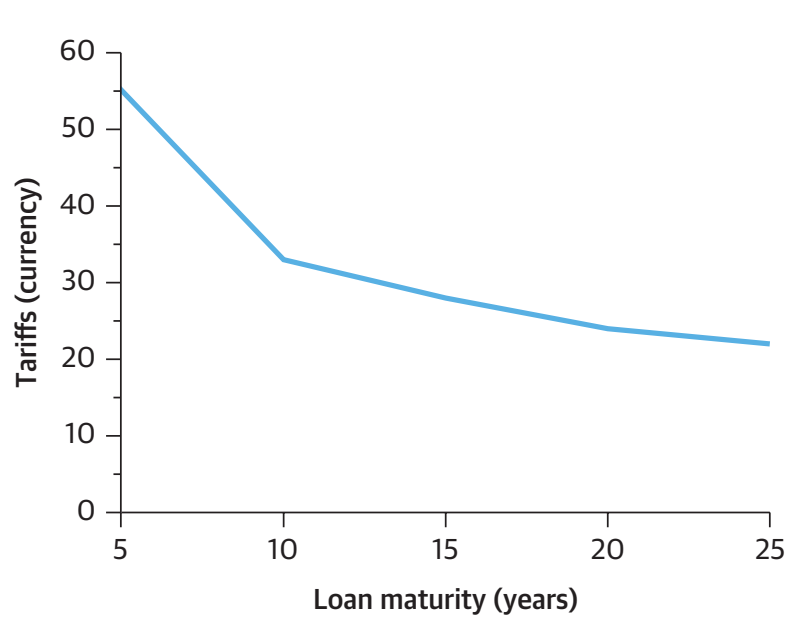

Source: Compiled from Baietti and Raymond 2005.

However, the pressure on tariffs also depends on the type of investments that are being financed. Major investments can include both those with longer payback periods, such as expansion of the network and development of a new water source, and those with shorter payback periods, such as new connections and performance improvement programs. Quick-paying investments could effectively support commercial borrowing with shorter maturities without necessarily affecting tariffs.

\section{Longer Maturity, Higher Total Debt Service Cost}

In addition, tariffs would preferably be adjusted gradually over time to reflect the forecast impact of longterm investment plans (and their associated financing, which would include a mix of maturities) rather than to cover the short-term costs of one specific investment. The calculation below show that even though annual repayments associated with medium-term commercial financing may be high, shorter maturities reduce the overall debt service costs.

Table B.1 presents a $\$ 50$ million loan (in local currency) at 10 percent interest with two different maturities: 15 years and 7 years. A service provider choosing to take a 15-year loan will pay 80 percent of the total debt service, or US\$40 million, in interest payments over
TABLE B.1. Loan Repayment on a Local Currency Loan at Different Maturities

\begin{tabular}{lcc}
\hline Repayment at 10\% interest & 15-Year & 7-Year \\
\hline Total principal (US\$, millions) & 50 & 50 \\
\hline Total interest (US\$, millions) & 40 & 20 \\
\hline Total debt service (US\$, millions) & 90 & 70 \\
\hline Annual amortization (US\$, millions) & 4 & 8 \\
\hline Interest (\% of total debt service) & 80 & 38 \\
\hline $\begin{array}{l}\text { Source: World Bank. } \\
\text { Note: Exchange rate assumed (local currency [LC] to U.S. dollar): } \\
\text { LC4,500 = US\$1. }\end{array}$ &
\end{tabular}

the life of the loan. In contrast, the 7-year option would cost only $\$ 20$ million, or just 38 percent of the total debt service, in interest payments. Figure B.2 compares the annual interest payments of the two loans: total debt service on a 15-year loan is nearly 30 percent more than on a 7-year loan. However, the trade-off is that the borrower must be able to service adequately the higher annual debt service within the shorter amortization period. In addition, loans of different maturities would in practice be provided at different interest rates to reflect lending risks, depending on market conditions.

\section{The Impact of Foreign Exchange Fluctuations}

A simulation comparing a concessional loan made in foreign currency against a commercial loan made in domestic currency shows the impact of currency fluctuations on the annual and total debt service costs. Table B. 2 shows two similar loans: one in local currency and one in foreign currency. A devaluation of the local currency will affect the repayment on a foreign currency loan on both the principal and interest charges.

Assessing the potential losses from local currency devaluations is no easy task, but assuming a purchasing power parity formula,, it is possible to forecast the likely fluctuation of the local currency against a hard currency such as the U.S. dollar. As shown in the results 
FIGURE B.2. Affordability vs. Total Debt Service: Loan Repayment Amounts, by Year, at Different Maturities

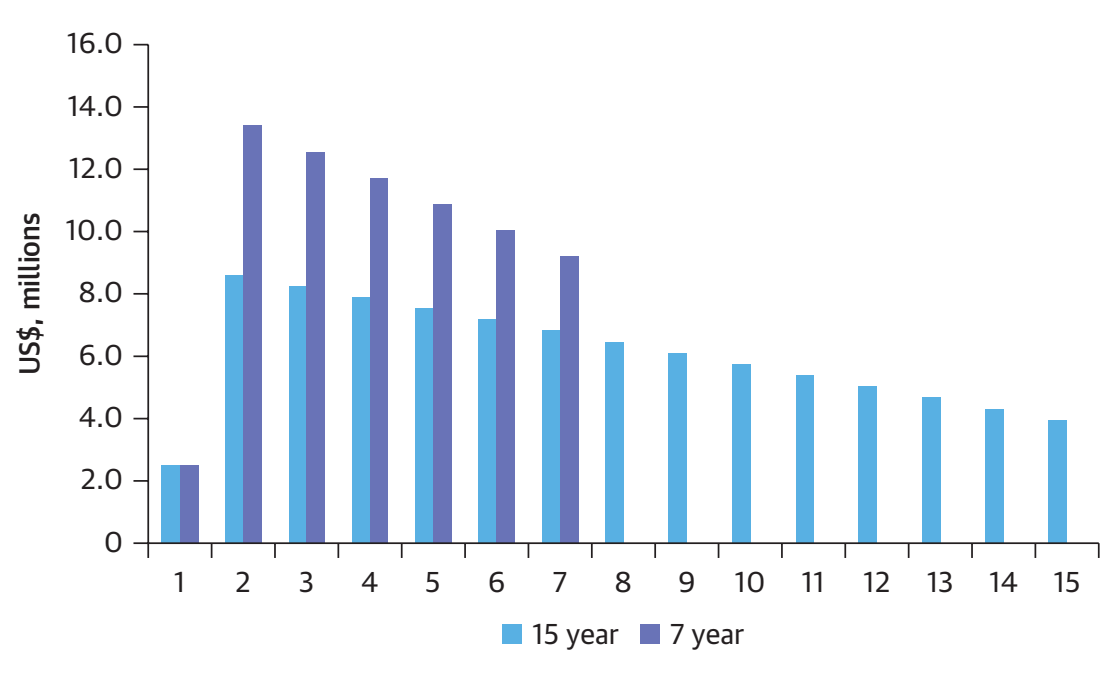

Source: World Bank.

Note: Figure shows annual repayment, by year, on a local currency loan (converted to US\$, millions) at two maturities: 7 years and 15 years. Exchange rate assumed (local currency [LC] to U.S. dollar): LC4,500 = US\$1.

TABLE B.2. Comparison of Foreign and Domestic Currency Loans

\begin{tabular}{lll}
\hline Variable & Foreign currency loan & Local currency loan \\
\hline Loan value (US\$ equiv.) & $\$ 50$ million & $\$ 50$ million \\
\hline Interest rate (\%) & 3.0 & $3.0^{\text {a }}$ \\
\hline Maturity & 15 years & 15 years \\
\hline Grace period & 3 years & 3 years \\
\hline Expected annual inflation $(\%)$ & 2.0 & 5.5
\end{tabular}

Source: World Bank.

a. Comparison for illustration only, given that it would be extremely rare to find a domestic local currency loan with the same terms as a concessional foreign curency loan in a low- to middle-income country.

of the simulation analysis (table B.3), a three percent annual devaluation of the local currency would add 29.9 percent to the anticipated total cost of the concessional loan (\$63.5 million), which is equivalent to the total debt service on the local currency loan.

Thus, if a commercial loan were to be offered at the same terms as a concessional loan, it would cost onethird less because of the elimination of the foreign exchange risk. However, in reality, domestic commercial loans generally have shorter maturities and higher interest rates. For the sake of comparison, the 15-year local currency loan at 10 percent interest, presented in table B.1, has a total loan repayment of $\$ 90$ million and is just slightly more expensive than the $\$ 82.5$ million concessional loan in terms of total debt service. Thus, the elimination of the foreign exchange impact more than compensates for the higher borrowing costs of using commercial finance when such finance is provided at higher interest rates.

\section{The Cost of Delay}

The second consequential cost associated with foreign currency concessional loans is the potential for delay in terms of arranging the loans. If there is some capacity and liquidity in the local finance market, domestic currency loans could be accessed more quickly than concessional loans, which typically require additional due diligence on the part of international financial institutions or international banks less familiar with the country. In addition, concessional loans often require counter sovereign guarantees, which can also cause delays.

Deferring projects while waiting for concessional finance can result in significant financial costs, resulting from the impact of currency devaluation and inflation. In addition, delaying investment would generate foregone social and economic project benefits, including social costs (fewer people with access to WSS services) 
TABLE B.3. 15-year Foreign and Local Currency Loan Repayment at 3 Percent Interest

\begin{tabular}{|c|c|c|}
\hline Portion of repayment & $\begin{array}{l}\text { Total debt service, LC loan } \\
\text { (US\$, millions) }\end{array}$ & $\begin{array}{l}\text { Total debt service, FX loan } \\
\text { (US\$, millions) }\end{array}$ \\
\hline Loan value & 50.0 & 50.0 \\
\hline Total principal payment & 50.0 & 67.1 \\
\hline Total interest payment (at 3\%) & 14.0 & 15.4 \\
\hline Total debt service FX loan (of which): & 64.0 & 82.5 \\
\hline Principal FX adjustment & n.a. & 17.1 \\
\hline Interest FX adjustment & n.a. & 1.9 \\
\hline Total cost of FX currency adjustments & n.a. & 19.0 \\
\hline Inflation impact & n.a. & 0 \\
\hline Total cost w/o FX and inflation impacts & n.a. & 63.5 \\
\hline Increase due to FX and inflation (\%) & n.a. & 29.9 \\
\hline
\end{tabular}

Source: World Bank.

Note: FX = foreign exchange; LC = local currency; n.a. = not applicable.

FIGURE B.3. Foreign Exchange Costs on a 15-Year Concessional Loan

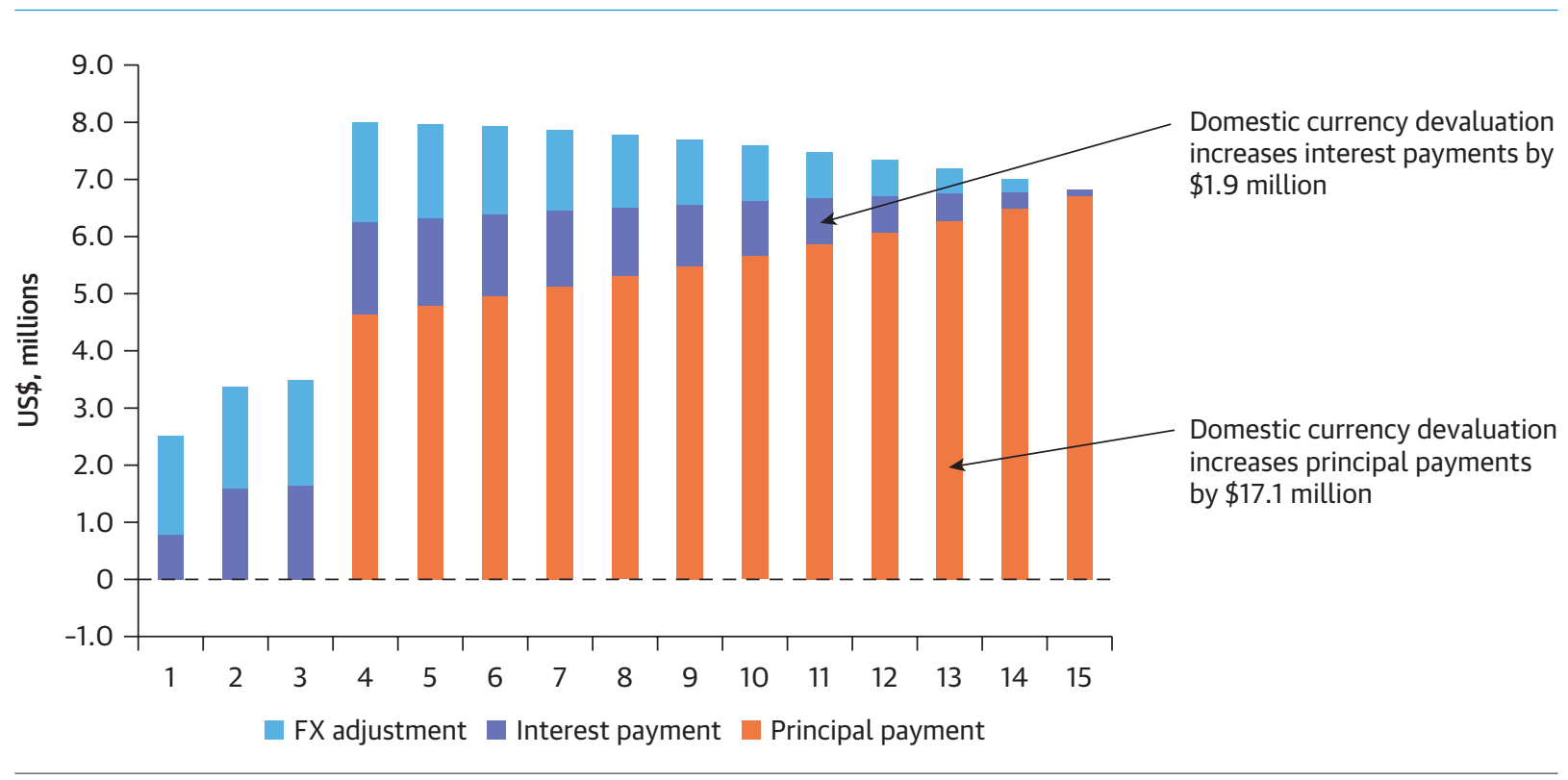

Source: World Bank.

Note: FX = foreign exchange. Figure shows annual repayment, by year, on a foreign exchange loan (converted to US\$, millions). Exchange rate assumed (local currency [LC] to U.S. dollar): LC4,500 = US\$1.

and economic costs (less water revenue taxed, less tariff-related income, and greater losses in economic productivity).

Table B.4 presents the foreign currency loan in table B.3 side by side with the same loan obtained after a five-year delay. In this illustrative example, the total debt service on the loan with a five-year delay is $\$ 104.3$ million compared with $\$ 82.5$ million for the loan with no delay. The cost of the delayed loan increases due to the impact of a three percent annual devaluation of the local currency versus the hard 
TABLE B.4. Concessional Loan Costs, with and without Five-Year Delay

\begin{tabular}{lcc}
\hline $\begin{array}{l}\text { Repayment category, 15-year FX loan at } \\
\mathbf{3} \% \text { interest }\end{array}$ & $\begin{array}{c}\text { Total debt service, loan with no } \\
\text { delay (US\$, millions) }\end{array}$ & $\begin{array}{c}\text { Total debt service, loan with 5-year } \\
\text { delay (US\$, millions) }\end{array}$ \\
\hline Total principal & 67.1 & 86.4 \\
\hline Total interest & 15.4 & 17.9 \\
\hline Total debt service, FX loan (of which): & 82.5 & 194.3 \\
\hline \multicolumn{1}{c}{ Principal FX adjustment } & 17.1 & 4.4 \\
\hline Interest FX adjustment & 1.9 & 24.2 \\
\hline Total cost of FX currency adjustments & 19.0 & 16.7 \\
\hline Inflation impact & n.a. & 40.9 \\
\hline Total impact of delay & n.a. & 63.5 \\
\hline Total cost w/o FX and inflation impacts & 63.5 & 64.3 \\
\hline Increase due to FX and inflation (\%) & 29.9 & \\
\hline
\end{tabular}

Source: World Bank.

Note: $\mathrm{FX}=$ foreign exchange; $\mathrm{n} . \mathrm{a}$. = not applicable. Table presents the cost of a foreign currency loan repayment in local currency but shown as a conversion to U.S. dollars at the original exchange rate for the sake of simplicity. Exchange rate assumed (local currency [LC] to U.S. dollar): LC4,500 = US\$1.

currency, including over the 5-year interim period), adding $\$ 24.2$ million in foreign currency-related costs. The costs of the delayed loan also increase by $\$ 16.7$ million due to inflation (equal to 3.3 percent annually) on the foreign currency, which would inflate costs of foreign inputs. If combined, these costs would add 64.3 percent to the total cost of the loan. This provides an upper-bound estimate of what the financial costs of delay would likely be, for illustration.

A comparison of the impacts of inflation and foreign exchange on the two loans is presented in figure B.4. Under the delayed loan, the impact due to inflation is significant (\$16.7 million) when
FIGURE B.4. Consequential Costs of FX Concessional Loans, with and without Five-Year Delay

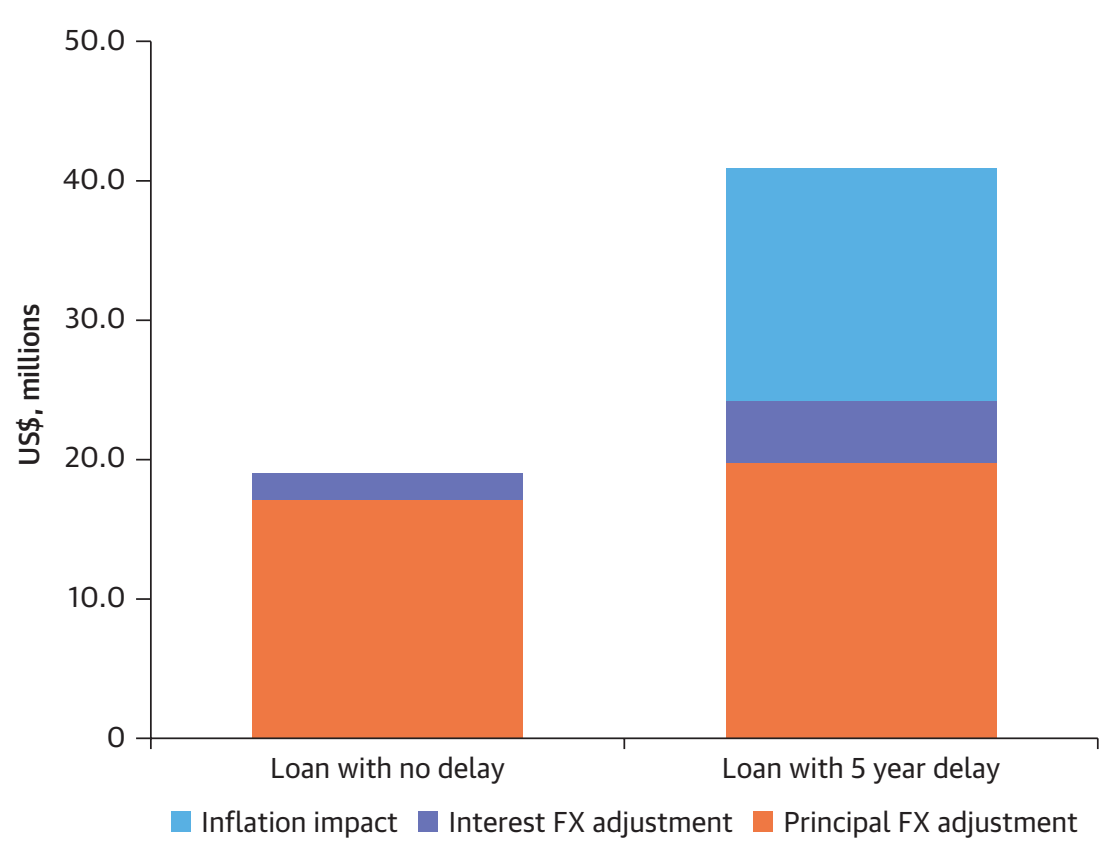

Source: World Bank.

Note: FX = foreign exchange. Figure presents the cost of a foreign currency loan repayment in local currency but shown as a conversion to U.S. dollars at the original exchange rate for the sake of simplicity. Exchange rate assumed (local currency [LC] to U.S. dollar): LC4,500 = US\$1. 
compared with the no-delay scenario. Again, for the sake of comparison and illustration only, the concessional loan at 3 percent and delayed by 5 years costs 16 percent more in terms of total debt service than the 15 -year commercial loan at 10 percent interest.

In conclusion, although these are hypothetical scenarios, inflation and exchange rates are significant variables that impact the total long-run cost of concessional finance and should be examined carefully on a case-by-case basis. It should be noted that these results were estimated based on evaluating the potential impacts of a "creeping" devaluation (that is, an annual small percentage over time). Greater losses could occur from "shock" devaluations of 5 percent or more or even a catastrophic devaluation such as what occurred during the East Asia financial crisis (Baietti and Raymond 2005).

Although affordability constraints are a major factor driving the decision to borrow concessional finance, borrowers should be aware that the considerations are often more complicated than comparing interest rates and tenors. There are very real implicit costs that can, in some circumstances, make concessional finance more expensive than one might initially assume. Borrowers should therefore consider commercial finance or blended approaches given their relative benefits, particularly for investments with a relatively rapid return on investment. At the very least, they should seek to model the impact of foreign exchange fluctuations on borrowing costs and consider alternatives (including domestic commercial financing in local currencies) when such impacts are likely to be substantial.

\section{Note}

1. The purchasing power parity formula is $\mathrm{S} 1 / \mathrm{So}=(1+\mathrm{Ifx})(1+\mathrm{IIl})$, where So is the spot exchange rate at the beginning of the time period (measured as the " $\mathrm{fx}$ " country price of one unit of currency lc); S1 is the spot exchange rate at the end of the time period; Iy is the expected annualized inflation rate for country y, which is the foreign country; and Ix is the expected annualized inflation rate for country $\mathrm{x}$, which is the domestic country. See www .Investopedia.com. 


\section{References}

2030 WRG (Water Resources Group). 2012. “The Water Resources Group: Background, Impact and Way Forward.” Briefing report prepared for the World Economic Forum Annual Meeting 2012 in Davos-Klosters, Switzerland, January 26. WRG, Washington, DC.

Adams, T. 2003. "Design-Build-Operate Gains Popularity in US Market”. Water World, Vol. 19, Issue 12. Penwell Corporation, Tulsa.

ADB (Asian Development Bank). 2013. Mongolia Water and Wastewate Operation Improvement Project. Final Report. ADB, Washington, DC.

AusAID (Australian Agency for International Development). 2011. "Independent Evaluation of Water and Sanitation Hibah Program Indonesia.” Final evaluation report for Indonesia Program, AusAID, Canberra.

Baietti, A. 2001. "Private Infrastructure in East Asia: Lessons learned in the Aftermath of the Crisis." Technical Paper No. 501, World Bank, Washington, DC.

Baietti. 2017. "Crowding-in Private Finance in World Bank Water and Sanitation Operations: A How to Guide for World Bank Task Teams.” World Bank, Washington, DC.

Baietti, A., and P. Raymond. 2005. "Financing Water Supply and Sanitation Investments: Utilizing Risk Mitigation Instruments to Bridge the Financing Gap." Water Supply and Sanitation Sector Board Discussion Paper 4, World Bank, Washington, DC.

Buchner, B., C. Trabacchi, F. Mazza, D. Abramskiehn, and D. Wong. 2015. “Global Landscape of Climate Finance 2015.” Climate Policy Initiative, London.

Dodane, P-H, M. Mbéguéré, O. Sow, and O. Strandel. 2012. "Capital and Operating Costs of Full-Scale Fecal Sludge Management”. Environ. Sci. Technol., 46, 3705-3711. American Chemical Society, Washington, DC.

García-Kilroy, C., and H. P. Rudolph. 2017. "Private Financing of Public Infrastructure through PPPs in Latin America and the Caribbean." Working Paper No. 114418, World Bank, Washington, DC.

Humphrey, C., and A. Prizzon. 2014. "Guarantees for Development: A Review of Multilateral Development Bank Operations.” Research report, Overseas Development Institute (ODI), London.

Hutton, G., and M. Varughese. 2016. “The Costs of Meeting the 2030 Sustainable Development Goal Targets on Drinking Water, Sanitation, and Hygiene.” Technical paper, Water and Sanitation Program, World Bank, Washington, DC.

IMF (International Monetary Fund). 2016. "From Global Savings Glut to Financing Infrastructure: The Advent of Investment Platforms." Working Paper No. 16/18, IMF, Washington, DC.

Kingdom, W., A. Baeumler, and A. Guzman. 2012. "Capital Subsidies Implict in Concessional Finance: How to Make Them More Transparent and Better Targeted.” Water Papers Series, Report, No. 69684, World Bank, Washington, DC.
Kolker, J. E., B. Kingdom, S. Trémolet, J. Winpenny, and R. Cardone. 2016. Financing Options for the 2030 Water Agenda. Water Global Practice Knowledge Brief. World Bank, Washington, DC.

Leigland, J., S. Trémolet, and J. Ikeda. 2016. "Achieving Universal Access to Water and Sanitation by 2030: The Role of Blended Finance.” Water Global Practice Discussion Paper, World Bank, Washington, DC.

Mbeng Mezui, C. A., and B. Hundal. 2013. "Structured Finance: Conditions for Infrastructure Project Bonds in African Markets.” Study, African Development Bank Group and the New Partnership for African Development (NEPAD) Regional Integration and Trade Department, Tunis.

Mehta, M. 2008. "Assessing Microfinance for Water and Sanitation: Exploring Opportunities for Sustainable Scaling Up.” Study for the Bill \& Melinda Gates Foundation, Ahmadabad, India

Mirabile, M., J. Benn and C. Sangaré. 2013. "Guarantees for Development”, OECD Development Co-operation Working Papers, No. 11, OECD Publishing, Paris.

Neder, D.K. 2016. Projeto Tacaimbo. Presentation to CAESB, June 2016.

OECD EAP Task Force (Organisation for Economic Co-operation and Development, Environmental Action Programme). 2006. "Financing Water Supply and Sanitation in Eastern Europe, Caucasus and Central Asia." Proceedings from a conference of EECCA Ministers of Economy/Finance, Environment and Water, Yerevan, Armenia, November 17-18, 2005.

OECD (Organisation for Economic Co-operation and Development, Environmental Action Programme). 2009. "Strategic Financial Planning for Water Supply and Sanitation.” Report from the OECD Task Team on Sustainable Financing to Ensure Affordable Access to Water Supply and Sanitation, OECD, Paris.

Pinsent Masons. 2012. Pinsent Mason's Water Yearbook 2012-2013, 14th ed. London: Pinsent Masons LLP.

RWSN (Rural Water Supply Network) Executive Steering Committee. 2010. Myths of the Rural Water Supply Sector. RWSN Perspective No 4, RWSN, St Gallen, Switzerland.

Sadoff, C. W., J. W. Hall, D. Grey, J. C. J. H. Aerts, M. Ait-Kadi, C. Brown, A. Cox, et al. 2015. Securing Water, Sustaining Growth: Report of the GWP/OECD Task Force on Water Security and Sustainable Growth. Oxford: University of Oxford.

Spears, D., A. Ghosh, and O. Cumming. 2013. “Open Defecation and Childhood Stunting in India: An Ecological Analysis of New Data from 112 Districts.” PLoS ONE 8 (9): e73784.

Trémolet, S. 2009. "Financing Water and Sanitation Services: Insights from The Water Dialogues.” Paper commissioned by The Water Dialogues, London.

Trémolet, S., and D. Binder. 2013. "Evaluating the Effectiveness of Public Finance for Household Sanitation in Dar es Salaam, Tanzania.” Report for 
WaterAid and Sanitation and Hygiene Applied Research for Equity (SHARE), London.

Trémolet, S., G. Mansour, and G. Muruka. 2015. "Microfinance for Sanitation: What Is Needed to Move to Scale?” Waterlines 34 (3): 227-40.

Van Ginneken, M., U. Netterstron, and A. Bennett. 2011. “More, Better, or Different Spending? Trends in Public Expenditure on Water and Sanitation in Sub-Saharan Africa.” Water Papers Series No. 67321, World Bank, Washington, DC.

Van Hofwegen, Paul. 2006. "Enhancing, Access to Finance for Local Governments, Financing Water for Agriculture.” Report 1 for the Task Force on Financing Water for All, World Water Council, Marseille.

WaterAid. 2015. "Essential Element: Why International Aid for Water, Sanitation and Hygiene Is Still a Critical Source of Finance for Many Countries." WaterAid Report with analysis by Development Initiatives, WaterAid, London.

—. 2016. "Water: At What Cost? The State of the World's Water 2016." Briefing, WaterAid, London.

WHO/UNICEF (World Health Organization and United Nations Children's Fund). 2015. Progress on Sanitation and Drinking Water: 2015 Update and MDG Assessment. Geneva: WHO.

Winpenny, J. 2003. Financing Water for All: Report of the World Panel on Financing Water Infrastructure. Final report of the panel chaired by Michel Camdessus, World Water Council, Marseille.

Winpenny, J., S. Trémolet, R. Cardone, Rachel, J. Kolker, W. Kingdom, L. Mountsford. 2016. Aid Flows to the Water Sector: Overview and Recommendations. World Bank, Washington, DC.

WHO (World Health Organization). 2012. "Global Costs and Benefits of Drinking-Water Supply and Sanitation Interventions to Reach the MDG Target and Universal Coverage." Analytical report, WHO/HSE/WSH/12.01, WHO, Geneva.

-. 2015. TrackFin Initiative: Tracking Financing to Drinking-Water, Sanitation, and Hygiene. Geneva: World Health Organization.

WHO/UN-Water (World Health Organization and United Nations Water). 2014a. Investing in Water and Sanitation: Increasing Access, Reducing Inequalities; UN-Water Global Analysis and Assessment of Sanitation and Drinking-Water (GLAAS) 2014 Report. Geneva: World Health Organization.

— . 2014b. "Do Pro-Poor Policies Increase Water Coverage? An Analysis of Service Delivery in Kampala's Informal Settlements.” Working Paper No. 85053, World Bank, Washington, DC.

World Bank. 2014a. "Applying Results-Based Financing in Water Investments.” Water Papers Series No. 89326, World Bank, Washington, DC.

—. 2015a. "International Financial Institutions Announce \$400 Billion to Achieve Sustainable Development Goals.” Press release, July 5.
—. 2015b. World Development Indicators 2015. Washington, DC: World Bank.

—. 2016a. "Case Studies in Blended Finance for Water and Sanitation." World Bank, Washington, DC.

—. 2016b. "Financing Options for the 2030 Water Agenda." World Bank, Washington, DC.

—. 2016c. "Private Participation in Infrastructure Annual Update 2016.” World Bank, Washington, DC.

—. 2016d. "Water, Sanitation, Hygiene and Poverty: What are the Linkages?” Tunisia Briefing Note. World Bank, Washington, DC.

- 2017a. A Wake Up Call: Nigeria Water Supply, Sanitation, and Hygiene Poverty Diagnostic. WASH Poverty Diagnostic. World Bank, Washington, DC.

—. 2017b. "Water Utility Turnaround Framework: Volume I." Unpublished manuscript, last modified June 23, 2017. Report No: AUS18030, World Bank, Washington, DC.

- Forthcoming (a). "Briefing Note on Capital Efficiency in the Water, Sanitation and Wastewater Treatment Sector.” World Bank, Washington, DC.

—. Forthcoming (b). "Global Study on Institutional, Policy, and Regulatory Incentives to Improve WSS Services.” World Bank, Washington, DC.

—. Forthcoming (c). "Pipe(d) Dreams: Water, Sanitation and Hygiene Progress and Remaining Challenges in Ecuador.” Water Supply, Sanitation and Hygiene (WASH) Poverty Diagnostic. World Bank, Washington, DC.

—. Forthcoming (d). “Tunisia WASH Poverty Diagnostic.” World Bank, Washington, DC.

WHO/UN-Water. 2017. Financing Universal Water, Sanitation and Hygiene under the Sustainable Development Goals: UN-Water Global Analysis and Assessment of Sanitation and Drinking-Water (GLAAS) 2017 Report. Geneva: World Health Organization.

World Bank/UNICEF (United Nations Children's Fund). 2017. Sanitation and Water for All: Priority Actions for Sector Financing. World Bank, Washington, DC.

WWAP (World Water Assessment Programme). 2012. The United Nations World Water Development Report 4: Managing Water under Uncertainty and Risk. Paris: United Nations Educational, Scientific and Cultural Organization.

WWC/OECD (World Water Council and Organisation for Economic Co-operation and Development). 2015. "Water: Fit to Finance? Catalyzing National Growth through Investment in Water Security.” Report of the High Level Panel on Financing Infrastructure for a Water-Secure World, WWC, Marseille. 
